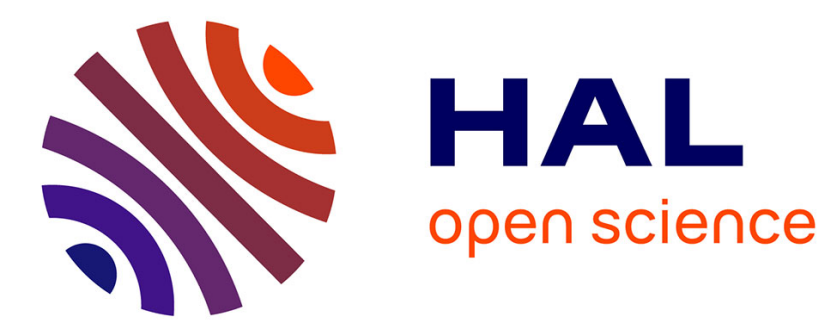

\title{
Toponymes portugais, galiciens, asturiens et pyrénéens : affinités et problèmes historico-linguistiques
}

Hector Iglesias

\section{To cite this version:}

Hector Iglesias. Toponymes portugais, galiciens, asturiens et pyrénéens : affinités et problèmes historico-linguistiques. Nouvelle Revue d'Onomastique, 2000, 35-36, pp.105-151. artxibo-00000121v2

\section{HAL Id: artxibo-00000121 \\ https://artxiker.ccsd.cnrs.fr/artxibo-00000121v2}

Submitted on 27 Oct 2008

HAL is a multi-disciplinary open access archive for the deposit and dissemination of scientific research documents, whether they are published or not. The documents may come from teaching and research institutions in France or abroad, or from public or private research centers.
L'archive ouverte pluridisciplinaire HAL, est destinée au dépôt et à la diffusion de documents scientifiques de niveau recherche, publiés ou non, émanant des établissements d'enseignement et de recherche français ou étrangers, des laboratoires publics ou privés. 


\title{
TOPONYMES PORTUGAIS, GALICIENS, ASTURIENS ET PYRÉNÉENS : AFFINITÉS ET PROBLÈMES HISTORICO-LINGUISTIQUES
}

\author{
Hector IGLESIAS \\ h.iglesias@biarritz.fr \\ Unité Mixte de Recherches 5478
}

Département Interuniversitaire d'Etudes Basques de Bayonne

Université Michel de Montaigne - Bordeaux III

Cet article constitue la version revue, corrigée et augmentée de deux articles intitulés respectivement «Sur quelques similitudes toponymiques galaïco-basques et le problème que posent certaines d'entre elles \} ^ { \mathbf { 1 } } \text { et «Affinités toponymiques } cantabro-pyrénéennes et énigmes historiques $\gg^{2}$. La région traitée par notre étude sera le plus large possible, englobant ainsi tout le Nord-Ouest de la péninsule Ibérique depuis le nord de l'actuel Portugal jusqu'au Béarn puisque c'est un fait admis en toponomastique que le facteur de distance n'est pas un argument suffisant au moment de nier la parenté de plusieurs toponymes. Il est vrai que dans la péninsule Ibérique, malgré des décennies de recherches et les travaux d'illustres chercheurs tels que Joan Coromines, pour ne citer que lui, beaucoup de questions n'ont toujours pas été éclaircies de façon définitive. Dans le cas du Nord-Ouest de la Péninsule les faits semblent parfois tout aussi ardus, voire la plupart du temps énigmatiques. Aussi le territoire étudié ici englobera essentiellement, entre autres, non seulement l'ancienne Asturia et Callaecia dont l'existence se reflète dans les titres des légats impériaux (Legati Augusti iuridici Asturiae et Callaeciae) mais également la Cantabria de l'Antiquité (c'est-à-dire grosso modo l'actuelle région de Santander), le Pays Basque dans son ensemble, c'est-à-dire l'ibérique et le continental, ainsi que I'Aquitania de Jules César.

Bien que les études toponymiques concernant la Galice aient toujours été beaucoup moins nombreuses que celles ayant pour objet le Pays Basque ou la Catalogne, il existe néanmoins certains articles et ouvrages linguistiques de grande qualité. Ces derniers mentionnent plusieurs noms de lieux galiciens, particulièrement ceux d'origine latino-romane ainsi que ceux issus du germanique, les principaux travaux étant principalement ceux de Joseph M. Piel. Les travaux de Joan Coromines, dont l'oeuvre est 
pourtant considérable, n'ont abordé que quelques rares points de toponymie galicienne ${ }^{3}$. On peut dire que les études toponymiques se trouvent actuellement en Galice dans un état moins avancé que d'autres régions d'Europe, vraisemblablement pour des raisons que nous aborderons plus loin. Dans le domaine de la toponymie dite pré-indo-européenne, il faut mentionner un court, mais fort intéressant, article de J. Gifford. L'auteur y souligne, sans pour autant les commenter, plusieurs similitudes présumées entre certains toponymes navarrais et certains toponymes galiciens.

Au début du siècle, Ramón Menéndez Pidal ${ }^{4}$, le maître de la philologie espagnole, avait déjà signalé que certains suffixes tels que -barre, -toi et -oi apparaissaient dans divers endroits de la Péninsule, tantôt en Galice et dans les Asturies, tantôt dans les Pyrénées occidentales. En outre, plusieurs auteurs, dont Henri Gavel ${ }^{5}$ et Fredrick Jungemann ${ }^{6}$, entre autres, avaient également noté certains parallélismes phonétiques entre ces régions pyrénéennes et cantabriques. Ces connexités phonétiques et toponymiques cantabro-pyrénéennes, et en particuliers les basco-galaïques, posent certains problèmes, relativement complexes, qui n'ont toujours pas été résolus.

D'un point de vue linguistique, on sait également que le fleuve appelé Le Miño - le plus important de Galice, en galicien $\boldsymbol{O}$ Miño - était couramment appelé par les Galiciens de I'Antiquité Bainis ou Baenis (Strabon, Géographie, III, 3, 4) ou Baites (Appien, Iberica, 73), le nom devant être comparé à l'ancien nom du Guadalquivir, c'est-à-dire autrefois Baitis, nom qui continue parfois à être utilisé en Espagne sous la forme Betis. Dans ces noms l'élément bai-, ayant vraisemblablement le sens hydronymique de «cours d'eau », est peut-être identique à celui qu'on trouve dans le nom Baïgorry, uaigorri, 1072 et probablement aussi dans celui de Bayonne, baiona, 1063 ainsi que dans le vocable basque $\boldsymbol{i b a i}$, « rivière, fleuve ». La voyelle initiale $\boldsymbol{i}$ serait, d'après Hugo Schuchardt ${ }^{7}$, un ancien préfixe devenu plus tard partie intégrante du thème, sa valeur originelle n'étant plus reconnaissable, d'où une évolution bai > ibai.

Cela, entre autres, amena Luis Michelena à penser qu'il faudrait « desceltizar tal vez hasta cierto punto Galicia $\gg^{\mathbf{8}}$ et celtiser davantage l'Aragon. Les problèmes, qui ne font pas l'objet de notre article, que pose l'existence de ces peuples du Nord-Ouest de la péninsule Ibérique sont nombreux et relativement ardus. J. Gifford se contente la plupart du temps de signaler avant tout des ressemblances dans le domaine de la toponymie pré-indo-européenne. En essayant d'élargir le champ de recherche, en y incluant les noms latino-romans et ceux d'origine germanique, nous présentons une liste non-exhaustive de toponymes qui se répètent ou semblent se répéter en Galice et en Pays Basque, parfois en Béarn ou en Aragon, voire présentent quelques affinités. 
Chaque fois qu'une similitude présumée a été notée par J. Gifford nous l'indiquons expressément. Les autres connexités présumées sont le fruit de nos recherches.

La Galice compte actuellement, comme le rappelle Ana Isabel Boullón, environ 60.000 documents médiévaux. Ce patrimoine documentaire est considéré comme étant I'un des plus riches de la péninsule Ibérique. De plus, un grand nombre de toponymes, ces derniers ayant la plupart du temps une allure très archaïque, est souvent difficile à expliquer. Leur interprétation est même parfois impossible. En outre, la langue galicienne présente généralement un caractère archaïque, sa phonétique étant considérée très conservatrice. C'est pourquoi, avant toute étude toponymique, il est utile de citer quelques faits de phonétique galicienne parmi les plus typiques et leurs affinités avec, entre autres, le gascon et le basque :

1) en galicien (comme en basque et en gascon, entre autres) $\boldsymbol{v}$ passe invariablement à $\boldsymbol{b}$ quel que soit sa position ;

2) à l'intérieur d'un mot - $\boldsymbol{f}$ - passe à -b- : defensa > debesa, trifoliu > trebo, etc., ce qui arrive aussi en basque où les changements $-\boldsymbol{f}$ - $>-\boldsymbol{f}$ - et $-\boldsymbol{f}$ - $>\boldsymbol{- p}$ - semblent être moins anciens que ceux $-\boldsymbol{f}->-\boldsymbol{b}-$;

3) un des changements les plus caractéristiques est la chute quasi automatique en galicien de tout I intervocalique : insula > ínsua, etc. ; mais parfois, comme en basque, il passe à -r-: cumulu > cómaro, etc. (en gascon -I- se maintient en général); au surplus, les $-\boldsymbol{r}$ - étymologiques ont tendance dans le langage quotidien à disparaître entre voyelles : queres > ques, «tu veux», eres > es, «tu es », etc., ce qui est aussi le cas dans le basque parlé et systématique en souletin où les -rintervocaliques, étymologiques ou non, ont disparu ;

4) en galicien lat. -II- passe à -I-, ce qui est le cas du basque; en revanche, en gascon il passe à -r- et en castillan il se palatalise ;

5) en galicien tous les - $\boldsymbol{n}$ - intervocaliques disparaissent comme en portugais, en basque et en gascon, excepté dans le suffixe latin -inu qui passe en galicien à -iño et dans le groupe $\boldsymbol{n y}$, avec semi-voyelle, qui passe à $\tilde{\boldsymbol{n}}$, comme en basque. C'est là une des principales caractéristiques de ces quatre langues, cela étant peut-être dû à un substrat commun, mais ce n'est pas sûr (cf. Rohlfs) ;

6) en galicien, en basque et en gascon lat. -nn- passe à - $\boldsymbol{n}$ - ; en castillan, il passe à -ñ- ;

7) en galicien, en basque, en castillan le groupe -nd- se maintient ; il passe à - $\boldsymbol{n}$ - en gascon et en catalan (et probablement aussi en aragonais, mais ce n'est pas l'avis de G. Rohlfs) ; 
8) En gascon, en castillan, en catalan, en basque et parfois en galicien, le groupe - $\boldsymbol{m b}$ - se réduit à $-\boldsymbol{m}$ - ;

9) en galicien, comme en gascon, la consonne $\boldsymbol{r}$ présente une instabilité importante, ce qui est à l'origine de nombreuses métathèses dans ces deux langues ;

10) en galicien, comme en basque, l'épenthèse d'un $\boldsymbol{i}$ consonne intervocalique, pour détruire des hiatus, est très fréquente ;

11) en galicien, la consonne $\boldsymbol{r}$ à l'initiale est parfois précédée de la voyelle prothétique $\boldsymbol{a}$, c'est-à-dire qu'on a $\boldsymbol{r}$ - > arr-, d'où gal. recuar et arrecuar, « reculer » ; rodeo et arrodeo, « détour», etc. ; en asturien cette voyelle prothétique est encore plus fréquente : arrodiu, arrodéu, arrodión, « détour», arrezar et rezar, «prier »; arrezu et rezu, «prière »; c'est également le cas du gascon (et parfois, mais très rarement, de l'ancien aragonais) où son apparition est constante jusqu'au Bassin d'Arcachon (cf. G. Rohlfs) et c'est également, et avant tout, une des principales caractéristiques phonétiques de la langue basque où aucun mot ancien ne peut commencer par $\boldsymbol{r}$, la voyelle prothétique n'étant pas cependant ici $\boldsymbol{a}$-comme en galicien, en asturien et en gascon, mais au contraire e-, dans errege < regem, erripa < ripam, etc.

\section{1) La Galice : une abondance surprenante de toponymes}

Parmi toutes ces régions ibériques, la Galice semble présenter un intérêt particulier du point de vue des études toponymiques et cela pour une raison fort simple quoique la plupart du temps ignorée, même du public cultivé. Comme nous avons déjà eu la possibilité de le signaler succinctement au cours d'un article précédent, on trouve en Galice la bagatelle de 35.000 toponymes majeurs, c'est-à-dire noms de villes, de «pays», de «communes» (c'est-à-dire en Galice des concellos, « conseils municipaux »), de villages, de hameaux, de paroisses (on en compte plus de 6.000 et chacune d'entre elles célèbre sa fête au cours de l'été) et de vallées auxquels il faut ajouter des milliers de noms de montagnes et de cours d'eau qui, eux, ne constituent pas des toponymes majeurs à proprement parler. Ainsi, la toponymie majeure de ce pays est plus abondante que celle de tout le reste de l'Etat espagnol réuni, ce qui constitue une réalité méconnue. Au cours des Jornadas de Onomástica organisées à Vitoria-Gasteiz en 1986 par l'Académie de la Langue Basque, I'intervenant galicien, Antón Santamarina ${ }^{9}$, ajouta même que si I'on devait comptabiliser tous les toponymes apparaissant dans les plans cadastraux, on atteindrait le nombre astronomique d'un million et demi de toponymes, certains apparaissant, naturellement, à plusieurs reprises. La Galice est, on l'a dit, un pays méconnu et, en ce qui concerne l'Antiquité, mal connu. La singularité du fait toponymique galicien est telle qu'aussitôt une question vient à l'esprit : comment un pays comme la Galice qui compte à peine un peu plus de 
$29.000 \mathrm{~km}^{2}$ (l'équivalent de l'Etat belge) peut-il à lui seul contenir plus de toponymes majeurs que l'ensemble de l'Etat espagnol dont la superficie est pourtant d'environ $500.000 \mathrm{~km}^{2}$ ? Pour répondre à cette question, il faut remonter, d'après certains spécialistes, jusqu'à l'Antiquité.

\section{2) Les Callaeci de I'Antiquité et la Callaecia romaine}

Dès que I'on aborde pour le Nord-Ouest de la Péninsule la période de l'Antiquité, les faits ont tendance à prendre une tournure pour le moins complexe. Comme le souligne Antonio de la Peña Santos ${ }^{\mathbf{1 0}}$, c'est un fait que toutes les histoires nationales et les opinions patriotiques sont basées sur des mythes. Face au mythe euskarien privilégiant un ethnocentrisme basé sur l'isolationnisme (et ses dérivés folkloriques que sont la théorie «basco-paléolithique », le matriarcalisme et l'animisme) qui se développa fortement en Pays Basque au cours d'une époque encore récente, la Galice développa également le sien : celui du «celticisme». Ce mythe connut un tel succès que des secteurs très divers de la société galicienne, parfois radicalement opposés, en firent leur principal cheval de bataille au cours des deux derniers siècles.

Aujourd'hui, la ferveur «celtisante » des historiens et des poètes galiciens du XIX ${ }^{e}$ siècle s'étant quelque peu apaisée, les spécialistes pensent désormais que les populations celtiques, non seulement étaient minoritaires en Galice à l'arrivée des Romains mais de surcroît que leur influence sur la région n'aurait été en définitive que très limitée : elles n'auraient constitué qu'une petite oligarchie militaire et il semblerait même, souligne Ramón Mariño Paz ${ }^{\mathbf{1 1}}$, qu'à I'arrivée de Rome leur langue fût déjà en voie d'extinction. D'après Johannes Hubschmid ${ }^{\mathbf{1 2}}$, à l'époque de la romanisation, le celte était peu présent en Hispania ou du moins fortement imprégné d'éléments pré-indo-européens et il est même possible que les langues pré-indo-européennes fussent tout à fait majoritaires. Alain Tranoy souligne, quant à lui, que le peuplement de la Galice dut se faire à partir d'un important fond de peuplement préceltique. Pour certains auteurs, ajoute-t-il, «les Callaeci seraient même restés en dehors de ces vagues indo-européennes et représenteraient un peuple de la fin de l'âge du Bronze, en pleine expansion $\gg^{\mathbf{1 3}}$.

\section{3) L'Ouest et le Nord-Ouest de I'Hispanie : raccourci historique}

Alors qu'il avait fallu moins d'une dizaine d'années à Rome pour conquérir définitivement I'ensemble de la Gaule, la conquête de I'Hispanie ${ }^{14}$ s'étendit sur deux longs siècles et ne prit fin que lors du dernier soulèvement des Asturiens sous le règne de Claude et de Néron. Itaque ergo prima Romanis inita provinciarum quae quidem continentis sunt postrema omnium nostra demum aetate ductu auspicioque Augusti Caesaris perdomita est, écrit Tite-Live (XXVIII, 12): autrement dit, I'Espagne, I'une des premières régions conquises, fut aussi l'une des 
dernières à être soumises. En 197 av. J.-C., Rome avait décidé de créer deux provinces: I'Hispania Ulterior et I'Hispania Citerior qui ne recouvraient, un demi-siècle après leur création, qu'une moitié du territoire ibérique. Les Lusitaniens furent les premiers à attaquer d'emblée les troupes romaines et à ravager l'Hispania Ulterior. Dès l'arrivée des Romains, au début du $\mathrm{II}^{\mathrm{e}}$ siècle av. J.-C., les guerres entre les Lusitaniens et les Romains furent en effet permanentes. Diodore de Silice dit que les Lusitani (ancêtres grosso modo des Portugais) étaient un peuple ibère et non celtibère ${ }^{15}$, mais leur origine n'a pas pu encore être déterminée avec exactitude.

En 147 av. J.-C., Viriathe ou Viriatus ${ }^{\mathbf{1 6}}$, le plus célèbre des Lusitaniens et des chefs indigènes que connut la Péninsule durant l'Antiquité («le brigand Viriathe » écrit Strabon, Géogr., III , 4, 5), déclencha une offensive générale contre Rome et après sept ans de guerre totale, le gouverneur de l'Hispania Ulterior fut encerclé et dut négocier avec lui l'indépendance de la Lusitanie. A Rome, le Sénat, stupéfait, désigna alors le proconsul $\boldsymbol{Q}$. Servilius Caepio, le frère du vaincu, afin de mener la contre-offensive. C'est ainsi qu'en 139 av. J.-C., il est fait mention pour la première fois des Galiciens. Appien (Iberica, 70) raconte qu'à cette époque $\boldsymbol{Q}$. Servilius Caepio fit une simple incursion chez les Vettones et les Callaeci (la forme Gallaeci utilisée dans la Chronique $\mathrm{d}^{\prime} \mathrm{Hydace}^{\mathbf{1 7}}$ semble plus tardive). C'est la première apparition de ce peuple dans I'Histoire. Un an ou deux ans plus tard, alors que les Romains luttaient toujours contre les Lusitaniens qui ne cessaient de pratiquer la guérilla avec l'aide de leurs femmes (chez les Lusitaniens et les Galiciens, les femmes et les hommes luttaient côte à côte d'après les auteurs anciens), ces derniers reçurent l'aide d'un peuple habitant au nord des rives du Douro et que les sources nomment de nouveau Callaeci, nom que I'on traduit d'ordinaire par Callaïques. Ce peuple habitait probablement l'actuelle région de Porto. Il fut réprimé par un général romain appelé Decimus Iunius Brutus ${ }^{\mathbf{1 8}}$ qui, à cause de la difficulté de cette guerre, reçut le surnom de Callaecus, au même titre que Scipion avait reçu celui d'Africanus après avoir vaincu les Carthaginois au cours de la bataille de Zama, en Afrique. Strabon (Géogr., III, 3, 2) l'indique : « Ces derniers [les Callaïques], à cause de leur âpreté au combat, qui est extrême, ont valu au Romain [Brutus] qui les a vaincus par les armes son surnom [Callaecus] ».

C'est à cette époque que les Romains donnèrent à l'ensemble des peuples habitant la région qui va du Douro jusqu'au littoral océanique situé au nord de l'actuelle Galice, un territoire qui devait leur être presque totalement inconnu, le nom du peuple auquel ils s'étaient affrontés: les Callaeci furent donc ce qu'on nomme d'ordinaire un peuple éponyme, c'est-à-dire que leur nom devient celui de toutes les populations d'une région et peu importe qu'il se fût agi de populi différents - ce qui était réellement le cas - ou non. Le fait devait être courant puisque lorsqu'il cite les peuples aquitains, Pline l'Ancien mentionne le nom d'un petit peuple (les Aquitani) qui était selon lui à l'origine du nom 
de la province appelée Aquitania. Il écrit en effet (Nat. Hist., IV, 33) : Aquitani, unde nomen provinciae. Si on en croit ses dires, ces Aquitani auraient donc également joué, à l'instar des Callaeci, le rôle de peuple éponyme ${ }^{\mathbf{1 9}}$.

\section{4) Les raisons de l'abondance extrême de toponymes en Galice}

L'abondance de toponymes majeurs en Galice s'expliquerait alors ainsi : en simplifiant un sujet complexe, on dira simplement que lorsque, après la conquête, le pouvoir romain commença à administrer les populations galaïques qui étaient sous son autorité, les fonctionnaires de Rome se seraient trouvés face à une organisation socio-politique indigène insolite et unique non seulement dans la péninsule Ibérique mais également, semble-t-il, dans l'ensemble de l'empire. Cette organisation politique pourrait se résumer grosso modo ainsi : les divers populi que les Romains nommèrent indifféremment Callaïques formaient une sorte de «fédération» de peuples (une centuria) et chacun de ces peuples composant une centuria, constituait lui-même une «fédération» d'unités plus petites (des castella). Alain Tranoy signale que «la centuria correspond à un contenu de caractère social et ethnique et le castellum a essentiellement une fonction géographique et sociale $\gg^{\mathbf{2 0}}$. Lorsqu'un Galicien déclinait son origo, celui-ci faisait savoir à son interlocuteur qu'il possédait en réalité deux nationalités distinctes et ayant chacune un rôle important bien déterminé. Ce sont, d'après les spécialistes, plusieurs inscriptions de nature épigraphique qui le laisseraient supposer ${ }^{21}$.

Cette organisation indigène, en raison de son contenu politique et territorial incompatible avec le système romain basé sur les civitas, organisation socio-politique propre à l'empire, sera vouée à disparaître au fur et à mesure qu'avancera la romanisation. Officiellement cette organisation disparaît, mais en fait cette ancienne réalité socio-politique continuera à exister de façon souterraine. Contrairement à ce qu'on aurait pu attendre, en Callaecia il n'y aura donc pas de véritables centres urbains, à l'exception de Lugo et de Braga qui sont des créations romaines.

La population continuera alors à être disséminée sur tout le territoire, les fonctions municipales en général ayant alors lieu dans un lieu névralgique appelé forum : on avait ainsi, entre autres, le forum Narbasorum qui était le lieu où se réunissaient « ceux qui appartenaient au peuple galaïque des Narbasi », cf. gr. Фópos N $\alpha \rho \beta \alpha \sigma \tilde{\omega} v$ (Ptol., II, 6, 48) ou bien le forum Iriensium, c'est-à-dire le forum de ceux de la localité d'Iria (moderne Padrón, La Corogne), etc ; ces derniers, on l'a vu, constituant eux-mêmes une « fédération » d'unités plus petites.

Cela expliquerait pourquoi, si on en croit certains spécialistes dont Gerardo Pereira-Menaut ${ }^{22}$, on trouve aujourd'hui plus de noms de lieux en Galice que dans tout le reste de l'Etat espagnol réuni. 


\section{5) L'étymologie du nom Callaeci}

Déjà à la fin du siècle dernier, Emile Hübner doutait que ce nom puisse avoir une quelconque parenté avec celui des Galates, peuple d'Asie Mineure. Il faut en effet d'emblée distinguer le nom étudié ici de plusieurs autres qui lui ressemblent :

a) Une région d'Ukraine et de Pologne est appelée Galicie, en latin médiéval Galicia, Regnum Galiciae, en polonais Galicja, en russe Galitsia, en ukrainien Galičina et en allemand Galizien. Ce nom n'aurait, malgré les apparences, aucun rapport avec celui de la Galice ibérique. Il serait issu du vieux-russe Galič, en polonais Halicz, nom d'une ancienne ville détruite en 1241 par les Mongols ${ }^{23}$.

b) Une ancienne province de l'Asie Mineure était connue sous le nom de Galatia. Elle était située dans l'actuelle Turquie, non loin de l'antique Cappadocia et de I'Arménie. C'était le pays des Galatae, nom qui serait en rapport avec celui des Galli, terme que les Romains utilisaient pour désigner tous les Celtes, à l'exception de ceux d'Asie Mineure. Les Celtes (on ne sait pas quel était le nom qu'ils se donnaient à eux-mêmes) furent d'abord appelés par les Grecs Keltoi, nom d'étymologie obscure, puis à partir du III ${ }^{\mathrm{e}}$ siècle Galatai, ce vocable étant synonyme pour ces mêmes Grecs du premier, terme qu'on a voulu identifier, malgré les réticences d'Emile Hübner ${ }^{\mathbf{2 4}}$, à celui des Callaïques. De nos jours, cette hypothèse semble désormais abandonnée à la suite des recherches les plus récentes, donnant ainsi raison à Hübner. En 1936, J. William Entwistle écrivait déjà : «Los galaicos, sin embargo (lat. GALLAECI, gr. Kallaikoi), no eran, probablemente, celtas, a pesar de la tentación de relacionar su nombre con el de los Galati o galos $\gg^{25}$.

c) La Gaule, en latin Gallia, c'est-à-dire les diverses régions peuplées par les Galli (Gaulois). D'après I'hypothèse la plus récente ${ }^{26}$, le nom Galli signifierait « les furieux » et se rattacherait au vieil irlandais gal, « vapeur, fureur ».

La majorité des auteurs semblent s'accorder pour voir dans le nom du peuple éponyme Callaeci / Gallaeci, d'où est issu le nom du pays Callaecia > Gallaecia > Galicia, un nom pré-indo-européen. Le nom des Callaici / Callaeci, en grec Kallaikoi (Appien, Iber., 70 et Strabon, Géogr., III, 3, 2) s'analyse d'ordinaire en Call(a)- + -aici + -us / Kall(a)- + -aiko-, avec suffixe *-aiko-. Ce suffixe indigène du Nord-Ouest hispanique avait pour fonction de transformer des noms de lieux (propres ou communs) en formes adjectivales, c'est-à-dire qu'il avait grosso modo la même valeur que le suffixe latin -ensi-. Le nom de peuple Kallaikoi serait un dérivé du terme pré-indo-européen *kalla-, sa signification étant alors *kallaiko-, «montagnard, habitant des hauteurs, des montagnes». Cette étymologie semble confortée par les propres dires de Strabon (Géogr., III, 3, 2), lorsqu'il cite «les Callaïques ${ }^{27}$, qui occupent une grande partie de la région montagneuse ». 
Alain Tranoy signale, en effet, qu'en « remontant du Tage vers le nord, Brutus eut, après avoir franchi le Douro, de nombreux combats à mener $\mathbf{~}^{\mathbf{2 8}}$ d'après Appien. De sorte que I'extension du nom des Callaeci à tous les peuples vivant au nord du Douro dut se faire à partir du nom du premier peuple que Brutus rencontra en remontant vers le nord, ce qui s'avère être en effet I'hypothèse la plus économique, donc la plus probable. En outre, il a été trouvé à une vingtaine de kilomètres de Porto, une dédicace à une divinité locale où l'on peut lire: CALAICIA[E] / RVFVS FL/AVI F(ilius) / S(acrum) $\boldsymbol{F}$ (aciendum) $\boldsymbol{C}$ (uravit). Cette divinité CALAICIA pourrait peut-être, d'après Alain Tranoy ${ }^{\mathbf{2 9}}$, constituer un indice attestant l'établissement des Callaeci dans la région de Cale, c'est-à-dire de l'actuel Porto, l'étymologie la plus courante de ce nom antique étant : Cale <*kallai, « les hauteurs, les collines», avec un nominatif pluriel pré-latin en -ai selon J. Untermann ${ }^{30}$. Ce toponyme correspondrait en outre pleinement aux caractéristiques géographiques du lieu de Porto. Il faut signaler la similitude de *kallai et du nom de peuple *kallaiko- avec le terme basque actuel garai, « haut, hauteur » avec sonorisation courante en basque de I'occlusive initiale. En outre, Luis Michelena signale que garai semble correspondre exactement au terme castillan *galai- que l'on trouve dans le mot espagnol galayo, « prominencia de roca pelada que se eleva en un monte $\gg^{\mathbf{3 1}}$.

\section{6) Les traditions indigènes et leurs répercussions sur les Etudes Basques}

En ce qui concerne tous les aspects, entre autres, ethnographiques concernant les peuples du Nord-Ouest de la péninsule Ibérique pendant l'Antiquité, le lecteur intéressé par cette question pourra consulter l'ouvrage d'Alain Tranoy, considéré comme un ouvrage de référence. De plus, cet aspect concerne indirectement le Pays Basque ou tout au moins les Vascones que I'on considère d'ordinaire comme étant les ancêtres de la plupart des Basques actuels. Les détails que nous livrent les auteurs anciens sur les moeurs de ces populations de Lusitanie et de Galice sont très intéressants. La participation active des femmes lusitaniennes et galaïques aux diverses guerres contre Rome est attestée par plusieurs auteurs antiques. Mais le plus étonnant est le témoignage qui suit : un auteur tardif, le patriarche Photius, se fondant sur les écrits, aujourd'hui disparus et intitulés Les choses incroyables que I'on voit au-delà de Thule, à savoir au-delà des limites du monde connu des Anciens, un ouvrage composé par un auteur grec du $\mathrm{I}^{\text {er }}$ siècle ap. J.-C., Antonius Diogène, raconte que chez les Artabres, un peuple galaïque qui habitait dans l'actuelle province de La Corogne, les femmes faisaient la guerre pendant que les hommes restaient à la maison. Julio Caro Baroja $^{32}$ rappelle que les récits de Diogène servirent de base à un écrivain français du XVIII ${ }^{\mathrm{e}}$ siècle, Mathieu de Chiniac de la Bastide, au moment d'écrire une Dissertation sur les Basques (Paris, 1786). Pour le reste, chez les Galiciens, les hommes avaient pour habitude de ne rien faire, sinon de se consacrer principalement, en dehors de la 
guerre, aux rapines et aux brigandages de toutes sortes, tandis que tous les travaux agricoles étaient assurés uniquement par les femmes, du moins si on en croit les témoignages de Justin, de Silius Italicus et de Clément d'Alexandrie ${ }^{33}$. Les Lusitaniens et Callaïques avaient également pour habitude de consulter le foie des victimes, de tenir compte du vol des oiseaux et des manifestations célestes telles que la foudre. Ils dansaient et chantaient en frappant le sol et en faisant résonner leur bouclier. Strabon nous dit aussi qu'ils jouaient de la musique avec des flûtes et des trompettes et qu'ils vénéraient la lune, fait que rapporte aussi Ptolémée ${ }^{34}$. Ce rite a effectivement survécu en Galice jusqu'au début du XXe siècle: dans une région de la province d'Orense, les paysans avaient en effet pour coutume, signale Alain Tranoy ${ }^{35}$, de se réunir les nuits de pleine lune pour danser et chanter en I'honneur de cet astre.

C'est à présent qu'il faut mentionner un témoignage de Strabon qui intéresse les Basques de I'Antiquité et les Etudes Basques en général. Pour des raisons qui nous échappent, probablement à la suite d'une interpretatio abusive, un des plus importants témoignages de Strabon sur les moeurs des populations d'Ibérie (Strabon est du point de vue ethnographique celui qui donne les informations les plus intéressantes concernant les peuples de l'Antiquité) a été constamment et, manifestement, abusivement attribué aux Vascones de l'Antiquité. Il est en effet de nos jours devenu courant, parmi certains auteurs, principalement du Pays Basque, d'attribuer aux Vascones et aux seuls Vascones une série de coutumes rapportées par Strabon. Cependant, un retour aux sources montre clairement que le témoignage de Strabon (Géogr., III, 3, 7) n'est rien d'autre qu'une description des coutumes des Lusitaniens et des Galiciens de I'Antiquité36. C'est Strabon (Géogr., III, 4, 20) qui nous I'indique : le «pays des Lusitaniens selon I'appellation ancienne, des Callaïques selon I'appellation moderne ». Voici les dires du géographe grec :

«Les Lusitaniens font des sacrifices. Ils examinent les entrailles sans ectomie. Ils examinent aussi les vaisseaux du flanc et se livrent à la divination en les touchant. Ils procèdent aussi à des consultations d'entrailles humaines sur la personne de leurs prisonniers de guerre ».

En outre,

« les montagnards [de Lusitanie, c'est-à-dire les Callaïques] sont tous sobres. Ils ne boivent que de l'eau et couchent à même le sol. Ils laissent descendre très bas leurs cheveux, comme des femmes, mais les relèvent sur le front par un bandeau pour le combat. Ils se nourrissent surtout de chair de bouc (...) les populations montagnardes [de Lusitanie] vivent pendant les deux tiers de l'année de glands de chênes. On les sèche et les concasse, puis on les réduit en farine pour en faire un pain qui se conserve longtemps. Ils boivent généralement de la bière, rarement du vin, et celui qu'ils ont est vite consommé dans les banquets familiaux. Ils remplacent l'huile par le beurre. Leurs festins se font assis : à chaque convive est réservé le long de la paroi un siège construit avec le mur, où l'on prend place selon son âge et son rang, puis les mets sont passés à la ronde. Quand on commence à boire, les hommes se mettent à 
danser, tantôt évoluant en choeurs au son de la flûte et de la trompette, tantôt aussi en sautant et en s'accroupissant alternativement (...). Les hommes sont tous habillés de noir, le plus souvent d'une saie. Ils s'en enveloppent pour dormir sur leurs litières de feuilles et $\mathrm{d}$ 'herbes sèches. Comme les Celtes [ce qui sous-entend que les Lusitaniens et les Callaïques ne l'étaient effectivement pas], ils usent de vases de cire ».

Puis, il signale «qu'on précipite du haut des rochers les condamnés à mort. On lapide les parricides, mais loin des montagnes et des cours d'eau » et «les malades, comme c'était anciennement le cas chez les Egyptiens, sont exposés sur la voie publique ». La confusion avec les Basques provient certainement du fait que Strabon conclut : «Tel est le genre de vie, comme je l'ai dit, des populations montagnardes [toujours de Lusitanie] ». Après quoi, il ajoute que les autres populations qui jalonnent le côté nord de I'Ibérie «jusqu'au Pays des Vascons et au Mont Pyréné (sic) » vivent de la «même manière ». Il semblerait cependant qu'on ne puisse pas, comme le font certains auteurs écrire : voici quel était le mode de vie des Basques de l'Antiquité. On devrait peut-être au contraire rapporter, afin de ne pas créer de confusions inutiles, les faits tels qu'ils sont. Autrement dit: voici quel était il y a deux mille ans, d'après Strabon, le mode de vie des Lusitaniens et des Galiciens, mode de vie qui était, toujours selon Strabon, également celui des Asturiens, des Cantabres et des Vascons ${ }^{37}$. Le témoignage de ce géographe grec apparaît en effet dans la deuxième partie du Livre III qui est entièrement consacrée à la description détaillée de la Lusitania et de ses habitants (et par conséquent de la Callaecia pour les raisons évoquées auparavant), la première partie étant quant à elle consacrée à la Turdetania qui était un pays couvrant principalement la vallée inférieure du Guadalquivir.

\section{7) Hydronymes préceltiques luso-cantabriques liés peut-être à la Sibérie}

Les noms de cours ou hydronymes constituent pour les spécialistes, qui semblent s'accorder au moins sur ce point, les couches les plus anciennes de la toponymie. Nos recherches sur ce sujet, à notre connaissance inédites sur bien des points et déjà exposées, en partie du moins, lors de notre dernier article ${ }^{38}$, semblent être en passe de donner des résultats intéressants, certains d'entre eux s'avérant même surprenants.

\section{a) Lena et Lea}

Nous avons en effet déjà eu l'occasion de signaler qu'une rivière biscaïenne s'appelle Lea (Lekeitio, Biscaye). Nous avions comparé ce nom avec celui d'un petit village galicien de Lugo connu sous le nom de Lea. D'autres recherches entreprises par la suite, et qu'à notre connaissance aucun autre auteur ne semble avoir menées, nous permettent de dire qu'il existe en fait deux villages en Galice ayant ce nom (Lea et Riberas de Lea) et, surtout, que ces deux localités tiennent manifestement leur nom de la petite rivière qui les traverse toutes les deux : la rivière galicienne appelée Lea, 
autrefois une des deux localités étant appelée par le même nom : Domnus Ciprianus, clericus de Lea, 1252 (cartulaire de Lorenzana). Ainsi, on constate que la Galice et la Biscaye ont chacune sur leur territoire respectif une rivière du même nom. En outre, nous avions comparé ces deux noms avec celui d'une localité située dans la montagne asturienne: Pola de Lena située au sud de Mieres. Ce que nous ne savions pas à l'époque était que cette localité montagneuse des Asturies, que nous avons eu I'occasion de visiter par la suite, tire également son nom d'une petite rivière appelée río Lena, d'où son nom: Pola de [la rivière] Lena, le mot asturien pola étant vraisemblablement, mais ce n'est pas sûr, l'équivalent du terme espagnol puebla. Or, en galicien et en basque, contrairement à ce qui se produit en asturien, les - $\boldsymbol{n}$ intervocaliques s'effacent, ce qui nous avait permis de reconstruire pour I'hydronyme galaïco-biscaïen un prototype *lena que l'existence du cours d'eau asturien conforte assurément (au XVI $\mathrm{I}^{\mathrm{e}}$ siècle, la véritable forme asturienne était Llena étant donné que dans cette région I'asturien palatalise systématiquement les $I$ - à l'initiale, le nom ayant été par la suite espagnolisé d'un point de vue phonétique ${ }^{39}$ : *lena $>$ Llena $>$ Lena. Une rivière du Portugal, située au sud-ouest de la ville de Coimbra et à l'ouest de Fatima, a également pour nom Lena. Elle est située entre le Douro et le Tage, dans une région qui constituait dans I'Antiquité le territoire des Lusitaniens à proprement parler.

En théorie, on eût dû s'attendre à une forme portugaise Lea (< Lena), comme cela est le cas en Galice et en Pays Basque, puisqu'en portugais la chute de la nasale intervocalique /n/ est régulière. La conservation de cette nasale dans la toponymie portugaise centrale constitue en revanche le reflet d'une ancienne couche toponymique mozarabe fossilisée : plusieurs noms de lieux portugais tels que Molino, Fontanas, Fontanelas, etc. situés au sud du fleuve Mondego (ce qui est le cas de notre rivière portugaise appelée Lena) témoignent en effet de cette période linguistique mozarabe ultérieurement éliminée par la superposition de l'élément linguistique galicien provoquée par la Reconquête ${ }^{\mathbf{4 0}}$. Ce fait prouve clairement que le Lena asturien et le Lena portugais doivent nécessairement avoir la même origine et en conséquence et indirectement que cela est également le cas du Lea galaïque et du Lea euskarien, en basque et en galicien I'évolution ayant été manifestement, quant à elle, *lena > Lea. Il semblerait en effet qu'on puisse tenir pour extrêmement probable que ces hydronymes ont la même origine. La phonétique historique du basque, de l'asturien, du galicien et du portugais (en territoire anciennement mozarabe) ne laisse en tout cas que peu de place au doute étant donné que toutes les pièces du puzzle phonético-géographique semblent correspondre.

Il s'agit dans les quatre cas d'hydronymes, on les appellera des hydronymes luso-cantabriques, c'est-à-dire une catégorie de noms que les spécialistes considèrent comme représentant les couches les plus profondes de la toponymie, ce qui, de surcroît, 
semble témoigner d'une certaine unicité ethno-linguistique de tout l'Ouest et le Nord-Ouest de la péninsule Ibérique à une époque indéterminée, unicité à laquelle Strabon, on l'a vu, semble faire référence. A l'évidence, de telles similitudes ne peuvent être dues au simple hasard. En outre, ces hydronymes sont à ranger dans la catégorie des hydronymes préceltiques et très vraisemblablement pré-indo-européens. Pour être tout à fait complet, il faut signaler que Joan Coromines avait au cours de ses études reconstruit une forme *lěna baptisée par lui pyrénéenne et à laquelle il attribuait le sens de «losa, dalle de pierre $»^{\mathbf{4 1}}$ (il citait le vocable du Pallars occidental Ilenat, «techo de pizarra», citons également une montagne catalane appelée $\boldsymbol{P}$. de Llena située à environ $40 \mathrm{~km}$. au sud du Val d'Aran). Il est curieux qu'il n'ait pas remarqué que cette forme existait déjà en réalité dans les Asturies sous forme d'hydronyme. La preuve qu'il ne l'avait manifestement pas vue semble se trouver dans ses écrits : «el área de *lěna hacia el oeste no pasa de Aragón, que yo sepa $\gg^{\mathbf{4 2}}$. Il faut cependant préciser qu'il s'agit d'une petite rivière de montagne et d'un village asturiens peu connus.

En outre, il faut également signaler en ce qui concerne le Lea biscaïen, qu'Alfonso Irigoyen signalait pour ce nom une forme médiévale Leia $^{43}$, ce qui ne change rien à notre démonstration puisqu'il est très courant en basque, et notamment en biscaïen, que des épenthèses $d^{\prime} \boldsymbol{i}$ consonnes intervocaliques se produisent après d'autres voyelles pour détruire des hiatus. Henri Gavel ${ }^{44}$ signale qu'en souletin et biscaïen le mot espagnol leal est couramment prononcé leial. Ce phénomène est également très courant en galicien $^{45}$ et également en basque commun. Par conséquent, la forme médiévale biscaïenne Leia constituait elle-même très probablement une forme secondaire issue d'un plus ancien Lena (cf. Asturies) > Le(n)a > Leia (avec $\boldsymbol{i}$ consonne détruisant le hiatus vocalique produit par l'effacement en basque de la nasale intervocalique) $>$ Lea (forme actuelle) > Liai ou Liei (formes populaires biscaïennes selon Irigoyen $^{\mathbf{4 6}}$ ).

\section{b) L'ouralo-altaïque : une vieille hypothèse très controversée}

On ne peut à présent ne pas signaler un fait extrêmement curieux qui demanderait des recherches beaucoup plus approfondies: un grand fleuve de Sibérie, qui, après avoir arrosé les plateaux de Sibérie centrale, coule au pied de la grande chaîne de montagnes de Verkhoïansk qui culmine à 2959 m., porte le nom de Lena. On ne peut dans l'état actuel de nos recherches dire s'il s'agit uniquement d'apparences trompeuses, qui existent mais que l'on ne doit en aucun cas exagérer, ou s'il s'agit d'une véritable piste toponymique qu'il faudra à l'avenir examiner sérieusement. Cependant, si les apparences trompeuses peuvent en effet exister comme le rappelle Jacques Allières ${ }^{47}$, qui signale que I'anglais bad, «mauvais » et le persan bad, «id. », malgré 
les apparences, ont une origine radicalement différente, elles ne sont pas d'ordinaire aussi nombreuses qu'on pourrait le croire.

Outre le fait qu'il s'agit dans tous les cas (portugais, galicien, asturien, basque et sibérien) de noms de cours d'eau dont l'origine préceltique, dans le cas des hydronymes luso-cantabriques, ne fait guère de doute, ce qui diminue considérablement le risque mais, il est vrai, ne l'élimine pas totalement - d'une apparence illusoire, on rappellera au demeurant que Jacques Allières souligne que la famille ouralo-altaïque montre « une stabilité remarquable; c'est ce que I'on a noté dans le domaine altaïque - les dialectes turcs, du Bosphore à la Sibérie, sont peu différenciés - et peut-être du basque, précisément, langue qui s'est très peu modifiée depuis les premiers textes ${ }^{\mathbf{4 8}}$. Il faudrait alors connaître la forme ancienne de cet hydronyme sibérien.

On sait, toutefois, que ce nom est déjà attesté au début du $X V I I^{e}$ siècle sous une forme manifestement identique à l'actuelle : «The delta was discovered in 1637 by the Cossack Elisei Busa, who sailed down the Lena and through the western arm of the delta to the Olenek river where he wintered $\gg^{\mathbf{4 9}}$. Nous n'avons pas pu nous procurer de formes plus anciennes, mais il est vraisemblable que celles-ci devaient probablement être, pour les raisons évoquées ci-dessus, proches sinon identiques à l'actuelle.

A notre connaissance, le seul auteur qui essaie d'expliquer cet hydronyme sibérien est André Cherpillod dont les étymologies, néanmoins, ne sont pas toujours, comme il le reconnaît lui-même, très sûres eu égard à la difficulté qu'entraîne l'analyse de certains de ces noms de Sibérie orientale. Selon lui, ce nom pourrait être issu de l'évenki (langue altaïque du groupe toungouse $)^{50}$. Il semblerait en effet acquis que ce toponyme ne soit pas un nom slave donné après la conquête de ces contrées par les Russes.

On ne pourrait guère, toutefois, invoquer l'invraisemblance d'une telle parenté toponymique présumée au nom de l'éloignement géographique et nier ainsi toute crédibilité à cette hypothèse ibéro-sibérienne puisque c'est un fait acquis aujourd'hui, tous les spécialistes s'accordent sur cette question, que plus on recule dans le passé plus le facteur distance doit être négligé, voire carrément écarté ${ }^{51}$.

Il est loin d'être inconcevable de supposer qu'à ces époques reculées des populations sibériennes se soient dirigées vers la péninsule Ibérique et l'aient atteinte en quelques mois, voire tout au plus en quelques années puisque ces groupes de chasseurs-cueilleurs du Paléolithique pouvaient, comme s'accordent à le penser actuellement les plus imminents spécialistes de la préhistoire ${ }^{\mathbf{5 2}}$, parcourir jusqu'à cinquante kilomètres par jour à la recherche de nourriture.

Ces populations sibériennes se seraient alors établies et disséminées le long de la Cordillère Cantabrique depuis le centre du Portugal, la Galice jusqu'à I'actuel Pays 
Basque, ce qui expliquerait la présence de noms de cours d'eau identiques dans ces régions et leur ressemblance tout à fait frappante avec I'hydronyme sibérien mentionné auparavant. Des reliquats de la langue de ces populations de Sibérie auraient pu se conserver dans la langue basque actuelle, qui reposerait alors sur un socle sibérien, puisque, on le sait, la ou plutôt les langues des Lusitaniens, des Callaïques, des Astures et des Cantabres ont quant à elles disparu. La piste semble intéressante et mériterait probablement d'être approfondie. C'est au demeurant I'hypothèse défendue par Michel Morvan ${ }^{53}$, bien que sa thèse ne concerne pas à proprement parler la toponymie.

En guise de conclusion, nous dirons - bien que l'ouralo-altaïque n'entre pas dans le domaine de nos compétences - que cette hypothèse sibérienne ${ }^{54}$ reprise récemment par Michel Morvan ne paraît pas invraisemblable. Les réticences de certains chercheurs face à ce type de travaux proviennent essentiellement du fait que se fonder sur des ressemblances lexicales actuelles, alors que l'on a affaire à des langues dépourvues de tradition écrite ancienne, apparaît encore à beaucoup de linguistes très discutable. En revanche, l'hydronymie fait appel à des formes fossilisées depuis, la plupart du temps, des millénaires, point sur lequel tout le monde s'accorde.

Cela rend plausible cette hypothèse concernant l'hydronyme sibérien Lena. Cependant, il faut reconnaître qu'à partir d'une seule équivalence toponymique, de surcroît hypothétique, toutes ces conjectures paraissent bien fragiles. En outre, il existe un autre fait qui semblerait fragiliser encore plus cette hypothèse ibéro-sibérienne : Gerhard Rohlfs ${ }^{55}$ rappelle qu'en Catalogne et en Aragon, voire en Gascogne et en Ariège, on rencontre plusieurs toponymes, notamment des oronymes, tels que Serra la Llena, Cova de les Llenes, Liena, Port de la Lleia, Lia, Lena, etc. pour lesquels il reconstruit une base préromane, en basant sur les travaux de Coromines et de Hubschmid qu'il cite, *lěna (cf. supra). Rohlfs signale également que ces vocables représentent

«le fonds le plus important parmi les survivances préromanes. Il s'agit de mots limités aux vallées pyrénéennes [manifestement, Rohlfs n'avait pas non plus remarqué les Lena portugais et asturien] et dont on peut souvent démontrer l'existence dans les parlers des deux versants. Dans les cas où de tels mots sont communs au gascon, à l'aragonais et au catalan, il est permis de parler d'un véritable vocabulaire pyrénéen ».

Il précise également qu'il s'agit de «mots d'origine mystérieuse, qui semblent appartenir à un peuple disparu $»^{\mathbf{5 6}}$. Il faut, toutefois, noter qu'il ne s'agit jamais, sauf erreur de notre part, d'hydronymes. Or curieusement, dans le centre du Portugal, en Galice, dans les Asturies, en Biscaye et en Sibérie, il s'agit dans tous les cas de noms de cours d'eau. Comment pourrait-on expliquer ce fait ? Il se peut aussi qu'il n'y ait pas de rapport entre eux. 


\section{d) Uncín et Untxin}

Nos recherches nous permettent également de signaler un fait qui, à notre connaissance et sauf erreur de notre part, n'avait pas été mentionné auparavant. Une petite rivière des Asturies occidentales traversant la localité d'Artedo, a pour nom Uncín. Il s'agit manifestement du même nom que celui de la rivière du village labourdin d'Urrugne appelée Untxin, autrefois Onzi, 1235 (Livre d'Or), Osin, 1580, Ouncin, $X X^{e}$ siècle $^{57}$. Une des explications envisageables, si I'on accepte cette similitude hydronymique basco-asturienne et si I'on veut l'interpréter, est de postuler un même peuplement ancien, c'est-à-dire que cette région des Asturies centrales et cette partie de la côte labourdine auraient été peuplées, à une époque indéterminée, par un groupe ethno-linguistique apparenté. On pourrait peut-être rapprocher ce nom du terme basque untzi, « récipient» et également «cuvette», sens que Jean-Baptiste Orpustan considère «acceptable en toponymie mais des plus incertains ${ }^{\mathbf{5 8}}$. Michel Morvan compare le basque ontzi, « récipient creux » au finnois onsi, « creux ${ }^{\mathbf{5 9}}$.

\section{8) Les hydronymes cantabro-pyrénéens Eo, Ego, Oo et les Egovarri de Pline}

On a ici probablement affaire à des appellations hydronymiques qui se perdent dans les couches les plus profondes de la toponymie. Ainsi, dans les montagnes luchonnaises, riches en lacs, un village et un lac sont appelés tous les deux Oo. L'appellation « le lac d'Oo » est probablement une construction tautologique, la forme $\boldsymbol{O o}$ étant issue, à la suite d'une assimilation vocalique, d'un plus ancien *eo. Dans la vallée d'Ossau, le terme communément utilisé pour désigner les lacs de montagnes de la région est ioû, éoû, héou, uoû, «lac de montagne ». Gerhard Rohlfs consacre tout un passage à ces hydronymes pyrénéens pour lesquels il reconstruit une base $\boldsymbol{*}_{\boldsymbol{i b o n}} \mathbf{e}^{\mathbf{6 0}}$. Or le prototype de cet hydronyme pyrénéen se serait conservé sous sa forme pleine, ce qui dénote une remarquable stabilité phonétique, dans le nom de la rivière basque appelée Ego, autrefois val de Ego, $1335^{\mathbf{6 1}}$, cours d'eau séparant les localités d'Ermua (Biscaye) et d'Eibar (Guipuzcoa). Mais le cas le plus intéressant est sans nul doute celui concernant le fleuve galaïco-asturien appelé Eo. Ce fleuve sépare aujourd'hui d'un point de vue administratif la Galice des Asturies, bien qu'il fût situé autrefois à l'intérieur du territoire des Callaïques. P. Fouché a restitué pour ce nom galaïco-asturien un prototype hypothétique *eoo alors qu'en réalité, à notre avis, l'explication est beaucoup plus simple : en fait le prototype qui doit être restituée pour cet hydronyme galicien est assurément $*$ ego. Ce qui complique un peu l'explication de ce nom est le fait que plusieurs erreurs se sont accumulées les unes sur les autres au cours du temps. Afin ne pas ajouter à la confusion, il faut tenter d'expliquer comment et où se sont produites ces méprises. 
a) les anciennes formes médiévales de ce nom de cours d'eau galicien sont: Yube, 775, Euve, Eube, 925, Euuio, 1128, et in Asturiis sicut dividit ripa Ove, 1157, usque in flumen Ove, $\mathrm{XII}$ siècle, en ce qui concerne les sources de cette rivière, les formes archaïques étant ${ }^{62}$ : Fonte Euve, 1188, F. Eve, 1269, Fonteu, 1301. La première erreur qui s'est produite est en effet également la principale, celle qui détermine toute la suite des événements. Cela étant, cette erreur ne peut être déduite que d'un point de vue phonétique. En effet, il existe une certitude : à partir des formes médiévales citées ci-dessus on ne peut pas aboutir à la forme actuelle Eo. Cela implique, aussi curieux que cela puisse paraître, que les scribes du Moyen-Âge se sont trompés et non, comme nous l'écrivions dans notre dernier article, V. Olano Silva. Effectivement, bien qu'ils écrivent in flumen Euve ou Ove, ce nom ne peut être que celui d'une paroisse galicienne appelée Obe située au sud de celle de Ribadeo et à côté de la rivière Eo. D'ailleurs, il existe un document médiéval qui fait expressément référence à cette paroisse connue de nos jours sous le nom d'Obe : in Santi Iohannis d'Euue, s. d. probablement XI-XII ${ }^{\mathrm{e}}$ siècle (cartulaire de Lorenzana, ici il ne s'agit pas du fleuve). En effet, les formes médiévales citées ci-dessus impliquent toutes un prototype, comme le suppose également Abelardo Moralejo Lasso ${ }^{63}$, *Egobe puisque I'évolution *Egobe > Eube > Ove > Obe serait alors tout à fait normale et régulière en phonétique galicienne. Autrement dit, ce que les scribes du Moyen-Âge croyaient être le nom d'un cours d'eau était en réalité celui d'une localité située à côté de celui-ci.

b) Pline I'Ancien (Nat. Hist., IV, 111) mentionne parmi les Callaïques luquois ou Callaeci lucenses un peuple (et non pas une «ville » comme le dit, probablement par inadvertance, Humboldt) connu sous le nom d'Egovarri. Mais il existe un fait qui vient passablement compliquer cette question. En effet, il y a deux lectures du texte de Pline : celle que nous avons citée et une autre, utilisée par la plupart des auteurs au cours principalement du $X{ }^{e}$ siècle, entre autres, par Hübner, et qui semble manifestement erronée, c'est-à-dire Egivarri ou Egi, Varri ${ }^{64}$. Humboldt, qui utilise une édition de Pline du XVIII ${ }^{\mathrm{e}}$ siècle (il utilise les éditions du jésuite français Hardouin, $1^{\mathrm{er}}$ éd. $1685 ; 2^{\mathrm{e}}$ éd. corrigée, Paris, 1723, $3^{e}$ éd. 1741) opte pour la forme, à notre avis correcte, Egovarri. Emile Littré, dans son édition parue en 1848, fait de même. A partir de là, il existe quatre autres éditions, toutes allemandes : celle de Sillig ( 6 vol., Hambourg et Gotha, 1851-1855), celle de Jan (6 vol., Leipzig, 1854-1865), celle de Detlefsen (5 vol., Berlin, 1866-1873) et enfin celle de Carl Mayhoff (5 vol., Leipzig, 1892-1906). Ce sont dans ces deux dernières éditions que I'on lit actuellement Pline avec le plus de confiance ${ }^{65}$. La plupart des auteurs qui étudie le texte de Pline utilisent en effet l'édition de Carl Mayhoff. Cependant, dans le cas de ce peuple galaïque qui relevait du conuentus de Lugo, Mayhoff ${ }^{66} \mathrm{~s}^{\prime}$ est très probablement trompé puisque contrairement à Emile Littré et 
à Humboldt, il préfère lire Egivarri ou Egi, Varri (quoique dans ses notes, il cite également la forme egoua- $v$ [arri]).

c) dans I'un de nos articles ${ }^{67}$, nous écrivions: «On peut affirmer que le nom Egovarri est à l'origine de l'hydronyme Eo pour une simple et unique raison : les actuels habitants des rives de ce fleuve aujourd'hui galaïco-asturien, c'est-à-dire principalement ceux des villages galiciens de Ribadeo et d'Obe et ceux des villages asturiens de Vegadeo et de Castropol, sont encore de nos jours désignés par le terme générique Egovarros ». Nous nous basions pour cela sur l'ouvrage d'un auteur asturien bien au fait des réalités locales : Xosé Lluis García Arias. Son ouvrage linguistique est considéré comme étant un travail de qualité, mais les vérifications que nous avons effectuées ultérieurement ne nous permettent pas de confirmer ses dires sur ce point. C'est qu'en réalité le texte de García Arias fait preuve à un moment donné d'une certaine ambiguïté. Celui-ci laisse en effet supposer, en employant peut-être abusivement le présent, que les gens de la région en question sont encore de nos jours désignés ainsi : «a los habitantes de sus riberas [de l'Eo] se les alude genéricamente como Egovarros ${ }^{68}$, écrit-il, ce qui pourtant ne paraît pas être le cas d'après les informations recueillies auprès du secrétariat général de la mairie de Ribadeo. En outre, nous ne savons pas si au cours du Moyen-Âge la forme Egovarros était encore employée pour désigner ces populations. Nonobstant, et cela peut paraître paradoxal, que cet auteur asturien ait commis ou non une erreur n'invalide pas notre précédente démonstration.

d) les Egovarri de Pline habitaient bien la région de I'Eo, comme le croit au demeurant la plupart des auteurs, et c'est manifestement la forme Egovarri utilisée par Humboldt et lue par Emile Littré, et non pas celle de Mayhoff que la plupart des chercheurs utilisent encore couramment de nos jours, qui est assurément la forme correcte étant donné que toutes les formes médiévales citées au début plaident en faveur de cette hypothèse: à partir d'une forme Egivarri on ne s'explique pas les formes médiévales Eube et Euve. En revanche, si on part d'une forme Egovarri, tout s'éclaircit en ce qui concerne l'initiale de ce nom : Egov-[arri] > Euv- > Eub- > Ob-, la chute du -g-intervocalique étant un phénomène de phonétique galicienne.

e) ce que nous ne savions pas alors expliquer, et que manifestement personne n'avait su expliquer, était la finale -varri. Humboldt, il est vrai à une époque considérée comme pré-scientifique, avait pensé qu'on avait affaire au nom d'une ville et que la finale -varri était le biscaïen barri, « neuf, nouveau » et en conséquence qu'il s'agissait d'un nom euskarien : ego-barri, «nouvelle demeure ». C'était bien entendu faux mais il avait toutefois raison sur un point : il s'agit effectivement d'un nom euskarien. On peut dire, sans exagérer, que cette découverte bouleverse en partie nos connaissances sur la 
Galice romaine - car à l'époque de Pline nous n'avons plus affaire à une époque dite pré-romaine. La forme latinisée Egovarri doit clairement être comparée à la forme médiévale Navarri : si cette dernière est une forme latinisée signifiant « les Navarrais » alors la forme Egovarri signifie tout simplement « les Egovarrais » et doit s'analyser en conséquence ainsi : $\boldsymbol{E g o b ( e ) - a r r , ~ a v e c ~ l e ~ s u f f i x e ~ b a s q u e ~ i n d i q u a n t ~ l ' o r i g i n e ~ - a r r , ~ - i ~}$ étant la déclinaison latine. On retrouve la forme *Egobe (d'où est issu le nom de la paroisse galicienne appelée Obe $<$ Ove $<$ Euve $<*$ Egobe) .

Les Egovarri de Pline étaient donc «les habitants du lieu appelé *Egobe, les Egovarrais» et le nom de l'antique localité luquoise (aujourd'hui paroisse) appelée *Egobe (aujourd'hui Obe) devait alors signifier « au pied, à l'embouchure de I'*Ego », la forme de cet hydronyme galicien ayant continué à évoluer : ${ }^{*} \boldsymbol{E g o}>\boldsymbol{E}$.

En guise de conclusion, on constatera que la démonstration peut sembler longue mais cela provient du fait qu'il a été commis au cours du temps, on l'a dit, plusieurs erreurs, principalement de lecture, qui ont rendu opaques des faits relativement simples au départ.

La conclusion de tout ceci semblera banale au profane qui ne s'intéresse que peu à ces questions, mais elle revêt une grande importance pour les Etudes Basques car ces faits contredisent en partie les théories actuelles sur l'étendue vers l'ouest de la Cordillère Cantabrique des parlers pré-indo-européens au cours de I'Antiquité.

Il semble désormais apparaître un fait fort simple au demeurant : chez les Callaïques du conuentus de Lugo, c'est-à-dire grosso modo dans le territoire constituant l'actuelle Galice, il y avait au cours de l'époque romaine certaines populations indigènes qui utilisaient les suffixes -arr et -be, indiquant I'un l'origine et l'autre la position, des suffixes qui se retrouvent encore de nos jours en basque moderne avec la même fonction.

Les dires de Pline de I'Ancien (Nat. Hist., III, 13) prennent alors un poids tout à fait remarquable : «La juridiction du conuentus de Lugo comprend seize peuples, qui à l'exception des Celtiques $^{69}$ et des Lémaves, sont d'origine obscure et ont des noms barbares, mais constituent néanmoins une population de 166.000 individus libres ».

En outre, cela expliquerait également un fait de phonétique galicienne qui n'a toujours pas reçu une explication satisfaisante. En galicien, on l'a dit, il existe, comme, entre autres, en basque, une tendance à éviter les $\boldsymbol{r}$ - à l'initiale et à les remplacer par arr-, c'est-à-dire avec $\boldsymbol{a}$ prothétique.

On a attribué ce phénomène à un substrat ibérique, fait que les auteurs galiciens dits « celtisants » se sont toujours efforcés de nier. 


\section{9) Les théories d'Ernst Gamillscheg}

Notre hypothèse n'est pas entièrement nouvelle. Elle avait déjà été suggérée, quoique pas exactement dans les mêmes termes, par le romaniste allemand Ernst Gamillscheg : d'après celui-ci, il aurait existé à l'époque pré-romaine et même romaine une unité linguistique allant depuis la Galice jusqu'aux Pyrénées orientales. Mais sa théorie ne fut pas acceptée par la communauté scientifique. Il faut dire, comme le rappelle Fredrick $\mathrm{H}$. Jungemann ${ }^{70}$, que la plupart de ses théories étaient abstruses. La plus curieuse concerne les Cantabres du VI ${ }^{\mathrm{e}}$ siècle. Selon cet auteur, c'est le roi wisigoth Léovigild qui aurait soumis définitivement les Cantabres dont l'origine était, toujours d'après lui, ligure et qui n'auraient jamais été complètement vaincus par les Romains. En 579, le nom de Cantabria est remplacé par celui d'Autrigonia. Selon Ernst Gamillscheg, ce changement s'explique ainsi : les Autrigons, qui étaient à cette époque sous le joug des Cantabres, leurs voisins et ennemis, aidèrent Léovigild à conquérir le territoire de ces derniers qu'ils reçurent alors en récompense. Afin d'éviter de nouvelles révoltes, les Wisigoths déportèrent une partie des Cantabres en Galice qu'ils avaient pour lors reprise aux Suèves. Entre temps, le reste des Cantabres se serait enfui dans les montagnes en compagnie des Vascons - qui pour lors avaient également été vaincus par les Wisigoths - et aurait envahi avec eux le versant aquitain. Cela aurait engendré un superstrat linguistique cantabre en Galice et dans les Pyrénées. E. Gamillscheg expliquait ainsi le phénomène de nasalisation des voyelles que connaissent conjointement le galaïco-portugais, le basque et le gascon. Cependant, cette hypothèse est considérée par tous les auteurs comme étant non fondée.

Ernst Gamillscheg avait manifestement vu juste sur un point, en partie du moins. Il y avait assurément en Galice, à l'arrivée des Romains, des populations qui non seulement utilisaient des langues préceltiques, ce qu'au demeurant on savait déjà, mais de surcroît, ce dont on doutait fortement il y a encore peu, que certaines de ces langues contenaient des éléments que I'on peut appeler pré-indo-européens apparentés, de loin ou de près, au proto-basque. En revanche, la supposée unité linguistique, allant depuis la Galice jusqu'aux Pyrénées orientales, mentionnée par Ernst Gamillscheg est plus que douteuse. En réalité, il devait exister plusieurs langues et certaines devaient même cohabiter sur un même territoire, et cela tout le long de la cordillère, tant cantabrique que pyrénéenne.

\section{0) Similitudes toponymiques galaïco-basques et cantabro-pyrénéennes}

Nous présentons par ordre alphabétique une liste non-exhaustive de toponymes qui, on l'a dit, se répètent ou semblent se répéter en Galice et en Pays Basque, voire parfois en Béarn et en Aragon. Nous utilisons presque toujours les formes anciennes recueillies, il y a plus de cinquante ans, par Víctor Olano Silva. 
-car / -kar: on n'a pas réussi à expliquer les toponymes basques Añézcar (Ansoáin, bailliage de Pampelune), Úcar (Valdizarbe, bailliage de Pampelune), Osácar (vallée de Juslapeña, bailliage de Pampelune) et Beloskar (montagne de Larrau, 1151 m., Soule), l'élément final -car ne pouvant être éclairci. On a essayé toutefois de rapprocher le premier du vocable souletin ainazkar, añazkar, «bruyère », les deux autres restant complètement énigmatiques. Dans la province de La Corogne, on trouve de nos jours le patronyme galicien Igléscar et dans la province d'Orense un village appelé Anícar, l'élément final étant inexpliqué. En Espagne, on trouve les toponymes Iscar (Valladolid, Castille-la-Vieille) et Izcar (Cordoue, Andalousie) où l'élément -car / -kar apparaît également. En basque le suffixe -kar semble se retrouver dans le navarro-labourdin hilkar, «tuerie, massacre, hécatombe ».

Aldai : une montagne de la localité d'Outeiro de Rei (Lugo) a pour nom Aldai (385 m.) d'après I'Institut Géographique National espagnol (IGN, échelle, $1: 25.000$, Rábade, feuille n 72-II). D’après Alfonso Irigoyen, un quartier de Baracaldo (Biscaye) a pour nom Aldai (cf. également le patronyme basque Aldai ou Alday). En outre, il signale un « "Aldana, cuesta de Santurce, 1863, barrio de Zaramillo (Güeñes)", este último mostrando la forma sin caída de - $\boldsymbol{n}$ - intervocálica, de donde procede aldai y alde, sul. althe, formas vascas conocidas, del bajo lat. *altana ${ }^{\mathbf{7 1}}$. Plusieurs montagnes et endroits d'Alava portent également ce nom : Alday, montagne d'Abecia, de Elosu et d'Acosta, quartier d'Amurrio et lieu-dit d'Arrieta (Treviño). L'évolution d'un autre toponyme galicien (cf. cartulaire de Lorenzana) semblerait confirmer I'hypothèse d'Irigoyen : in Uilla Noua de Archaa, 1177 > Uilla Noua de Archay (moderne Arca, Abadin, Lugo), la forme Archaa étant probablement issue d'une ancienne forme *Archana, ce qui permet de supposer par ailleurs, en ce qui concerne l'oronyme luquois, une évolution semblable et tout à fait vraisemblable *Altana > Aldana > *Aldaa $>$ *Aldae $>$ Aldai (forme actuelle) comme probablement dans Aspae > Aspai, cf. infra.

Ames : la forme ancienne du toponyme béarnais Ogenne (canton de Navarrenx) est Ogene, XI $\mathrm{I}^{\mathrm{e}}$ siècle, Oiena, XIII ${ }^{\mathrm{e}}$ siècle, Oyene, 1385. Michel Grosclaude considère qu'il s'agit du basque oihan, «forêt», hypothèse qui semble faire l'unanimité. Dans la province de La Corogne, on trouve une paroisse appelée Santo Tomás de Ames (municipalité de Negreira), autrefois Sci. thome de oianes, 1228, l'évolution ayant vraisemblablement été oianes $>\boldsymbol{*}$ o anes (confusion avec l'article masculin galicien $\boldsymbol{o}$ ) $>$ *anes > ames. On remarquera la terminaison inexpliquée -es dans oianes qui semble correspondre à un ethnique. La signification de ce nom galicien n'est pas connue.

Andelo: parmi les Vascones, Pline (Nat. Hist., III, 24) cite le peuple des Andelonenses, de la cité d'Andelo, l'ethnique se lisant aussi dans CIL II, 2963. Pour 


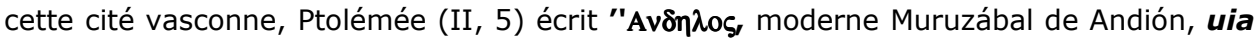
de Andione, 1060, au sud de Puente la Reina (Navarre). A Andión se trouvent les ruines d'une importante localité romaine. Un lieu de la province d'Orense a pour nom Andelo (localité de Peroja, paroisse de San Vicente de Graices), autrefois eu Gomez Eanes, cavalleyro d-Andello, 1296 (cartulaire d'Oseira).

Anós: d'après G. Rolhfs ${ }^{72}$ le toponyme Agnos, Anhos, 1364 (canton d'Oloron-Sainte-Marie) est issu du gentilice Annius, mais en revanche les noms des villages appelés Anos, 1243 (canton de Morlàas) et Anoz (vallée d'Ezcabarte, Navarre) seraient peut-être issus du cognomen Andus + suffixe aquitanique *-ossu, le changement de -nd- à - $\boldsymbol{n}$ - étant normal en gascon. En Navarre, ce changement ne peut cependant être dû, comme le rappelle Luis Michelena ${ }^{73}$, qu'à l'influence du parler aragonais : *Garindoain > Garínoain, Garinnoain en 1072 (Olite, Navarre). Dans la province galicienne de La Corogne, on trouve un village appelé Anós, accentué sur la dernière syllabe. Le nom n'est expliqué par aucun auteur et il ne semble pas qu'on en connaisse la forme ancienne. En galicien, le groupe -ny- passe normalement à $-\tilde{\boldsymbol{n}}-\boldsymbol{\text { , }}$ le gentilice Annius, et sa variante Annianus, étant ainsi à l'origine, comme le rappelle Joseph M. Piel ${ }^{74}$, de plusieurs noms tels que Añá (La Corogne), probablement Añón (La Corogne), Vilañán (Lugo), Añobres / Añobre (La Corogne), etc., ce dernier étant un quasi homonyme du toponyme navarrais Añorbe signalé par J. Gifford, mais il s'agit manifestement d'un paronyme. Grâce aux lois phonétiques du galicien nous pouvons restituer l'étymon qui serait peut-être à la base du nom galicien Anós, c'est-à-dire probablement (avec une terminaison en $\mathbf{o -}^{-}$-ōnis ) *Annōnis > *Annones (avec évolution romane et normale du -i- dans -ōnis qui passe à -ones) > *Anõẽs > *Anõõs > Anós.

Aralde : un village de Lugo et un autre de Pontevedra ont pour nom Aralde. Luis Michelena ${ }^{75}$ cite ce nom parmi celui des pecheros ou roturiers de I'Ordre de Saint-Jean en Navarre apparaissant dans un document du XIII ${ }^{\mathrm{e}}$ siècle. Dans la partie consacrée aux «villages de la Montagne», le document fait état d'un Lope Araldeco ou Lope d'Aralde, autrement dit d'un certain Lope originaire d'un lieu-dit ou d'une maison appelé Aralde au même titre qu'il est également fait état dans ce document médiéval d'un Eneco Iturbideco ou Eneco d'Iturbide. Il est probable que nous avons ici affaire au même nom que celui apparaissant en Galice. Or, il est également possible qu'il s'agisse d'un nom germanique puisqu'il s'avérerait douteux que les Aralde galiciens soient d'origine basque. Un village portugais a pour nom Baralde (Ponte do Lima, district de Viana do Castelo) dont I'origine germanique ne fait guère de doute d'après Joseph M. Piel ${ }^{76}$, ce qui dans la foulée nous laisse supposer que les deux Aralde galiciens le sont également. 
Arán : plusieurs lieux galiciens portent ce nom. Nos recherches nous permettent de citer la forme ancienne de l'un d'entre eux, probablement celui situé dans la province d'Orense : in loco qui vocantur Aran, in termino de Canba, 1240 ; in monasterio Ursarie, do et offero in presenti eidem monasterio totum quinionem meum quod habeo vel habere debeo in loco qui vocatur Aram, in terra de Canba, 1245 (cartulaire d'Oseira).

Aranga : la signification du nom de ce village galicien de La Corogne, situé dans une vallée entourée de montagnes d'une altitude moyenne de $700 \mathrm{~m}$. n'est pas connue. Le nom apparaît au Moyen-Âge dans une bulle confirmant les possessions de l'Eglise de Compostelle: et Superato et Aranga et Montejaurino quomodo diuidit cum Parrega de Prutiis et Bisanquis, 1178. La plus ancienne mention du nom de ce bourg de La Corogne date de 966 (10-XII) et non de 1178 comme nous l'avions indiqué : sic omnia uobis concedo sicut et uos mihi simul uestro et nostro castello Aranga cum omne sua prestantia (cartulaire de Sobrado). Le nom est attesté à plusieurs reprises et toujours sous la même forme : una cum fratres et sorores de Aranga, 1016. La signification de ce nom est inconnue. Le patronyme Aranga que I'on trouve en Amérique du Sud un nom de famille d'origine galicienne et non pas basque, contrairement à ce qu'on croit souvent, quoique à la rigueur il puisse s'agir d'un patronyme basco-galicien. Dans ce cas, il faut alors faire appel à la généalogie pour déterminer l'origine exacte des individus le portant. L'élément -anga se trouve, rappelle Luis Michelena77, dans les patronymes basques Estanga, Uranga, Uzkanga, etc. et n'a jamais été expliqué de manière satisfaisante. En outre, deux autres villages galiciens de la province de La Corogne s'appellent respectivement Arangas et Laranga. Le nom apparaît également fréquemment dans les Asturies : Arango (municipalité de Pravia), Las Arangas (municipalité de Grado, en asturien Grau), Arangas (municipalité de Cabrales), Aranguín (Pravia), etc. et en Navarre, on a le village appelé Elcóaz Arangoz dans un document ${ }^{78}$ du $\mathrm{XV}^{\mathrm{e}}$ siècle (vallée d'Urraúl, bailliage de Sangüesa), aujourd'hui manifestement Arangozki. Ces noms sont peut-être à mettre en rapport avec un hypothétique vocable pré-latin *ara apparenté probablement avec le basque (h)aran, ara(n)-, « vallée ». Voici la liste des noms de villages et paroisses galiciens où apparaît la forme aran et qui font difficulté, l'absence, pour la plupart d'entre eux, des formes anciennes empêchant toute explication. Province de Lugo : Arán, Fontarán, Arangón, Malvarán, San Pedro de Arante, autrefois S. P. de Alanti, 935 ; province de Pontevedra: Aranés, Arantey et San Pedro de Arentey; province de La Corogne: Arán (autre), Fonte Arán, Araño (cf. Arano, bailliage de Pampelune).

Arantón (San Vicente de): autrefois Aranton, 830, nom qui rappelle la ville vasconne d'Alantone cité dans l'Itinéraire d'Antonin et située à l'époque entre Aracaeli ou Araceli (Huarte-Arakil) et Pampelune. On aurait tendance de nos jours à 
identifier ce toponyme vascon Alantone avec l'actuel village navarrais appelé Atondo (Cendea d'Iza, bailliage de Pampelune). L'équivalence galaïco-vasconne Alanti, 935 (Arante, Lugo) $=$ Aranton, 830 (Arantón, Lugo) = Alantone dans l'Itinéraire d'Antonin (probablement Atondo, Navarre) doit être notée.

Aranza : Les deux villages galiciens appelés Aranza (Pontevedra et Lugo), malgré une surprenante homonymie, n'ont rien à voir avec le nom navarrais Arantza (village de Cinco-Villas, bailliage de Pampelune) et probablement non plus avec le patronyme Aranza cité par Michelena étant donné que la forme navarraise Arantza est récente, l'ancienne forme du nom de ce village étant Aranaz, 1280, Aranaz de las cinco villas de Lerin, 1644. Les formes anciennes des noms des villages galiciens appelés Aranza ne sont pas, sauf erreur, connues et le nom est inexpliqué. Nos recherches ultérieures nous permettent de signaler la forme ancienne du nom d'au moins l'une de ces localités, probablement celle de Lugo : in suas casas hic in Naraia quod eicisent de Pena ante iudice Vermudu Menendizi hic in Aranza, (13-XII-1058, cartulaire de Samos, Lugo). Même remarque que pour le nom précédent : le patronyme Aranza est un nom de famille basco-galicien. Il faut par conséquent et nécessairement faire appel à la généalogie pour déterminer l'origine exacte des individus ainsi nommés. D'autre part, ce nom galicien n'a aucun rapport, comme nous l'avions déjà indiqué dans notre dernier article, avec celui du village navarrais appelé Arantza (Cinco-Villas), autrefois Aranaz, 1280.

Arga / Argá : la signification du nom de la rivière navarraise appelée Arga est inconnue. Un village de la province de Lugo s'appelle Argá (ici toutefois il s'agit d'un oxyton), une rivière et une montagne de cette province étant également connues sous le nom de Argán qui, d'après Azkue, signifie en biscaïen «terrain pierreux ». En théorie, Argán pourrait s'expliquer par le basque arr(i) + gain > argain > argan, « hauteur rocheuse » comparable au toponyme labourdin *aitz + gain > azkain. Il est difficile de savoir quelle peut être la relation entre ces toponymes car les formes anciennes des noms galiciens ne sont pas, sauf erreur, connues. Joan Coromines ${ }^{79}$ cite également un arga pré-latin, sans en donner le sens, qu'il suppose d'origine celtique ou ibérique. Le nom se retrouve également, sous une forme vraisemblablement paroxytone, dans le nord du Portugal, dans la région de Braga. Il s'agit du nom d'une zone montagneuse culminant à 823 m. : Serra de Arga. La signification de ce toponyme cantabro-portugais est difficile à établir, il s'agit probablement d'un terme pré-latin < *arga, «brillant, blanchâtre », cf. top. asturiens L'Argaxá, Argaxo, (Tierra) I'Arguexu, la montagne asturienne appelée La Argarama, 1818 m., etc. Nous signalions également qu'une montagne et une rivière galiciennes avaient pour nom Argán. Une origine euskaroïde semble toutefois douteuse pour ce dernier, quoique 
plausible : < *arr(i) + gain. Nous n'avons pas pu retrouver les anciennes formes de tous ces noms, ce qui rend difficile leur analyse.

Argote : un village de La Corogne a pour nom Argote. La forme ancienne n'est pas connue. Un autre village galicien de La Corogne s'appelle Argonte, autrefois in villa Argonti, 955 (cartulaire de Sobrado) et deux villages portugais portent le même nom : I'un Argonde (Felgueiras, district de Porto) et Argonte (district d'Évora). Il s'agit dans les trois cas, indique Joseph $\mathrm{M}$. Piel ${ }^{\mathbf{8 0}}$, de noms d'origine germanique. Et il en est très probablement de même pour la variante Argote. En Pays Basque, un lieu-dit alavais est appelé de nos jours Argote (Treviño), autrefois c'était le nom d'un village : Argote, 1025, Argot, 1257. Ce nom basque n'ayant jamais pu être expliqué à partir de la langue basque, il est extrêmement probable qu'il s'agit dès lors, à l'instar de son homonyme galicien, d'un nom d'origine germanique. En outre, le patronyme Argote pouvant être de nos jours porté par un Portugais (cf. l'érudit portugais du XVIII ${ }^{\mathrm{e}}$ siècle Jeronymo Contador de Argote), un Galicien et un Basque de souche, il est par conséquent indispensable de faire appel à la généalogie si l'on veut connaître la véritable origine des individus ayant ce nom pour patronyme.

Arinez / Ariñez / Arínes: le nom de village alavais cité par José Miguel de Barandiarán Arinez / Ariñez, autrefois Ariniz, semble être identique à celui porté par une paroisse et une rivière galiciennes: Arínes (La Corogne).

Arros : dans la province de La Corogne, une juridiction et un archiprêtre s'appellent Arros (paroxyton, sauf erreur). Il ressemble aux toponymes bas-navarrais et béarnais Arros, le bas-navarrais étant prononcé en basque Arrotz. G. Rohlfs cite, entre outre, Arrós (Alto Pallars, province de Lérida) et Arrós (Val d'Aran, province de Lérida). En ce qui concerne le toponyme galicien, il pourrait être issu, mais ce n'est pas sûr, du « cognomen Arro attesté dans des inscriptions d'Espagne et de Lusitanie (CIL, II, 2735 et 5610 ) », selon G. Rohlfs ${ }^{\mathbf{8 1}}$. D'après nos recherches, le nom est déjà attesté dans un document suève du $\mathrm{VI}^{\mathrm{e}}$ siècle connu sous le nom de Parochiale. Mais il s'agit assurément d'une interpolation $d u X \mathrm{XI}^{\mathrm{e}}$ siècle $^{\mathbf{8 2}}$. On pense $\mathrm{d}^{\prime}$ ordinaire que ce nom galicien est en rapport avec celui d'un peuple du conuentus de Lugo appelé Arroni (Pline, IV, 111). Ce peuple considéré d'origine préceltique aurait occupé les régions d'Ortigueira situées à l'extrême nord de la province de La Corogne, ce qui correspondrait à la juridiction et à l'archiprêtré médiévaux d'Arros. Nous avions comparé ce nom, entre autres, au nom du village bas-navarrais appelé Arros ainsi qu'à ceux des villages pyrénéens ayant le même nom : Arrós (Alto Pallars, Lérida) et Arrós (Val d'Aran, Lérida).

Arteaga : ce nom se retrouve fréquemment en Pays Basque: on a le village navarrais appelé Arteaga (vallée de Allín, Estella), les villages et quartiers de Biscaye 
appelés respectivement Arteaga (quartier de Derio et de Zamudio), Arteaga-Uria (quartier de Gauteguiz de Arteaga) et le village appelé Arrati-Arteaga (en espagnol Castillo-Elejabeitia). Le sens est clair : «lieu de chênes-verts ». Or, d'après I'Institut Géographique National espagnol (IGN, $1: 25.000$, Arteixo, feuille $n^{\circ} 45-\mathrm{I}$ ), une montagne située à environ $7 \mathrm{~km}$. au sud de la ville de La Corogne a pour nom Arteaga. Une erreur de I'IGN est à écarter ${ }^{\mathbf{8 3}}$. La deuxième possibilité serait de supposer que le nom de cette éminence de La Corogne, une des plus élevées du secteur (244 m.), est un patronyme basque devenu un oronyme. Cependant, il s'agit d'une zone montagneuse inhabitée d'après I'IGN et le nom des autres montagnes ne paraît pas d'origine patronymique : Monte Runs (184 m.) à $2 \mathrm{~km}$. au nord-est de la montagne Arteaga, celui d'O Picoto (162 m.) situés à $1 \mathrm{~km}$. à l'est, les autres montes s'appelant : A Raña (142 m.), Filgueiras (id. 142 m.), Folgueira (270 m.), Coto de Fonte Mayor (181 $\mathrm{m}$.). Les villages situés au pied de la montagne Arteaga s'appellent, quant à eux, Orro, Toroño (cf. la montagne d'Alava appelée Toloño, 1271 m.) et Ledoño avec chute de la nasale courante en galicien * Lendoño $>$ Ledoño $^{\mathbf{8 4}}$. Comment pourrait-on dès lors expliquer cet étrange oronyme corognois Arteaga ? Le principal village du secteur est situé à environ $5 \mathrm{~km}$. à l'ouest de cette montagne et a pour nom Arteixo (autrefois en espagnol Arteijo, situé à environ $9 \mathrm{~km}$. au sud-ouest de la ville de La Corogne). Il existe plusieurs toponymes galiciens en art- inexpliqués: Arteixo (et la localité asturienne d'Artedo), Arteixiña (lieu-dit de la paroisse de Robledo, localité da Rúa, Orense), Artes (paroisse de San Xurxo de Artes, Carballo, La Corogne et Artes, lieu-dit de la localité de Ribeira, La Corogne, cf. le toponyme catalan Artés et le landais Arthez-d'Armagnac). On peut uniquement, dans l'état actuel de nos connaissances, postuler pour cet oronyme de La Corogne un prototype $*$ Arteaca $>$ Arteaga ${ }^{\mathbf{8 5}}$.

Asma : de nos jours un village situé au pied d'une montagne de $838 \mathrm{~m}$. et un fleuve de Lugo sont appelés Masma, autrefois le fleuve et toute la région étant appelés : in nasue, 747 ? (avec $\boldsymbol{u}=\boldsymbol{b}$, c'est-à-dire nasue = nasbe) ; Asma, $832 ;$ territorio Assue (= Assbe) et Asme, 871 ; Asua et Asma, 897 ; Asma, 1154, 1158 ; ambas Asmas, 1173 ; aujourd'hui Masma. Ce nom galicien rappelle étrangement celui de la vallée d'Aspe (Béarn autrefois Aspa, 1017), celui du village navarrais appelé Azpa (vallée d'Egüés, Sangüesa, autrefois Aspa, 1197) et les noms de villages pyrénéens Asme (Basse-Navarre, autrefois azpe, 1413, azme, 1481), Aspet (Haute-Garonne), Aspin (Hautes-Pyrénées) ainsi que celui d'un village aragonais, aujourd'hui abandonné, appelé Aspe, (autrefois Aspe et Aspa, XI $\mathrm{I}^{\mathrm{e}}$ siècle) et pour lesquels la quasi totalité des auteurs admet une origine pré-romane : aitz + - pe, « en bas de la hauteur rocheuse ». Le toponyme galicien Assue, Asua, Asma, Asme doit probablement signifier la même chose, car sinon il paraît inexplicable. Un autre village et une rivière de la province de Lugo ont pour nom Asma, le village étant situé au pied d'une montagne de $760 \mathrm{~m}$. 
Aspai : il s'agit du nom de village de Lugo que nous avions déjà mentionné. Il est situé au pied d'une montagne de $735 \mathrm{~m}$. Des recherches ultérieures nous permettent d'en citer la forme ancienne : unum casale in parrochia sancte Eugenie in villa que vocatur Aspay, 1234, in ecclesia sancti Salvatoris de Pinaria, que iacet in terra de Asma. Quicquid vero in predicta ecclesia habeo ex successione patris mei Garsie Roderici, militis de Aspay, 1242, Iohannis Fernandi de Aspae, 1242 (cartulaire d'Oseira). En outre, il existe deux villages appelés Asma dans la province de Lugo. Celui dont la forme ancienne est mentionnée ci-dessus et un autre dont nous avions déjà fait état et dont les formes anciennes sont citées par Olano Silva : in nasue (= nasbe), 747 ?, Asma, 832, territorio Assue (= Assbe), Asme, 871, Asua (= Asba), Asma, 897, ambas Asmas, 1173, il s'agit de nos jours du nom d'un village et d'une rivière de Lugo appelés Masma. Signalons également qu'un village de la province d'Alicante situé dans une zone montagneuse à $12 \mathrm{~km}$. au Nord-Ouest d'Elche (autrefois Ilicis, ancien territoire des Ibères appelés Contestani) a pour nom Aspe.

Azanza : au Moyen-Âge, comme le rappelle Jean-Baptiste Orpustan, Cambo (Labourd) était connu «surtout par le nom de maison noble Azantza». Il ajoute «d'étymologie apparemment basque mais obscure ${ }^{\mathbf{8 6}}$, cf. autrefois Sancho de Açança, 1249, Petrus de Assansa, 1311. En Galice, les documents médiévaux mentionnent un monastère, situé probablement dans la province de Lugo, qui n'a pas pu être identifié : Sancte Marie de Azanza, XII ${ }^{e}$ siècle (cartulaire de Lorenzana). En outre, un village de Lugo appelé de nos jours Anzas et situé dans la région de Ribadeo (à l'extrémité nord-est de la Galice) s'appelait autrefois Asanza : In Asanza ecclesiam Sancti Vicenti cum suis adiunctionibus, 7-VI-969; ego, Urraca Ueremudiz, facio cartam testamenti de media ecclesia Sancta Maria de Asanza, 1132 ; ego, Urraca Ueremudiz (...). Tali modo concedo uobis mea ecclesia sancta Maria de Asança, 26-X-1132 (cartulaire de Lorenzana). Citons également le village navarrais appelé Azanza (vallée de Goñi, Estella), autrefois Asança, Assança, 1233, 1280.

Baiona (graphie galicienne et officielle) / Bayona (graphie espagnole) / Baiona (aujourd'hui en français Bayonne). Il s'agit bien évidemment du cas le plus célèbre. Alfonso Irigoyen n'acceptait pas l'hypothèse de Jean-Baptiste Orpustan selon laquelle dans le nom labourdin Baiona on a probablement affaire à l'élément pré-indo-européen bai-, « cours d'eau» (cf. supra) car, écrivait-il, « en relación con el caso del de Galicia nos haría entrar en elucubraciones complejas de muy difícil solución ${ }^{\mathbf{8 7}}$. Il ne prenait pas en compte le fait que l'ancien et véritable nom de ce village galicien était jusqu'au $\mathrm{XII}^{\mathrm{e}}$ siècle Erizana, époque à laquelle il changea de nom pour s'appeler Baiona. D'après Eugène Goyheneche,

« il s'agit sans doute d'un repeuplement, d'une ville neuve, fondée au même endroit qu'Erizana (terme ancien) dépeuplée par les Invasions » étant donné qu'« on donnait à ces 
villes, souvent un nom déjà porté par une autre ville, plus célèbre ou plus ancienne. Il n'est donc pas impossible qu'en 1130 Alphonse VIII ait donné ce nom à Bayona de Galice, en se souvenant de notre Bayonne ${ }^{\mathbf{8 8}}$.

Les faits paraissent moins clairs que prévu. Ce nom galicien apparaît au début du XII ${ }^{\mathrm{e}}$ siècle. Or, le territoire où est située la ville de Baiona est chrétien depuis le début du VIII ${ }^{\mathrm{e}}$ siècle étant donné que la domination musulmane sur ce territoire (du moins l'emprise théorique car en réalité l'influence arabe en Galice et dans la partie nord du Portugal fut inexistante) dura à peine plus de vingt ans. En effet, les Arabes et les Berbères envahirent la Péninsule en 711 . En 739, sous le règne d'Alphonse $I^{\text {er }}$, la « frontière » entre le monde chrétien et le monde musulman était déjà située sur le fleuve Miño, c'est-à-dire sur l'actuelle frontière entre la Galice et le Portugal, et sous le règne d'Alphonse III (866-910) la limite était le fleuve Douro qui traverse la ville de Porto ${ }^{89}$. En conséquence, Baiona n'a pas pu être repeuplée au XII ${ }^{\mathrm{e}}$ siècle puisqu'à l'époque elle était déjà chrétienne depuis quatre siècles. L'énigme semble devoir perdurer puisqu'on ne sait toujours pas exactement pourquoi cette ville de Pontevedra porte le même nom que l'ancienne capitale du Labourd. Toutefois, il est probable qu'Eugène Goyheneche avait vu juste, c'est-à-dire qu'au XII ${ }^{\mathrm{e}}$ siècle, on donna peut-être ce nom à cette ville galicienne en souvenir de la cité basque dont le prestige était considérable à l'époque. Le nom Erizana existe encore de nos jours : Cabo Erizana, «Cap d'Erizana » (Pontevedra), nom considéré par certain comme étant d'origine pré-indo-européenne. La forme ancienne est inconnue, mais il est probable qu'à l'initiale l'évolution a été : $\boldsymbol{E r i -}<\boldsymbol{*} \boldsymbol{I} \boldsymbol{I} \boldsymbol{i}$-, cet élément $* \boldsymbol{I I I}$ - se retrouvant sous la forme $\boldsymbol{I r} \boldsymbol{i}$ - dans le nom du village galicien de Lugo appelé Orizón, autrefois Irizon, 1032. Menéndez Pidal $^{\mathbf{9 0}}$ rappelle que la ville galicienne actuellement appelée Padrón (La Corogne) s'appelait dans I'Antiquité Iria Flavia, nom inexpliqué et qu'on a voulu rapprocher du vocable ili- / iri- présent dans les noms Illiberris (Elvira à côté de Grenade, Andalousie), Illiberis (Pline), Eliberri (Mela), Ilibirris (Strabon), aujourd'hui Elne (Pyrénées- Orientales), etc.

Bardaos: dans la province galicienne de Pontevedra, on trouve la paroisse de Santa María de Bardaos (municipalité de Tordoia), autrefois Bardanis, 1228. Ce nom se rapproche curieusement de celui des Bardenas, en Navarre, autrefois, bardenas, 1155, Bardena, 1212, dont on n'a pas trouvé d'explication satisfaisante. Dans la province de La Corogne, on trouve également un village appelé Bardullas qui rappelle le nom de peuple Vardulli ou Varduli - ancêtres grosso modo des Guipuzcoans actuels - cité par Mela (Livre, III, 15) et Pline (Nat. Hist., Livre III, 27). Julio Caro Baroja $^{\mathbf{9 1}}$ rappelle que dans l'Antiquité, un peuple de Lusitanie était également appelé par le même nom : Bardili (Pline, Nat. Hist., Livre IV, 118). 
Bares : à l'extrémité nord-ouest de la province de La Corogne, au milieu d'un littoral extrêmement découpé, une bande de terre atteignant, dans sa partie la plus élevée, une hauteur de $210 \mathrm{~m}$., s'avance dans la mer sur une distance d'environ $5 \mathrm{kms}$. L'endroit est appelé de nos jours Punta da Estaca de Bares situé presque à la limite de la pointe de Bares, se trouve le village de Vila de Bares appelé dans l'Antiquité Burum (Ptolémée, II, 6). Ce toponyme galicien de l'époque romaine contient manifestement le vocable pré-indo-européen (et aujourd'hui basque) buru, « extrémité, cime, cap, tête ». L'Itinéraire d'Antonin cite un lieu galicien appelé Burbida situé probablement, d'après Menéndez Pidal, à côté de l'actuelle paroisse de Santiago de Borbén (Pontevedra). Toujours d'après M. Pidal, il s'agirait de buru, « cima » y bide, « camino, camino de la montaña $\gg^{\mathbf{9 2}}$. Joan Coromines ${ }^{\mathbf{9 3}}$ pense également qu'il s'agit de buru-bide.

Beade : le nom du village de Santa María de Beade (Orense) est attesté au Moyen-Âge sous la forme Sanctae Mariae de Vilate, 1112. Nous avions, à l'instar de Gifford, comparé ce nom au nom d'un col navarrais appelé Velate (graphie basque Belate). Pline (Nat. Hist., IV, 33) cite parmi les peuples aquitains les Vellates dont le territoire n'a pas pu être identifié. Certains auteurs ont proposé de voir dans le nom navarrais un souvenir de ce peuple et de faire de ce col navarrais la frontière entre les Aquitani et les Vascones, ce qui n'est pas impossible. Si cela devait être le cas, alors l'étymologie basque que l'on attribue d'ordinaire au toponyme navarrais Belate (< bela- + ate < bele + ate, « porte, passage des corbeaux 》) serait erronée. Il est fort probable, en effet, que le nom de peuple Vellates est un nom d'origine celtique étant donné qu'il désignait également un peuple celte originaire de la région italienne du Pô : les Veleiates (Pline, Nat. Hist., III, 116).

Beariz : le nom de la paroisse galicienne appelée Santa María de Beariz (municipalité de Beariz, Orense) est un toponyme d'origine germanique, les formes anciennes étant : viarici, 1034, uiarici, uiariz, 1053, veariz, $1220^{\mathbf{9 4}}$. Le nom est issu de l'anthroponyme germanique, attesté en Galice (ainsi qu'en Espagne et au Portugal) comme le rappelle Ana Isabel Boullón Agrelo, Viaricus, romanisé par la suite en Viarigo. Dans un article paru récemment dans Fontes $^{95}$, nous avons émis I'hypothèse selon laquelle le toponyme labourdin Biarritz, autrefois beariz, 1150, bearriz, 1150, bearidz, 1186, bearritz, 1249, bearys, 1344, bearitz, 1511, pourrait avoir la même origine que ce nom galicien, d'autres toponymes basques d'origine germanique étant attestés en Navarre. Nous ne reviendrons pas sur l'argumentation développée dans cet article auquel il suffira de se reporter. Nous rappellerons simplement qu'il existe une difficulté pour accepter notre hypothèse. Il faudrait être en effet certain, ce qui n'est pas le cas, que dans les formes anciennes du nom Biarritz, c'est bien la vibrante faible intervocalique $\boldsymbol{- r}$ - qui est étymologique et non l'inverse. Si c'était le cas, l'équivalence Veariz / Beariz galicien / Beariz, Bearriz labourdin serait envisageable, car le 
parallélisme est tout à fait frappant. Cependant, il se peut que la vibrante forte soit étymologique puisque lorsqu'on a affaire dans les formes médiévales d'un nom à l'alternance -r- / -rr-, c'est presque toujours la forme avec vibrante faible qui est fautive et dans le nom Biarritz la forme avec -rr- forte est constante depuis les premières attestations. Il existe deux autres paroisses galiciennes portant le même nom : San Martín de Beariz (municipalité de San Amaro, Orense) et Santa Magdalena de Baariz, 1392 (municipalité de Paradela, Lugo).

Beascós: dans la province de Lugo, on trouve le village de Santa Marina de Beascós (municipalité de Carballeda), autrefois Sancto Martino de Velascones, 1175. Ce nom rappelle le nom aquitain, attesté à l'époque romaine, Belexconis (et sa variante Belasconis citée par Michelena et Irigaray) et qui pourrait être d'après ces deux auteurs à l'origine du nom Bricous, en basque Beskoitze, autrefois Berascoiz(co), «(de) Briscous » d'après Lissarague qui en était natif. La chute du -nintervocalique et le passage de $\boldsymbol{- l}$ - intervocalique à $\boldsymbol{- r}$ - sont des phénomènes courants en basque. Jean-Baptiste Orpustan ${ }^{96}$ propose également une autre hypothèse. En ce qui concerne le toponyme de Lugo, il est certain qu'il provient d'un plus ancien *Velascōnis, en galicien l'évolution romane de la voyelle $\boldsymbol{i}$ à $\mathbf{e}$ dans la terminaison -nis étant tout à fait normale et régulière, les exemples qui le montrent étant nombreux, et par conséquent, il est sûr qu'en Galice on a eu une forme plus ancienne Velasconis ou Belasconis qui a normalement évolué en Velascones puis en Beascós: soit $\boldsymbol{V e}(\boldsymbol{I}$ )ascones > *Beascõẽs en ancien galicien (Fernandez, 1991 : 66, § 3.20) > *Beascõõs > Beascós avec changement de $\boldsymbol{v}$ en $\boldsymbol{b}$ et amuïssement automatique de la latérale ainsi que de la nasale intervocaliques.

Beasque: nous avons trouvé dans la municipalité galicienne de Ponteareas (Pontevedra), un hameau appelé Beasque (81 habitants en 1980), nom qui rappelle le toponyme bas-navarrais Béhasque. On ne connaît pas la forme ancienne du nom galaïque, mais les lois phonétiques du galicien permettent de la reconstituer. Cette forme ne peut-être manifestement que Velasco puisqu'en galicien $\boldsymbol{v}$ passe à $\boldsymbol{b}$, la latérale intervocalique s'efface et -o final s'affaiblit en -e (comme dans le toponyme galaïque actuel Gondaisque < Gandaisco, 1128); d'où en galicien Velasco > Beasque. Ce nom viendrait appuyer l'hypothèse selon laquelle le nom navarrais Béhasque est issu lui aussi, comme le pense également Jean-Baptiste Orpustan ${ }^{\mathbf{9 7}}$, de l'anthroponyme Velasco; avec cependant un suffixe d'appartenance -anum. Jean-Baptiste Orpustan cite également une autre hypothèse purement toponymique. Toutefois, bien que le résultat soit apparemment le même dans Beasque / Béhasque, l'évolution qui a été celle de ces deux noms est différente. En basque le passage de $\boldsymbol{v}$ à $\boldsymbol{b}$ existe, mais la chute de la latérale n'est pas automatique comme en galicien. L'évolution a donc été : Velasco + -anum > Belask(o) + -ain > Berask(o) + -ain 
(avec -I- > - r-) > Behask(o) + -ain avec vibrante faible qui s'atténue entre voyelles jusqu'à $\boldsymbol{h}$ (cf. uralde $>$ uhalde, etc.). A la finale non plus, l'évolution n'a pas été la même puisque c'est l'accentuation gasconne qui explique le passage Beháskain > Behásken > Behásque, la forme basque étant Behaskane.

Beleia / Velegia / Pons Vellegia : I'Itinéraire d'Antonin cite un endroit galicien appelé Pons Vellegia (aujourd'hui Ponte Vea, La Corogne). Le nom paraît devoir être rapproché de celui de la ville des Caristes appelée dans l'Antiquité Ouéleia / Beleia ou Velegia (aujourd'hui Iruña, Alava).

Bestar : l'anthroponyme médiéval Belastar, San Millán, 952, d'origine basque d'après Gonzalo Díez Melcón ${ }^{98}$ et dans lequel on croit voir, comme le rappelle Luis Michelena99, le suffixe basque -(t)ar, se retrouve également dans le nom de la paroisse galicienne de Santa María de Bestar (municipalité de Cospeito, Lugo), autrefois Sancta Maria de Valestar, 897, Belestari (datif), 1062. On le rencontre probablement aussi dans le nom de la paroisse également luquoise de San Pedro de Besteiros, autrefois S. P. de Baestarios, 1164 < *Balestairos < *Balestarios, en galicien $\boldsymbol{i}$ semi-voyelle dans le groupe $\boldsymbol{r y}$ reculant jusqu'à la syllabe précédente : $-\boldsymbol{r} \boldsymbol{y}$ - $>\boldsymbol{>}$-ir-. A cette époque la chute de la latérale intervocalique avait déjà eu lieu en galicien.

Bioron / Biurraran / Biurrun : d'après Gifford la rivière galicienne appelée Luyña ou Naviego (Orense) était appelée autrefois Bioron, 1112, le nom n'étant manifestement ni d'origine celtique ni latine. Cependant, Gifford a dû se tromper en ce qui concerne la localisation de cette rivière, car à notre connaissance il n'existe pas en Galice de rivière appelée Luyña ou Naviego. En revanche, dans les Asturies occidentales il existe une rivière connue sous le nom de río Luiña (traversant la localité de Luiña) et dans les Asturies centrales une autre rivière appelée Naviego qui prend sa source au pied de la montagne d'Arbás (2007 m.). Dans le village navarrais de Lesaka (bailliage de Pampelune), il existe une rivière sinueuse appelée tantôt Uarte, tantôt Biurgarai et un quartier connu sous le nom de Biurrarango auzua, «le quartier de Biurraran ». Gifford compare le nom médiéval de cette rivière asturienne, qu'il croit manifestement galicienne, avec celui du village navarrais appelé Biurrun (Valdizarbe, Pampelune), autrefois Bihurrun, 1272, Biurun, 1345, issu du basque bi(h)ur, « tordu » et -un, « lieu, endroit ». Le nom asturien médiéval Bioron (< *biurrun) n'est pas expliqué.

Bizcaia : un hameau galicien est appelé Bizcaia (paroisse de San Pedro de Láncara (Lugo), ancienne graphie espagnole Vizcaya (cf. «Bizkaia, caserío de Ranero (Carranza), 1671, Bizcaya » cité par Irigoyen). Une région située dans la vallée navarraise d'Aibar est également appelée Vizcaya, le nom étant orthographié le plus souvent en basque Bizkaia. A côté de la montagne appelée Aldai (Lugo, cf. supra), un 
endroit montagneux est également appelé Os Bizcaios (< *OS Bizcainos, «les Biscaïens » à la suite de la chute normale en galicien du $\boldsymbol{- n}$ - intervocalique, ce terme désignant à une époque les Basques en lieu et place de l'ancien terme Vascones). Alfonso Irigoyen rappelait que le nom du monte Igueldo de Saint-Sébastien (cf. la montagne galicienne appelée Gueldo et l'asturienne Agueldo, 1248 m.) apparaît dans un document du Moyen-Âge accompagné du terme Bizchaya pour désigner la montagne: concedo totum quod in iheldo Bizchaya ${ }^{100}$. Par le passé, ce mot a probablement dû être utilisé dans tout le Nord de l'Espagne avec le sens de montagne, ce qui expliquerait sa présence en Galice.

Buño : la montagne de $738 \mathrm{~m}$. surplombant la ville galicienne d'Aranga (La Corogne) est appelé Buño, nom que porte également un village proche de la ville de La Corogne. Ces deux noms doivent être vraisemblablement rapprochés du radical oronymique pré-latin bun-101, «hauteur » présent dans le toponyme bas-navarrais Bunus, bunos, 1304 (suivi ici du suffixe aquitanique -os) et également dans le lexique basque actuel sous les variantes nasalisées muno, munho, muño, « colline ».

Burés : dans la province de La Corogne - non loin du cap Finistère, autrefois appelé Promonterium Nerio, du nom de la tribu galaïque des Nerio appartenant d'après Pomponius Mela à la vaste confédération des Artabri - dans un endroit montagneux situé en bord de mer, on trouve le village de Burés dont le nom rappelle curieusement le toponyme béarnais Buros dans lequel il faut peut-être voir le thème pré-latin *bur-102, « hauteur » (cf. basque buru, «tête ») variante du radical bun- déjà cité. Dans la province de Pontevedra, on trouve également deux montagnes appelées respectivement Buroz et Burizo.

Caaveiro : dans la province de La Corogne, on trouve également le village de Caaveiro, autrefois sci. iohannis de calauario, 936?, scm. Johannem de Calaueyro, 1199. Toujours dans cette province, une plage et une pointe rocheuse s'avançant dans la mer s'appellent Caveiro. La forme ancienne de ce nom n'est pas connue, mais ici aussi il est probable que le ca- initial est issu d'un plus ancien *cala-, tout comme dans le nom du village luquois appelé Caamonde, issu probablement d'un ancien *calamundi.

Caboi : dans la province de Lugo, on trouve la paroisse de San Martín de Caboi (municipalité d'Otero de Rei) appelée autrefois Calabogi, 959, Cabogi, 1127, Caabogi, 1231 avec chute de la latérale intervocalique. L'élément initial cala- de ce nom galicien est identique à celui qu'on trouve, entre autres, dans le toponyme attesté à l'époque romaine Calagurris (Calahorra), ce dernier étant le nom d'une ville considérée à l'époque comme vasconne. 
Ceánuri / Zeanuri : Alfonso Irigoyen $^{\mathbf{1 0 3}}$ avait rapproché le nom de la ville biscaïenne de Ceánuri, dont la forme ancienne n'est pas connue, comme le rappelait Luis Michelena, des nombreux noms de lieux galiciens appelés Ceán, dont celui d'un village de la province de Pontevedra et d'une montagne de La Corogne. Le sens de Ceánuri serait «ville de Ceán». Luis Michelena y voyait un *Azenar-uri avec dissimilation de la vibrante et chute en basque du $-\boldsymbol{n}$ - intervocalique : «ville d'Aznar ${ }^{104}$.

Cedeira / Cettaria : le village de Cedeira est situé en bord de mer, au nord-ouest de la province de La Corogne. A l'époque romaine, il était appelé Cettaria $(\boldsymbol{c}=\boldsymbol{k})^{\mathbf{1 0 5}}$. L'évolution Cettaria > Cedeira est normale en galicien. Une montagne de La Corogne de $600 \mathrm{~m}$. s'appelle également Cedeira. La forme Cettaria doit peut-être être rapprochée du nom du village labourdin appelé Guéthary, autrefois Cattarie, 1193 d'après Paul Raymond, et aussi sans doute du Getaria guipuzcoan. En ce qui concerne le village labourdin de Guéthary, on n'y a retrouvé des traces d'un camp romain, mais la signification exacte du nom n'est pas assurée.

Deba / Deva : cet hydronyme est d'origine celtique. Le fleuve guipuzcoan appelé Deba (c'est aussi le nom d'une ville guipuzcoane) séparait dans l'Antiquité le peuple des Caristes (ancêtres grosso modo des Biscaïens actuels) de celui de Vardules (ancêtres grosso modo des Guipuzcoans actuels). Le nom est également celui d'un fleuve cantabro-asturien puisqu'il sert aujourd'hui de frontière aux communautés autonomes des Asturies et de Cantabrie, ce fleuve étant situé dans I'Antiquité en territoire cantabre. En Galice, ce nom apparaît écrit, tantôt Deva, tantôt Deba : c'est celui d'une rivière traversant les provinces d'Orense et de Pontevedra et c'est également le nom d'une paroisse de Pontevedra.

Ibía / Ibías / Ibias : dans les Asturies occidentales on trouve une rivière appelée río Ibias, manifestement sans accent (IGN, Degaña, 1 : 25.000, 100-II) traversant la localité asturienne de Degaña située à $837 \mathrm{~m}$. (cf. le toponyme alavais et le patronyme basque Egaña < egi-gaiña < egi, «línea de los montes, ladera», selon L. Michelena ${ }^{\mathbf{1 0 6}}$ et correspondant parfaitement à la situation géographique de cette localité asturienne). En Galice, dans la localité de Barreiros, province de Lugo, on trouve un ruisseau et un hameau appelés Ibía, autrefois unde in directo ad Sancto Laurencio unde ad Ibia et per iuga montis super Coarcos uia, 17-VI-969; per iuga montis usque Ibia et sicut determinatur per circuitu omnem cautum usque in flumine Masma, 18-V-1087 (cartulaire de Lorenzana). Une autre petite rivière de Lugo s'appelle également Ibías. Un village de La Corogne et un autre de Pontevedra ont également pour nom Ibia (sans accent tonique comme dans le cas de I'hydronyme asturien). Ces 
hydronymes galaïco-asturiens doivent être comparés au basque $\boldsymbol{i} \boldsymbol{b} \boldsymbol{i}$, « ruisselet » en Soule, « gué » en Navarre (Lhande).

Igon : on a en Béarn un village appelé Igon (canton de Nay-Est), autrefois Ygon, 1385. Un autre village béarnais a pour nom Eygun (canton d'Accous), autrefois Igun, 1449. L'origine de ce nom est considérée d'ordinaire comme pré-indo-européenne. En Aveyron ${ }^{\mathbf{1 0 7}}$, on trouve également un autre Igon (dans le Tarn, on a un lieu appelé I'Igal, cf. le village navarrais appelé Igal, en basque Igari, dont la signification est inconnue, autrefois Igali, 1085, Igal, 1174). En Galice, on rencontre un village appelé Igón (Lugo). Des recherches ultérieures nous permettent en outre de citer une paroisse du même nom dans la province d'Orense : San Cristóbal de Regodeigón (localité de Beade), c'est-à-dire en galicien rego, « ruisseau » de (E)igón, autrefois Aygon, Eigon, 1219, Eygon, 1223, 1226, 1242, Eygun, 1249, Eigom, 1251, Eygum, 1253, in caminum quod vadit ad Eygun, 1253, Eygon, 1259 (cartulaire d'Oseira).

Igueldo / Gueldo / Agueldo : une montagne galicienne s'appelle Gueldo (La Corogne), nom qui rappelle curieusement la montagne de Saint-Sébastien appelée Igueldo (graphie basque Igeldo) et la montagne asturienne connue sous le nom d'Agueldo, $1248 \mathrm{~m}$.

Izaro / Ézaro : d'après Azkue, l'île située dans la baie de Bermeo (Biscaye) a pour nom Izaro, mot qui pourrait peut-être signifier, toujours d'après cet auteur, « île » en général. Juan Antonio de Moguel, dans son roman intitulé Peru Abarca, dit que le mot signifie «círculo de mar». On retrouve manifestement le même nom dans la province de La Corogne où un village situé en bord de mer s'appelle Ézaro, l'alternance i- / edemandant cependant à être expliquée, à moins que le biscaïen Izaro ne soit au contraire issu d'un ancien *ezaro, quoique la langue galicienne connaît l'alternance vocalique $\boldsymbol{i} / \mathbf{e}$, principalement à l'intérieur des mots : único > úneco, etc. en asturien cette alternance vocalique pouvant se rencontrer également devant une sifflante: historia > hestoria, hestóricu, etc. Le village d'Ézaro, situé à côté du Cap Finistère, se trouve au pied d'une petite montagne qui tombe à pic dans la mer. Le village est situé à l'intérieur d'une toute petite baie en forme de demi-cercle. Le fleuve appelé Xallas ou Ézaro, situé pratiquement au dessus du village, se jetait autrefois directement dans la mer depuis une hauteur de $300 \mathrm{~m}$., ce qui en faisait un spectacle presque unique en Europe. Plus tard, l'entreprise espagnole FENOSA supprima cette chute d'eau. Aujourd'hui, le fleuve se jette dans la mer le long de canalisations qui fournissent de l'énergie électrique. L'équivalence présumée Izaro biscaïen = Ézaro galicien avait déjà été remarquée et soulignée par Carlos Jordán Cólera ${ }^{\mathbf{1 0 8}}$, qui compare également, entre autres, les hydronymes Isara et Ésera, ce toponyme galaïco-basque n'étant sans doute pas, comme le pensait Azkue et Moguel, un mot basque, mais plutôt un mot d'origine 
inconnue où il faudrait voir la racine, vraisemblablement hydronymique, $\boldsymbol{*}_{\boldsymbol{i}}$ - ou $\boldsymbol{*}_{\mathbf{e z}}$-, Carlos Jordán Cólera allant même jusqu'à proposer une racine hydronymique paléo-européenne $*$ eis / $*$ is, « se mouvoir avec rapidité, violemment ». Dans le nom Iso (nom d'une rivière de province de La Corogne), il semblerait qu'il y ait également cette racine. Un village de Lugo s'appelle Izá (oxyton). Le nom semblerait être issu de

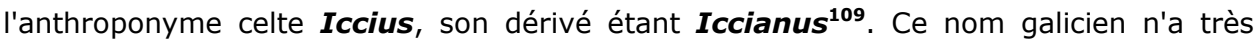
probablement rien à voir avec le toponyme navarrais Iza, autrefois Hiiça, Hiiza, 1124, issu manifestement du basque $\boldsymbol{i}(\boldsymbol{h}) \boldsymbol{i}+\boldsymbol{- t z a}$, « jonchaie ».

Láncara / Lángara : un ancien village d'Alava s'appelait Langara, 1025, moderne Nanclares de Gamboa selon López de Guereñu, cf. les lieux-dits alavais: Langarabidea, Langarabide, Langararabidea, Langarasaspia. Hubschimd ${ }^{110}$ cite plusieurs toponymes où on rencontre un suffixe atone '-ara tels que Brácara (Braga), Lózara (Lugo), Tállara (La Corogne), etc. Pour notre part, citons : Río Záncara (20 km. à l'est de Cuenca, Castille-la-Manche). Dans notre dernier article, nous citions le village de Lugo appelé Láncara, autrefois per termino de Elarin et per termino de sancto Vicentio de Lancara, 1059 (cartulaire de Samos). Nous indiquions qu'en basque la sonorisation de l'occlusive après $\boldsymbol{n}$ est normale : Láncara > Lángara. Nos recherches nous permettent également d'en citer également une variante en Estrémadure : le village et la rivière de Lácara ${ }^{111}$. En outre, nous en avons trouvé d'autres en Galice : un hameau situé à côté de la ville de Betanzos (IGN, Betanzos, La Corogne, 1 : 25.000, 45-II/5-5) est appelé Lángara (avec une séquence -n- au lieu de -nc-). Toujours au nord de Betanzos, on trouve également le lieu-dit appelé Pazo de Láncara. Un quartier du village alavais d'Arratzu-Ubarrundia est appelé Langara, nom qui se retrouve dans celui d'un village, d'une montagne et d'une vallée de la province de Lugo appelés tous les trois Láncara (proparoxyton), au Moyen-Âge également Lancara (cf. GGRG), en basque la sonorisation de l'occlusive après $\boldsymbol{n}$ étant normale : * Lankara > Langara. Luis Michelena cite également le toponyme et patronyme basques Langarika (quartier d'Iruraitz-Gauna, Alava) dans lequel le suffixe -ika, très abondant en Biscaye et en Alava serait d'origine celtique ${ }^{\mathbf{1 1 2}}$.

Larrate : il existe en Navarre deux lieux appelés Larrate. Le premier est le nom d'un lieu-dit qui se trouve dans la municipalité de Fitero, Larrate de Vinuelas, 1254, aujourd'hui La Rate (municipalité située dans l'extrême sud de la Navarre et appartenant au bailliage de Tudela) et le second est le nom d'une colline située à côté du village de Carcastillo (bailliage de Tudela, la rat, 1319 et la Rate, 1844). Plusieurs auteurs, dont, entre autres, Jesús Arzamendi, Ricardo Ciérbide ${ }^{\mathbf{1 1 3}}$ et Luis Michelena, y voient probablement un nom basque : «porte, passage de la lande » ou «lieu de landes » si le suffixe -ate est ici une variante du suffixe locatif -eta. Erlantz Urtasun ${ }^{\mathbf{1 1 4}}$ pense que ce nom pourrait être une preuve de l'emploi autrefois de la langue basque 
dans cette région. Cependant, J. Giffford fait état d'un toponyme galicien Larrate en 853 (province d'Orense). Considérer que ce nom galicien médiéval est un basquisme s'avère délicat. Par conséquent, on peut raisonnablement douter de la basquité des deux toponymes navarrais précités.

Lorbé / Lurbe : le petit village de Lorbé (oxyton), situé à côté de la ville de La Corogne, se trouve en bord de mer dans une région où la côte, surnommée "La Côte de la Mort » (A Costa da Morte), est très découpée et regorge de falaises. Les formes anciennes de ce nom ne semblent pas, sauf erreur, être connues. Le nom ressemble à celui porté par le village béarnais de Lurbe (Lurbe-Saint-Christau), autrefois Lurbe, 1385, qui s'explique par le basque lur , «terre » et -be, «sous », c'est-à-dire sans doute, d'après Michel Grosclaude, «terre basse ». Seules les formes anciennes de ce nom galicien nous permettraient probablement de savoir de quoi il s'agit exactement.

Meano : le village navarrais appelé Meano (vallée d'Aguilar, bailliage d'Estella) se retrouve, comme le souligne J. Gifford, dans la province de Pontevedra sous la forme Meaño (avec $-\tilde{\boldsymbol{n}}$ - intervocalique).

Ois: l'origine du toponyme Ois paraît sûre (Santiago de Ois, village de La Corogne), autrefois in loco Adones, 910 dont l'évolution n'a pu être manifestement que : Adones $>$ *Aõẽs $>$ *a Ois (confusion avec l'article galicien féminin a) $>$ Ois, ce dernier étant peut-être en rapport avec les toponymes Oiz, en basque Oitz (montagne de Biscaye et village de Navarre, Malerreka, Pampelune) et peut-être avec celui de Aoiz, en basque Agoitz, Aoitz (bailliage de Sangüesa). Le toponyme galicien Adones, doit être comparé avec le nom de personne Aio, genitif Aionis, retrouvé par Alfonso Irigoyen ${ }^{\mathbf{1 1 5}}$ dans une inscription romaine d'Estrémadure : Camilius / Arrus / Aionis $\boldsymbol{f}$. / Clun. an. / LXX hic. Ce nom serait à l'origine, d'après cet auteur, du toponyme navarrais Aoiz (chute du [j] , du $\boldsymbol{- n}$ - intervocalique et équivalence $\boldsymbol{s}$ latine $=\boldsymbol{z}$ fricative dorso-alvéolaire basque d'après Luis Michelena, neutralisée en basque en position finale en tant qu'affriquée $-\mathbf{z}>\mathbf{- t z}$ ), le nom étant prononcé par les bascophones Agoitz avec -g- anti-yod. Alfonso Irigoyen cite également la variante romanisée et médiévale noble don Per Ahones, 1320, très proche de notre Adones galicien et également médiéval.

Oka / Oca : le fleuve traversant la ville biscaïenne de Guernica s'appelle Oka. Le nom se retrouve en Galice. Il s'agit du nom de trois villages de La Corogne : Oca, Oca de Abaixo et Oca de Enriba (formes galiciennes). Pour les toponymes Oca, attestés en Pays Basque, on pourra se reporter à l'article d'Alfonso Irigoyen ${ }^{\mathbf{1 1 6}}$. En Galice, il ne peut guère s'agir cependant du latin tardif d'origine celtique olca (Grégoire de Tours) qui a donné le français ouche, «champ labourable» (et le toponyme bas-navarrais Occos, autrefois Olcotz, 1249) car, dans ce cas, nous aurions dû impérativement avoir une forme galicienne Ouca, ce qui n'est pas le cas. Le fait que la forme médiévale de 
ces noms galiciens est Oqqua vient confirmer cette analyse et montre clairement qu'il s'agit d'autre chose, sans que l'on sache exactement quoi.

Orons / Oronz: le nom du village navarrais appelé Oronz (vallée de Salazar, bailliage de Sangüesa), en basque Orontze, n'est toujours pas expliqué. Un village de la province de La Corogne s'appelle Orons.

Sada : en Navarre, on trouve le village de Sada, 1112, en basque Zare, 1127 (bailliage de Sangüesa). P. Salaberri117 a essayé de comparer, en vain comme il reconnaît lui-même, la forme basque Zare avec le toponyme labourdin Sara, autrefois Sare 1289 (en français Sare). La forme Zare n'est rien d'autre qu'un avatar basquisé et populaire du nom Sada, l'alternance $-\boldsymbol{d}->\boldsymbol{- r}$ - entre voyelles étant extrêmement courante en phonétique basque comme le rappelle Henri Gavel. Ce qu'il faut expliquer, c'est Sada. Il s'agit, comme le rappelle J. Gifford, du même nom que celui de la ville galicienne de Sada située à côté de La Corogne. L'explication du nom donnée par ce dernier est tout à fait satisfaisante : ce toponyme basco-galicien est issu du latin satus, plu. sata, «terres ensemencées » avec sonorisation normale en galicien du -tintervocalique. En Navarre, la sonorisation, ici d'origine obligatoirement romane, a également eu lieu comme dans le toponyme également navarrais et voisin Artieda, arteda, 1178 (vallée d'Urraúl, Sangüesa).

Senari ( $<$ *senarr-, $-i$ ) : une inscription funéraire aquitanique découverte près de Luchon (Cazaril-Laspène, Haute-Garonne) porte l'épitaphe suivante: Hotarri . Orcotarris . f(ilio) / Senarri [datif]. Eloni . Filiae / Bontar .Hotarris . f(ilius) . ex . Testamento. Comme le rappellent Julio Caro Baroja, Luis Michelena et Joaquín Gorrochategui, on ne sait pas exactement s'il faut lire Sentarri (d'après Ricci) ou Senarri (d'après Sacaze). En Galice, un hameau de la paroisse de Santiago de Entrambasaguas (municipalité de Guntín, Lugo) a pour nom Sear. L'endroit est dit en 897, d'après les recherches de V. Olano, Scti. iacobi de Senari (sic) [très probablement Senarri] quae dicitur de intra ambas aguas. A notre connaissance, ce fait n'est rapporté par aucun auteur. L'amuïssement, normal en galicien, du -nintervocalique explique la forme moderne Sear $[\boldsymbol{r}]$. Dans la province de Pontevedra, un hameau porte le même nom. En outre, I'Itinéraire d'Antonin cite chez les Astures augustani (actuelle province de Léon) un lieu appelé Uttaris (probablement le village appelé Ruitelán, province de Léon) qui ressemble au nom aquitanique Hotarris (génitif). Dans sa récente thèse de doctorat ayant pour objet l'anthroponymie médiévale galicienne du VIII ${ }^{\mathrm{e}}$ au XIII ${ }^{\mathrm{e}}$ siècle, Ana Isabel Boullón Agrelo cite les noms de personne galiciens Oihenia et Hahanxi, les deux étant féminins, qu'elle compare au vocable basque oi(h)an, «forêt » et à l'anthroponyme féminin aquitain Hahanni figurant sur 
une inscription retrouvée dans la ville de Saint-Bertrand-de-Comminges (Haute-Garonne).

Tamariz / Tamaríz / Tamaris / Támara / Tambre : Julio Caro Baroja ${ }^{\mathbf{1 1 8}}$ cite le toponyme Tamariz qui désigne, précise-t-il, une montagne navarraise. Il s'agit également, dit Julio Altadill, d'une corraliza ou basse-cour située sur la route qui va d'Alfaro à l'Ebre. On retrouve le toponyme dans le nom de lieu galicien Tamaríz cité par Ramón Menéndez Pidal. Il s'agit également de la forme ancienne du nom du fleuve galicien connu aujourd'hui sous le nom de Tambre (La Corogne) : Tamaris flumen (époque romaine), uillam de anna in Pistomarcos in ripa Tamaris, $X^{\mathrm{e}}$ siècle > Tamare, 934 > Tambre. D'après notre auteur, il représente le peuple, non celtique selon Meyer-Lübke, des Tamarici cité par Mela et Pline et qui habitait au bord du fleuve galicien Tamaris, également connu par les auteurs gréco-latins sous le nom de Tamara, nom qui est encore de nos jours porté par une rivière de La Corogne : río Támara (proparoxyron) ${ }^{\mathbf{1 1 9}}$. Ptolémée dit qu'il y avait dans le pays des Cantabres (c'est-à-dire grosso modo l'actuelle Cantabrie) une ville appelée Tamarica, capitale probable, d'après Julio Caro Baroja ${ }^{\mathbf{1 2 0}}$, de la nation ou lignée cantabre des Tamarici. Certains auteurs lisent Camarica au lieu de Tamarica.

Tena / Tea : bien qu'elle ne soit pas située en Pays Basque, il faut citer la rivière aragonaise appelée de nos jours Gállego (proparoxyton) qui était située dans l'Antiquité dans le territoire des Ilergetes, voisins des Vascones. Elle devait servir vraisemblablement, d'après Julio Caro Baroja, de frontière à ces deux peuples. Au Moyen-Âge, elle est appelée Gallico, Gallecum, Gallegum, Gallicus, XI ${ }^{\mathrm{e}}$ siècle. Cela étant, il est à noter que cette rivière aragonaise divise en deux parties une vallée connue sous le nom de Tena (valle de Tena), dont le nom est déjà documenté en 1076 : usque ad montes gaelicos cum tota Tena ${ }^{121}$. Ce nom se retrouve en Galice, dans la province de Pontevedra. Il désigne une vallée et une rivière : río Tea et valle de Tea, autrefois, Tena, ripa Tenae, $\mathrm{XII}^{\mathrm{e}}$ siècle. La chute du $\boldsymbol{- n}$ - intervocalique est normale en galicien. Il s'agit du même nom.

Treviño : en Pays Basque, on trouve le comté de Treviño. Bien qu'enclavé dans la province d'Alava, il dépend d'un point de vue administratif de la province espagnole de Burgos. Le nom est issu, dit Julio Caro Baroja, du latin. Il est également porté par un village de La Corogne. Un village asturien est également appelé Treviño situé à $700 \mathrm{~m}$., cf. IGN, Camaleño, $1: 25.000,81-\mathrm{I} / 16-6$

Uasconos : dans un document galicien du $\mathrm{XI}^{\mathrm{e}}$ siècle (cartulaire de Sobrado), on lit : in terra Parrice Uillanoua, Bacim, Uillar Plano, Sancto Uincentio, Castro Potamio, Uasconos, 1037. Ce dernier représente manifestement l'ethnonyme 
Vascones. Il s'agissait probablement d'un établissement vascon postérieur à la Reconquête.

Ulía / Uli / Uría : les toponymes navarrais Uli (village d'Uli-Alto, Uli en 1052, vallée d'Arce, bailliage de Sangüesa) et Uli (vallée de Lónguida, Sangüesa) sont considérés comme étant d'origine inconnue. Au XVI ${ }^{\mathrm{e}}$ siècle, les bascophones appelaient ces endroits Uli (aujourd'hui Ulibeiti d'après Euskaltzaindia) et Uliberri, « nouvel Uli ». Mais le nom n'aurait, semble-t-il, aucun rapport avec le nom également navarrais Ulibarri, «ville neuve », Uriuarri la mayor, 1277 (vallée de Lana, bailliage d'Estella) comme l'indique Julio Caro Baroja qui rappelle que le nom de la vallée d'Arce « en la parte occidental occidental y meridional de Navarra podría equipararse a « uli » 0 《uri » en compuestos. No aquí $\gg^{\mathbf{1 2 2}}$. Le nom étant considéré comme énigmatique, aucun auteur n'émet d'hypothèse. Le nom navarrais Uli paraît correspondre à celui du fleuve galicien appelé aujourd'hui Ulla, autrefois fluuii Ulia, 883; Ulia, 934 ; la palatalisation ultérieure de la latérale étant normale en galicien. Le nom ancien de ce fleuve galicien est identique, comme l'avait déjà noté Humboldt ${ }^{123}$, à celui que porte encore de nos jours la montagne guipuzcoane appelée Ulía (227 m.), située entre Saint-Sébastien et Le Passage de Saint-Jean et dont la signification exacte n'est pas connue. Une des chaînes de montagnes qui séparaient dans I'Antiquité les Gallaïques des Astures a de nos jours pour nom Sierra de Uría. Peut-être faut-il également rapprocher cet oronyme asturien, dont la forme ancienne nous est inconnue mais qui semble cependant être très ancien, de celui qu'on trouve en Guipuzcoa ainsi que de l'hydronyme galicien. Strabon (Géographie, III, 2, 1) mentionne plusieurs villes du sud de l'Espagne (actuelle Andalousie), dont une appelée $\boldsymbol{U l i a}^{\mathbf{1 2 4}}$. Humboldt avait déjà souligné l'équivalence Ulia galicien = Ulia guipuzcoan (où le groupe vocalique -ia- ne forme pas une diphtongue) = Ulia ville de la Bétique (époque romaine).

Uriz / Oriz: les noms des villages navarrais de Úriz, en basque Uritz (vallée d'Arce) et de Óriz, en basque Oritz (vallée d'Elorz, bailliage de Sangüesa) se retrouvent dans ceux des villages galiciens appelés Uriz et Oriz (province de Lugo). La seule différence qui existe entre eux est la suivante : les galiciens sont oxytons alors que les formes espagnoles des toponymes navarrais sont accentuées sur la pénultième (cf. infra).

Urria : Alfonso Irigoyen comparait les nombreux Urrea et Urria attestés en Aragon, ainsi que dans le nom d'un village de Burgos (proche de la vallée de Mena) appelé également Urria, avec les nombreux toponymes euskariens Urriategui, Urriaurra, Urricosola, etc. Alfonso Irigoyen semblait extrêmement étonné, en revanche, d'en trouver deux dans les Asturies centrales: le village d'Urria (municipalité de Pola de Somiedo) situé au pied d'une montagne de $1660 \mathrm{~m}$. et une paroisse appelée Santa 
María Magdalena de Urria (municipalité de Teverga) située dans une zone montagneuse culminant à $1419 \mathrm{~m}$. Cet étonnement, dont l'auteur ne faisait aucun mystère (« [es] perturbador que aparezca dos veces en Asturias », soulignait-il ${ }^{125}$ ), s'explique aisément. Il s'est développé au cours de ces dernières décennies dans le domaine des Etudes Basques, surtout parmi les chercheurs du Pays Basque méridional, un parti pris qui a quasiment été érigé en dogme, à savoir : au cours de I'Antiquité l'extension de la langue basque vers l'Ouest n'a pas dépassé, ou à peine, les actuelles Encartaciones biscaïennes (Biscaye occidentale). Cette hypothèse a fait école en Pays Basque. Elle est même devenue pour beaucoup une certitude - la plupart des auteurs du Pays Basque Sud ont pris toutefois la précaution de préciser que dans I'Antiquité le territoire de la langue basque recouvrait d'un point de vue géographique l'actuelle région basque, ce qui, pour les raisons que nous avons déjà indiquées dans notre dernier article, ne nous paraît pas invraisemblable, mais cependant non prouvé car il existe des indices nous permettant de penser que les Varduli et les Caristii n'étaient peut-être pas des proto-bascophones ${ }^{\mathbf{1 2 6}}$, ce qui peut paraître paradoxal puisqu'on suppose par ailleurs qu'une partie des Asturies pouvait en revanche l'être. C'est qu'en réalité, il ne faut pas s'imaginer dans I'Antiquité des aires linguistiques compactes, mais au contraire des poches linguistiques différenciées et disséminées tout le long de la cordillère. Ainsi, Alfonso Irigoyen, ne pouvant pas expliquer la présence de ces Urria asturiens, avait alors pris la décision d'esquiver la question (il indiquait : «prescindimos, por ahora, de los [Urrias] asturianos ${ }^{\mathbf{1 2 7}}$ ). Or, il est probable que parmi les Astures transmontani, il existait des populations préceltiques de type euskaroïdes, même à l'époque romaine (Pline, Nat. Hist., VIII, 166, signale que les Astures appelaient leurs chevaux Thieldones, c'est-à-dire tield-ones ou Celdones, nom qui a été comparé, rappelle Julio Caro Baroja ${ }^{\mathbf{1 2 8}}$, au basque zald-, $\boldsymbol{i}$, «cheval»). La deuxième hypothèse consisterait à supposer que ces toponymes asturiens Urria ne sont pas de type euskaroïde, ce qui est également plausible, mais dans ce cas rien ne permet alors de dire que les basco-aragonais le soient. Une des plus hautes montagnes des Asturies (Pics d'Europe) a pour nom Pico Urriellu (2519 m.) où le terme urri- apparaît de nouveau. La forme Urriello est la forme espagnole et Urriellu celle asturienne. Ce nom asturien doit être comparé au toponyme alavais Urrialdo, 1025, Urrialdu, 1702, village dont la dernière maison disparut en 1937 à la suite d'un incendie d'après López de Guereñu. Le changement -ld- > -II- étant très bien attesté (cf. au XVIII ${ }^{\mathrm{e}}$ siècle la maison d'Anglet Landalde > Landalle), une évolution Urrialdo > *Urriallo > Urriello $>$ Urriellu serait tout à fait banale. Un autre village de montagne des Asturies occidentales a pour nom Uría. A côté on trouve la Sierra de Uría. Il faut noter que le patronyme Uría, au-delà de son étymologie première, n'est pas un nom de famille basque à proprement parler, mais basco-asturien, ce qui explique pourquoi il est si 
courant dans les Asturies. Pour déterminer si un individu ayant ce nom est un Asturien de souche ou un Basque, il faut obligatoirement faire appel à la généalogie.

Urrós / Urros / Urro(t)z / Urriés / Urria / Urriellu / Urrialdo : dans la municipalité galicienne d'Allariz (Orense), on trouve un hameau appelé Urrós (oxyton). Ce nom est apparemment identique, comme le signale J. Gifford, à ceux portés par les villages navarrais d'Urrotz (vallée de Malerreka, Pampelune) et d'Urroz (bailliage de Sangüesa). G. Rohlfs cite la localité aragonaise appelée Urriés ${ }^{\mathbf{1 2 9}}$. Si le toponyme Urriés est issu, comme le pense cet auteur, de l'anthroponyme non attesté *Urrus (il citait pour cela le nom de personne Urranus attesté en Espagne, Cuenca), alors il devrait en être de même pour le nom galicien Urrós, avec cependant ici une déclinaison en -o, -onis (génitif) : *Urrus > *Urrōnis > *Urrones (avec évolution romane et normale du -i- dans -ōnis qui passe à -ones) > *Urrõẽs (chute normale du -nintervocalique) > *Urrõõs > Urrós. Quoi qu'il en soit, ce nom galicien reste inexpliqué, un hameau de la localité galicienne d'Allariz (Orense) ayant également pour nom Urrós (oxyton). Des recherches ultérieures nous permettent de citer deux autres localités du même nom dans le Nord-Ouest du Portugal : un Urrós (accentué manifestement sur la dernière syllabe) situé à $24 \mathrm{~km}$. au sud-ouest de la ville frontalière de Miranda do Douro et un Urros (sans accent, sauf erreur) situé à $76 \mathrm{~km}$. au sud-ouest de ce même Miranda do Douro. Dans ces conditions et contrairement à ce qu'on a pu penser, les toponymes navarrais ne doivent probablement avoir aucun rapport avec le basque (h)urr, «noisette, noisetier 》 (< (h)urr- + -otz). Il doit s'agir dans tous les cas, comme le pensait Rohlfs, de noms à base anthroponymique. En tout cas, l'existence des toponymes portugais semble plaider en faveur de cette hypothèse. En outre, étant donné que Joseph $\mathrm{M}$. Piel ne les cite pas dans son ouvrage sur la toponymie portugaise d'origine germanique, on peut supposer qu'ils n'ont pas une telle origine.

Ustariz / Ustarriz / Ustaritz / Ustaitze / Osteri(t)z, soit une évolution -(R)ICUS > -(r)iki > *-(r)itse (Gamillscheg, $1932: 256)>-(\boldsymbol{r}) \boldsymbol{i}(\boldsymbol{t}) \mathbf{z}$. En Galice, il y existe de nombreux toponymes finissant en -riz. Ce sont en général des noms germaniques composés de deux éléments, le deuxième étant reiks, gotique « prince », vieux haut-allemand rihhi, «puissant» d'après Marie-Thérèse Morlet ${ }^{\mathbf{1 3 0}}$, morphologiquement latinisée par la suite en -RICUS > -riki génitif > -riz / -rís. Certains semblent se retrouver en Pays Basque et sous une forme identique : le village navarrais appelé Oderi(t)z < *(uilla) Oderici < Odericus, attesté en 861 (Morlet ${ }^{\mathbf{1 3 1}}$ ) ; en Galice on a Villaodriz (Lugo), autrefois uilla odorici, 1037 (cartulaire de Sobrado, il s'agit peut-être d'un autre Villaodriz situé dans la province de La Corogne), cf. également en Galice : Anderici, 989 ?, casale de Anderiz, s. date, probablement $X^{e}$ siècle (cartulaire de Sobrado) et les toponymes navarrais Enériz, autrefois, Eneriç, 1233 et Endériz, autrefois Enderiz, 1257 (< probablement 
germanique Andricus cité par M.-Th. Morlet ${ }^{132}$ et Andericus cité par Boullón Agrelo ${ }^{133}$ avec par la suite en Navarre -nd- $>\boldsymbol{- n n}->\boldsymbol{- n}$-), etc. Les hispanophones ont pour habitude d'accentuer ces noms galiciens sur l'avant-dernière syllabe, ce que ne font pas les galaïcophones qui accentuent toujours sur la dernière : cela explique pourquoi un Espagnol prononcera les toponymes galiciens Uriz, Oriz, Alderiz, Baldariz, Esmoriz, Goiriz, Astariz (cf. le patronyme basque Dastaritz), etc. $\rightarrow$ Úriz, Óriz, Aldériz (cf. les toponymes navarrais identiques prononcés Úriz, Óriz et Aldériz en espagnol, basque Uritz, Oritz et Alderitz) Baldáriz, Esmóriz, Goíriz, Astáriz et un Galicien Uriz, Oriz, Goiriz, etc. sur la dernière. Les Espagnols prononcent l'Ustaritz labourdin $\rightarrow$ Ustáriz et Biarritz $\rightarrow$ Biárriz. En Galice, dans la municipalité d'Otero de Rei (Lugo), une petite «montagne » est connue sous le nom de Monte de Ustariz. Cet oronyme galicien est peut-être un anthroponyme d'origine germanique, sans doute Ost- / Austericus (cf. M.-Th. Morlet) > (villa) *Osterici > Osteriz / Ostariz / Ustariz. On le retrouve peut-être dans le toponyme navarrais Osteritz, autrefois aussi Ostariz, 1280 (vallée d'Esteribar, Sangüesa), étant donné que plusieurs villages navarrais, portent un nom germanique comme, par exemple, celui appelé Oderitz (vallée de Larraun, bailliage de Pampelune) dont l'origine germanique est établie: Odericus attesté en 861 (cf. Marie-Thérèse Morlet), d'où (villa) *Oderici > Oderiz, en basque Oderitz. En ce qui concerne le toponyme labourdin Ustaritz, il faut se reporter à l'ouvrage de Jean-Baptiste Orpustan. Le nom de lieu de Lugo appelé Ustariz (accentué sur la dernière), que les Espagnols prononcent par erreur Ustáriz et qui rappelle évidemment I'Ustaritz du Labourd et les Osteritz (accentué en espagnol Ostériz, autrefois Ostariz, 1280, prononciation basque Osteritz) et Ustaize de Navarre. López de Guereñu cite un Ustarriz alavais (avec $-\boldsymbol{r r}$ - au lieu de $\boldsymbol{- r}$-, à la suite probablement d'un renforcement analogique de la vibrante) qui est, écrit-il, une fontaine de «San Vicente de Arana ». La forme Ustaize est une forme populaire salazaraise, et d'après Salaberri ${ }^{134}$ plus ancienne, du toponyme navarrais Ustés (forme romane), ce implique un plus ancien *Ustariz > Ustaize avec -e paragogique. Nous ne nous prononcerons pas sur ces toponymes basques. Ce qui en revanche paraît probable est que l'Ustariz galicien est nom d'origine germanique : Austericus $>$ *uilla Osterici (la forme austdu premier élément de composition étant également attestée sous la forme ost-, cf. Morlet ${ }^{135}$ ) > Osteriz > Ostariz > Ustariz. Tous ces toponymes galaïco-basques en -riz mériteraient qu'on leur consacrât une étude particulière. En ce qui concerne le Goiriz galicien (village de Lugo), Alfonso Irigoyen pensait y voir une forme patronymique issue du nom basque Goiri. Mais sa présence en Galice devant être toutefois expliquée, I'auteur concluait: «posiblemente difundido a partir del País Vasco $\gg^{\mathbf{1 3 6}}$. Néanmoins, et contrairement aux apparences, ce nom galicien n'a manifestement rien à voir avec le basque, quoique son étymologie ne semble pas être clairement et définitivement établie: Santiago de Goiriz, autrefois S. Jacobus de 
Quirice, 747 (date qui ne plaide pas en faveur d'une diffusion à partir du Pays Basque), en réalité devant être lu Cuirice $>$ *Goirice $>$ Goiriz selon Olano Silva ${ }^{137}$, Goeriz, 1128. Alfonso Irigoyen signalait que la forme ancienne qu'il citait est une falsification du XII ${ }^{\mathrm{e}}$ siècle : Ecclesiam Sancti Jacobi de Goiriz, 897.

Varduli ou Vardulli (Mela, Choro., III, 15, Pline, Nat. Hist., III, 26, 27) : les ancêtres grosso modo des actuels Guipuzcoans étaient connus dans l'Antiquité sous le nom de Vardules. Strabon (Géogr., III, 4, 12), dont l'oeuvre se base en grande partie sur les écrits de Posidonius d'Apamée ${ }^{\mathbf{1 3 8}}$ qui rédigea une partie de son oeuvre après 72 av. J.-C., mentionne les «Bardyètes, qu'on appelle aujourd'hui Vardules». Or, fait curieux, Pline (Nat. Hist., IV, 118) cite, parmi les peuples de la Lusitania, «les Turdules, dits Bardules » (Turduli qui Barduli [cognominatur]). Le seul auteur, à notre connaissance, à mentionner ce fait est Julio Caro Baroja ${ }^{\mathbf{1 3 9}}$. Toutefois, deux lectures du texte de Pline sont possibles: I'une, celle de Mayhoff, opte pour une leçon Bardili (quoique cet auteur signale également dans ses notes la forme Barduli). En revanche, Emile Littré, qui se base sur le texte du jésuite Hardouin, rapporte une forme Barduli. Les Turdules était à l'origine un peuple ibère établi dans la région de Cordoue et sur le bas-Guadalquivir. Ils étaient peut-être apparentés aux Turdétans. Une partie de ces Turdules s'installèrent dans la Lusitania où Pline (Nat. Hist., IV, 113) cite les Turduli veteres surnommés, on I'a vu, Barduli. Strabon (Géogr., III, 3,4) raconte en effet comment les Celtici - dont il ne faut pas confondre le nom avec celui des Celtes à proprement parler - s'étaient installés en Galice, à l'époque de Strabon cet événement devant être encore relativement récent. Celui-ci rapporte en effet que les Celtiques ou Celtici (le sens serait « apparentés aux Celtes, qui ont la manière des Celtes ») du bord de I'Anas [I'actuel fleuve appelé Guadiana < wada + ana, « la rivière Ana » en arabe],

« ayant participé aux côtés des Turdules à une expédition militaire dirigée contre cette région [la Galice], ils se révoltèrent après avoir franchi le cours du Limaeas [actuel Lima, nord du Portugal]. A la suite de cette révolte, comme ils avaient par surcroît perdu leur chef, ils seraient restés dans la contrée [en Galice] en s'y dispersant ».

Ces recherches devraient probablement être poursuivies car tout ce que nous venons de citer ne représente en réalité qu'un échantillon d'un sujet très vaste et relativement, du moins en Galice et dans les Asturies, peu étudié eu égard à ce qui se fait dans d'autres régions d'Europe. D'autant plus, on l'a vu, que le stock toponymique galicien est impressionnant.

\section{1) Origines des « Vascongadas »}

D'autre part, si on écarte les similitudes toponymiques dans lesquelles nous avons manifestement affaire à des anthroponymes d'origine latino-romane, voire germanique, similitudes toponymiques galaïco-basques, parfois hypothétiques, souvent indéniables, 
qui demanderaient cependant à être expliquées, il reste plusieurs similitudes qui posent problème. En effet, il reste à expliquer le pourquoi des doublets toponymiques galaïco-guipuzcoano-biscaïens Ézaro / Izaro, Lea / Lea (et les Lena portugais et asturien), Oka / Oca, Ulia médiéval / Ulía moderne (et peut-être les deux Uli navarrais), Deva / Deba, Ego / Egovarri, les noms de montagnes Igueldo (basque) / Gueldo (galicien) / Agueldo (asturien), pour ne citer que les plus curieux d'entre eux et, surtout, à expliquer pourquoi ils ne peuvent pas manifestement s'expliquer le basque. Cela nous renvoie à un débat qui n'a jamais été résolu de façon définitive et qui concerne la basquité originelle des Caristes et des Vardules ou, si on préfère, la basquité première des Biscaïens et des Guipuzcoans de l'Antiquité. Il s'agit d'une question très ardue comme le reconnaissent, entre autres, Joaquín Gorrochategui et Luis Michelena. A. Schulten ${ }^{\mathbf{1 4 0}}$ fut I'un des premiers à défendre l'idée selon laquelle les Caristes et les Vardules, et à plus forte raison, les Autrigones (les habitants grosso modo des actuelles Encartaciones biscaïennes et de la partie nord-est de la province de Burgos) et les Berones (c'est-à-dire grosso modo les actuels habitants de la Rioja) n'étaient peut-être pas des proto-Basques mais, au contraire, des peuples d'origine indo-européenne ou, tout au moins, des peuples parlant une langue indo-européenne. Mais ce sont surtout, reconnaissait Luis Michelena, les travaux du savant espagnol Manuel Gómez-Moreno ${ }^{141}$, à l'origine du déchiffrage de l'alphabet ibérique, qui vinrent appuyer de manière convaincante cette thèse. Pour contourner la difficulté posée par les travaux de ce dernier et dont la valeur était incontestable, ceux de Schulten étant plus discutables, Luis Michelena et par la suite Joaquín Gorrochategui firent appel à la sociolinguistique. Autrement dit, les Caristii et les Varduli - les Vascones posant également un autre problème que nous n'aborderons pas ici - utilisaient une anthroponymie et une toponymie indo-européennes tout en parlant basque ou plutôt proto-basque. Luis Michelena, qui manifestait une certaine réticence à l'égard de l'idée selon laquelle les Caristii et les Varduli n'étaient pas des proto-bascophones, reconnaissait cependant que

« aunque nos esforcemos de atenuar por todos los medios la fuerza de estos testimonios [indo-européens en Pays Basque], tendremos que acceptar que su coincidencia difícilmente puede explicarse sin admitir que gentes de habla vasca conocían y usaban también, en mayor o menor número, algún dialecto indoeuropeo $»^{\mathbf{1 4 2}}$.

Luis Michelena admettait que les Caristes et les Vardules devaient nécessairement parler une langue autre que le proto-basque, mais il préférait cependant penser, contrairement à Gómez-Moreno, qu'il s'agissait quand même de proto-Basques. A cela vient s'ajouter encore un autre question: celle de l'origine des dialectes basques, notamment ceux du Pays Basque méridional. Tous les spécialistes admettent qu'en basque les divergences dialectales s'estompent au fur et à mesure que l'on remonte 
dans le temps jusqu'aux premiers textes basques connus, ce qui à terme signifie nécessairement, comme le rappelle Luis Michelena ${ }^{\mathbf{1 4 3}}$, qu'il a dû exister autrefois une langue commune. Là où la question prend une tournure des plus complexes est qu'on ne s'explique pas alors

« la remarquable similitude - souligne B. Oyharçabal - entre les aires couvertes par le navarrais et biscaïen en Guipuzcoa, et les territoires occupés il y a deux mille ans les Vascones et les Caristii dans leur voisinage avec les Varduli ${ }^{\mathbf{1 4 4}}$.

Autrement dit, en se basant sur les données fournies par le géographe Ptolémée, les démarcations territoriales qui étaient dans l'Antiquité celles des peuples ou tribus appelés respectivement Caristes, Vardules et Vascones correspondent exactement aux aires dialectales modernes du biscaïen, du guipuzcoan et du haut-navarrais septentrional, tout au moins dans leur partie septentrionale là où la langue s'est conservée jusqu'à nos jours. Cela sous-entend qu'au début de notre ère les principaux dialectes méridionaux existaient déjà, ce qui semble être manifestement en contradiction avec le fait, admis par tous les spécialistes, qu'en basque les divergences dialectales s'atténuent au fur et à mesure qu'on remonte dans le temps.

Pour contourner cette difficulté, nous pensons qu'on pourrait citer les dires de Julio Caro Baroja qui avait proposé une hypothèse allant dans le sens de celle émise par Gómez-Moreno. D'après lui, il n'était pas invraisemblable de supposer que les Vardules et les Caristes constituaient des fractions issues de la nation des Cantabres qui, ayant acquis une certaine importance au fur et à mesure que passait le temps, seraient devenues « autonomes », c'est-à-dire qu'on aurait eu affaire à

« una desmenbración de la estirpe cántabra, parecida a otras que se observaron en sociedades regidas por el sistema de linajes en que, pasando un número determinado de generaciones, las ramas van tomando nombres propios »

étant donné, ajoute-t-il, que les inscriptions de l'époque romaine

« nos reflejan que en este orden várdulos y caristios eran parientes, afines, de los cántabros $y$ astures » et que par conséquent cela « nos obliga a plantearnos de nuevo el problema del que pudiéramos llamar cantabrismo de los pueblos del Noroeste litoral, que una crítica rigurosa parecía haber reducido a cero $\gg^{\mathbf{1 4 5}}$.

En résumant un sujet qui est complexe, les tribus présumées alors cantabriques des Caristes (Biscaïens) et des Vardules (Guipuzcoans) et parlant une langue indéterminée, peut-être indo-européenne, mais nécessairement différente du proto-basque, auraient, à une date et pour des raisons qui nous échappent, été basquisées ou plutôt « vasconisées ». Il faut reconnaître que cette hypothèse présente quelques avantages :

a) elle expliquerait pourquoi les anciens territoires des Caristii et des Varduli correspondent exactement aux actuelles divisions dialectales méridionales; autrement 
dit, ces deux peuples de l'Antiquité se seraient mis à parler proto-basque tout en conservant dans leur manière de le parler certains traits de leur langue primitive et jusqu'à présent indéterminée, ce qui expliquerait la singularité du parler guipuzcoan et surtout celle du dialecte biscaïen ;

b) elle expliquerait pourquoi Jules César, relatant la conquête de l'Aquitaine menée par son lieutenant Crassus en 56 av. J.-C., parle « des cinquante milles hommes fournis par l'Aquitaine et le pays des Cantabres ${ }^{\mathbf{1 4 6}}$, ces derniers ayant accouru au secours des premiers, quoique certains y aient vu une erreur - hypothétique cependant - de César qui aurait confondu les Caristes et les Vardules avec les Cantabres « authentiques » ;

c) elle expliquerait, enfin, pourquoi on retrouve en Galice certains toponymes, hydronymes et oronymes biscaïens et guipuzcoans apparemment inexplicables par le basque.

Néanmoins, cette hypothèse sur le «cantabrisme» présumé des peuples du Nord-Ouest de la Péninsule n'explique pas pourquoi les Caristes, les Vardules et les Autrigones, s'ils appartenaient véritablement à la nation des Cantabres, ne prirent pas part, pas plus que les Vascones d'ailleurs, à la guerre que les Galiciens, les Asturiens et les Cantabres menèrent contre Rome : une guerre qui dura dix ans ${ }^{\mathbf{1 4 7}}$ (29-19 av. J.-C.) et qui provoqua la venue sur place de l'Empereur Auguste. Il faudrait aussi supposer que les Autrigones n'auraient pas été affectés par cette présumée «vasconisation » dont nous avons fait mention puisque, semble-t-il, il n'existe pas d'éléments tendant à montrer un emploi autrefois de la langue basque dans ce qui constituait leur territoire, pays qui englobait, entre autres, les actuelles Encartaciones biscaïennes. Une autre possibilité effleurée, entre autres, par Julio Caro Baroja, est de supposer que les Caristes et les Vardules n'appartenaient plus à la nation des Cantabres tout en étant néanmoins d'origine «cantabroïde » (et non pas «bascoïde ») ou encore qu'ils n'étaient ni d'origine « cantabroïde $»$ ni $\ll$ bascoïde ${ }^{\mathbf{1 4 8}}$, leur origine restant indéterminée.

On ne sait pas quelle était l'origine exacte des Cantabres et des Astures, pas plus que celle des Galiciens, excepté qu'il est certain qu'il y avait parmi ces peuples, comme au demeurant chez les Caristes et les Vardules, des populations d'origine celtique. On pourrait également admettre que les Caristes et les Vardules étaient d'origine «bascoïde» ou, si on préfère, qu'ils parlaient proto-basque, mais cela implique nécessairement, pour les raisons évoquées plus haut, que les dialectes appelés de nos jours biscaïen et guipuzcoan existaient déjà il y a deux mille ans, ce qui s'avère également problématique. L'affaire, on l'aura compris, est complexe car d'un autre côté plusieurs toponymes galiciens ne semblent pas explicables par une langue celtique. 







\section{Bibliographie}

AGUD, M. \& TOVAR, A., 1989-1993, «Diccionario etimológico vasco », ASJU, T. I-VII, Saint-Sébastien.

ALBERTOS FIRMAT, Ma. L., 1966, La Onomástica personal primitiva de Hispania : Tarraconense y Bética, Université de Salamanque.

ALLIÈRES, J., 1998, « Michel Morvan : Les origines linguistiques du Basque », in Lapurdum III, pp. 315-317.

ALONSO AVILA, A., 1987, «Navarra y los vascones durante la época visigoda », in Primer Congreso de Historia de Navarra, 2, Pampelune, pp. 277-292.

ALTADILL, J., 1914, Geografía General del Reino de Navarra, 2 vol.

AZKUE, R.-M., 1905-1906, réed. 1984, Diccionario Vasco-español-francés, Bilbao.

BELASKO, M., 1996, Diccionario etimológico de los nombres de los pueblos, villas y ciudades de Navarra, Ed. Pamiela, Pampelune.

BOULLÓN AGRELO, A. I., 1994, Contribución ó estudio da antroponimia medieval galega (séculos VIII-XIII), thèse doctorale inédite, Université de Saint-Jacques de Compostelle, exemplaire microfilmé.

BÚA, C., 1997, «Dialectos indoeuropeos na franxa occidental hispánica », in Galicia fai dous mil anos. $O$ feito diferencial galego. I. Historia, G. Menaut-Pereira, coord., Saint-Jacques de Compostelle, Ed. Musée du Peuple Galicien, vol. 1, pp. 51-100.

CABEZA QUILES, F., 1992, Topónimos de Galicia: a súa orixe e o seu significado, Ed. Montes e fontes, Xerais.

CARBOEIRO, cart., LUCAS ÁLVAREZ, M., 1958, « La collección diplomática del Monasterio de San Lorenzo de Carboeiro », Compostellum II, 4, 1957, pp. 549-573; III, 2, 1958, pp. 228-308; III, 4, pp. 549-638. Contient 90 documents de 788 à 1500.

CARO BAROJA, J., 1942, «Breve historia del vascoiberismo », Boletín Emerita, T. X, 2, pp. 236-286 et in Sobre la lengua vasca, 1988, Estudios Vascos, T. IX, Ed. Txertoa, $2^{\mathrm{e}}$ éd, Saint-Sébastien.

CARO BAROJA, J., 1943, « Observaciones sobre la hipótesis del vascoiberismo considerarda del punto de vista histórico », Boletín Emerita, T. XI, 1, pp. 1-59 et in Sobre la lengua vasca, 1988, Estudios Vascos, T. IX, Ed. Txertoa, $2^{\mathrm{e}}$ éd, Saint-Sébastien.

CARO BAROJA, J., 1945, réed. Ed. Txertoa, Saint-Sébastien, 1990, Materiales para una historia de la lengua vasca en su relación con la latina, Estudios Vascos, XIX, Université de Salamanque. 
CARO BAROJA, J., 1958, «Los estudios geográfico-históricos sobre el país vasco y la dialectología », RDTP XIV, pp. $425-440$ et in Sobre la religión antigua $\boldsymbol{y}$ el calendario del pueblo vasco, 1984, Estudios Vascos, T. I., Ed. Txertoa, Saint-Sébastien.

CARO BAROJA, J., 1972, Etnografía Histórica de Navarra, Caja de Ahorros de Navarra, Pampelune.

CARO BAROJA, J., 1977, Los pueblos del norte de la Península Ibérica, 2e éd. 1976 (2 vol.), Madrid, $3^{\mathrm{e}}$ éd. 1977, Txertoa, Saint-Sébastien.

CARO BAROJA, J., 1985, Los Vascones y sus vecinos, Estudios Vascos, T. XIII, Txertoa, Saint-Sébastien.

CARO BAROJA, J., 1988, Sobre el mundo ibérico-pirenaico : datos, nuevas ideas sobre el Iberismo, Estudios Vascos, XVIII, Ed. Txertoa, Saint-Sébastien.

CHERPILLOD, A., 1986, Dictionnaire étymologique des noms géographiques, Ed. Masson, Paris.

COROMINES, J. \& PASCUAL, J. A., 1980, Diccionario crítico etimológico castellano e hispánico, 5 vol., Gredos.

COROMINES, J., 1960, «La toponymie hispanique préromane et la survivance du basque jusqu'au bas Moyen-Âge. Phénomènes de bilinguisme dans les Pyrénées Centrales », Actes et Mémoires du IVème Congrès International de Sciences Onomastiques, München, pp. 105-146. Nous utilisons la nouvelle version revue et corrigée publiée ultérieurement in Estudis de Toponímia Catalana, T. I, Barcelona, 1965, «La survivance du basque jusqu'au bas Moyen-Âge... », pp. 93-151.

COROMINES, J., 1972a, «De toponimia vasca y vasco-románica en los Bajos-Pirineos », FLV , n० 12, Pampelune, pp. 299-319.

COROMINES, J., 1972b, Tópica Hespérica. Estudios sobre los antiguos dialectos, el substrato y la toponimia romances, Madrid.

COROMINES, J., 1973, «Du nouveau sur la toponymie occitane », Beiträge zur Namensforschung, 8, Heidelberg, 193-308.

COROMINES, J., 1974, «Elementos prelatinos en las lenguas romances hispánicas », Actas del I Coloquio sobre lenguas y culturas prerromanas de la Península Ibérica, Salamanca.

DAUZAT, A.et ROSTAING, Ch., 1989, Dictionnaire étymologique des noms de lieux en France, Paris, nouvelle édition.

DAVID, P., 1947, Etudes historiques sur la Galice et le Portugal, du $\mathrm{VI}^{\mathrm{e}}$ au $\mathrm{XII}^{\mathrm{e}}$ siècle, Paris.

DE HOZ, J., 1997, « Lingua e etnicidade na Galicia antiga », in Galicia fai dous mil anos. O feito diferencial galego. I. Historia, G. Menaut-Pereira, coord., Saint-Jacques de Compostelle, Ed. Musée du Peuple Galicien, vol. 1, pp. 101-142. 
DE LA PEÑA SANTOS, A., 1997, « Os pobos castrexos antes da conquista romana », in Galicia fai dous mil anos. $O$ feito diferencial galego. I. Historia, G. Menaut-Pereira, coord., Saint-Jacques de Compostelle, Ed. Musée du Peuple Galicien, vol. 1, pp. 143-192.

DÍEZ MELCÓN, G., 1957, Apellidos castellano-leoneses (siglos IX-XIII, ambos inclusive), Université de Grenade.

DION CASSIUS, 1960, édité par Ph. Boissevain, Berlin, 1895-1931, réimpr. 1955 ; édité par E. W. Cary, Londres.

ENCYCLOPÆDIA BRITANNICA, 1929-1964, 23 vol., Ed. Université de Chicago.

ENTWISTLE, W.-J., 1936, The Spanish Language, together with Portuguese, Catalan and Basque, Londres, Faber and Faber.

ETCHETO, H., 1997, «Le pays Basque Sud au temps de la conquête romaine : Vascons et Romains. 'L'amitié romano-vasconne' », in Ekaina, Revue d'Etudes Basques, nº 63, pp. 163-188.

EUSKALTZAINDIA, 1990, Nafarroako herri izendegia / Nomenclátor euskérico de Navarra, Pampelune.

EUSKALTZAINDIA, 1991, Onomasticon Vasconiae 4. Actas de las I jornadas de onomástica, toponimia, Vitoria-Gasteiz, abril 1986 / I onomastika jardunaldien agiriak. Toponimia, Gasteiz, $1986 k o$ apirila, Ed. Euskaltzaindia.

FERNÁNDEZ REI, F., 1991, Dialectoxía da lingua galega, Ed. Xerais.

FOUCHÉ, P., 1939, « A propos de l'aragonais 'Ibón' », in Melanges Martinenche, Paris.

GAMILLSCHEG, E., 1950, Romanen und Basken, Wiesbaden, Franz Steiner.

GAMILLSCHEG, E., 1932, « Historia lingüística de los visigodos », Revista de Filología Española, XIX, pp. 117-150 et 229-260.

GARCÍA ARIAS, X. LL., 1977, Pueblos asturianos : el porqué de sus nombres, Ed. Ayalga, Collección Popular Asturiana, Gijón.

GAVEL, H., 1921, « Eléments de phonétique basque », RIEB, XII, an 15

GAVEL, H., 1931, «Du nom de Bayonne et de quelques autres : noms de lieux aquitains ou espagnols », SSLAER, $\mathrm{n}^{\circ} 7$.

GAVEL, H., 1936, «Remarques sur les substrats ibériques, réels ou supposés dans la phonétique du gascon et de l'espagnol », RLR, T. XII, n45-46.

GGRG = Geografía General del Reino de Galicia, 1980, 13 vol., sous la direction de F. Carreras y Candi, Ediciones Gallegas, Editorial La Gran Enciclopedia Vasca, La Corogne-Bilbao.

GIFFORD, J., « Topónimos gallegos y topónimos navarros », BRSVAP, 1955, XI, pp. 227-231.

GOMEZ-MORENO, M., 1925, «Sobre los iberos y su lengua », Homenaje ofrecido a Menéndez Pidal, III, pp. 225-240. 


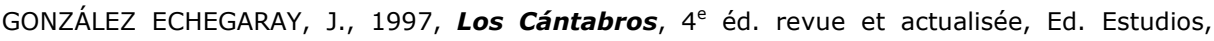
Santander.

GORROCHATEGUI CHURRUCA, J., 1984, Estudio sobre la onomástica indígena de Aquitania, Ed. Université du Pays Basque (UPV-EHU), Bilbao.

GORROCHATEGUI CHURRUCA, J., 1995, «Basque and its neighbors in Antiquity », in Towards a History of the Basque Language, J. Benjamins, Amsterdam/Philadelphie, pp. 31-64.

GORROCHATEGUI CHURRUCA, J., 1997, «Gallaecia e as linguas prerromanas da Península Ibérica », in Galicia fai dous mil anos. $O$ feito diferencial galego. I. Historia, G. Menaut-Pereira, coord., Saint-Jacques de Compostelle, Ed. Musée du Peuple Galicien, vol. 1, pp. 15-49.

GOULARD, R., 1997, «Wascones in plana descendunt... Civitas Lapurdum... », in Lapurdum II, pp. 257-282.

GOYHEneCHE, E., 1966, Onomastique du Nord du Pays Basque au Moyen Age. XI-XV siècles, thèse de doctorat dactylographiée, Bordeaux.

GROSCLAUDE, M., 1991, Dictionnaire toponymique des communes du Béarn, Pau.

HUBSCHMID, J., 1960, «Lenguas prerromanas de la Península Ibérica. A.- Lenguas no indoeuropeas. 2.- Testimonios románicos», in M. Alvar et alii, Enciclopedia Lingüistica Hispanica (ELH), Madrid, vol. 1, pp. 27-66 ; pp. 127-149 ; pp. 447-493.

HUMBOLDT, W. V., 1921, Prüfung der Untersuchungen über die Urbewohner Hispaniens vermittelst der Vaskischen Sprache, Imp. F. Dümmler, Berlin, 192 pages. Traduction espagnole de T. Aranzadi : «Examen de las investigaciones sobre los aborígenes de España mediante la lengua vasca, traducción directa del alemán ( $2^{\mathrm{e}}$ edición) por Telesforo de Aranzadi », RIEB, 1934, pp. 475-520 et RIEB, 1935, pp. 44-92; pp. 499-552. Version française: Recherches sur les habitants primitifs de I'Espagne à I'aide de la langue basque, Traduction de M. A. Marrast, Paris, impr. Tolnon, 1866.

HYDACE, Chronique, 1974, édité par Alain Tranoy, 'Sources Chrétiennes', ns 218-219, Paris.

IGLESIAS, H, 1998a, « Le toponyme Biarritz », $\boldsymbol{L} \boldsymbol{V}, \mathrm{n}^{\circ} 78, \mathrm{pp} . \mathbf{2 8 1 - 2 8 8 .}$

IGLESIAS, H., 1998b, «Sur quelques similitudes toponymiques galaïco-basques et le problème que posent certaines d'entre elles », Lapurdum III, 1-29.

IGN, Instituto Geográfico Nacional. Plusieurs cartes $1: 25.000$ et $1: 50.000$ concernant la Galice et les Asturies ainsi que Atlas routier et touristique Espagne \& Portugal, 1999, échelle 1 : 400.000, Ed. Michelin.

IRIGARAY, A. \& MICHELENA, L., 1955, « Nombres vascos de persona », BRSVAP, XI, pp. 405-425.

IRIGOIEN, A., 1985, «Sobre los topónimos Oca y su entorno », Symbolae Ludovico Mitxelena septuagenario oblatae, Université du Pays Basque (UPV-EHU), Instituto de Ciencias de la Antigüedad, Vitoria, pp. 1007-1017. 
IRIGOYEN [IRIGOIEN], A., 1986, En torno a la toponimia vasca y circumpirenaica, Deusto.

IRIGOIEN, A., 1987, « Leku-izenen euskarazko formak Nafarroan », De re philologica linguae uasconicae, Bilbao, pp. 263-264.

IRIGOIEN, A., 1992a, «Lea-Artibai alderdia», De re philologica linguae uasconicae IV, Bilbao, pp. 357-358.

IRIGOIEN, A., 1992b, « Miscellanea toponymica et anthroponymica (III-IV) 》, De re philologica linguae uasconicae IV, Bilbao, pp. 213-224; 225-230.

JAUPART, F., 1981, Le nom de Bayonne, les lieux, les personnes. T. I et II, Bayonne.

JUBIA [mod. XUBIA], cart., 1935, MONTERO DÍAZ, SIECLE, La collección diplomática de San Martín de Jubia [Xubia, Ferrol], Saint-Jacques de Compostelle. Contient 130 documents allant de 977 à 1199.

JUNGEMANN, F., 1955, La teoría del sustrato y los dialectos hispano-romances y gascones, Madrid.

LAFON, R., 1958, « Noms de lieux d'aspects basque en Andalousie », tiré à part des Actes et

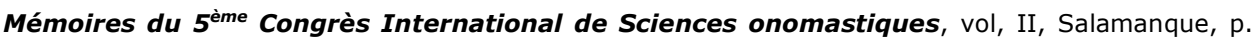
3-12.

LAFON, R., 1973, « La langue basque », BMB, pp. 57-120 et in Vasconiana, in Iker-11, 1999, pp. 3-55.

LAMBERT, P.-Y., 1994, La langue gauloise, Ed. Errance, Paris.

LANGANEY, A., CLOTTES, J., GUILAINE, J. \& SIMONNET, D., 1998, La plus belle histoire du monde, Ed. Seuil, Paris.

LECUONA, M., 1960, «El euskera en Navarra a fines del siglo XVI », Geografía histórica de la lengua vasca (siglos XVI al XIX), Collección Auñamendi.

LÓPEZ de GUEREÑU GALARRAGA, G., 1989, Toponimia alavesa seguido de mortuorios o despoblados y pueblos alaveses, in Onomasticon Vasconiae 5, Euskaltzaindia.

LORENZANA, cart., RODRÍGUEZ GONZÁLEZ, A. \& REY CAIÑA, J.-A., 1992, Tumbo de Lorenzana, Saint-Jacques de Compostelle. Contient 222 documents allant de 969 à 1266 à partir d'un manuscrit ancien déposé aux Archives Historiques Nationales de Madrid.

LOSIQUE, S., 1971, Dictionnaire étymologique des noms de pays et de peuples, Ed. Klincksieck, Paris.

LOUANDRE, CH., 1931, Commentaires de Jules César. Guerre des Gaules, Traduction nouvelle avec le texte, des notes et un index, Ed. E. Fasquelle, Paris.

LUCHAIRE, A., 1874-1875, «Du mot basque IRI et de son emploi dans la composition des noms de lieux de I'Espagne et de I'Aquitaine antique », BSSLAP, pp. 18-27.

MADOZ, P., 1845-1850, Diccionario geográfico-estadístico-histórico de España y sus posesiones de Ultramar, 16 vol., Madrid. 
MARIÑO PAZ, R., 1998, Historia da lingua galega, Ed. Sotelo Blanco, Saint-Jacques de Compostelle.

MARTINEZ BARBEITO, C., 1971, Galicia, Ed. Destino, Barcelone, $3^{e}$ éd.

MARTINO, E., 1995, Roma contra cántabros y astures. Nueva lectura de la fuentes, Collección Brevarios de la Calle del Pez, Ed. Diputación Provincial de León.

MELA, P., 1935, De chorographia, édité par K. Frick, Leipzig.

MELA, P., 1875, Euvres complètes, avec la traduction en français, publiées sous la direction de M. Nisard de l'Académie Française, Inspecteur Général de I'Enseignement Supérieur, Ed. Firmin-Didot, Paris.

MENÉNDEZ PIDAL, R., 1968, Toponimia Prerrománica Hispánica, Gredos, Madrid.

MEZQUÍRIZ, M. A., 1986, «Pavimientos decorados hallados en Andelos», in Trabajo de Arquelogía Navarra, 5, pp. 237-249.

MICHELENA, L., 1964, Sobre el pasado de la lengua vasca, Collección Auñamendi, Saint-Sébastien.

MICHELENA, L., 1981, «Lengua comun y dialectos vascos », ASJU, XV, pp. 291-313 et in Palabras y Textos, 1987, pp. 35-55.

MICHELENA, L., 1982, «Sobre la historia de la lengua vasca », ASJU, XVI, pp. 143-156 et in Palabras y Textos, 1987, pp. 9-21.

MICHELENA, L., 1989, Apellidos Vascos, 4éd., Txertoa, Saint-Sébastien.

MICHELENA, L., 1990, Textos arcaicos vascos, ASJU, Saint-Sébastien ; $1^{\text {er }}$ éd. Minotauro, Madrid, 1964.

MORALEJO LASSO, A., 1944, «Observaciones sobre el estudio de la toponimia gallega », Cuadernos de Estudios Gallegos, I, pp. 59-72.

MORALEJO LASSO, A., 1977, Toponimia gallega y leonesa, Ed. Pico Sacro, Saint-Jacques de Compostelle.

MORALEJO LASSO, A., 1978, « Ojeada a los topónimos hispánicos y especialmente a los gallegos de origen prelatino de J. Corominas », Verba 5, Anuario galego de filoloxía, pp. 13-24, Université de Saint-Jacques de Compostelle.

MORLET, M.-Th., 1972, Les noms de personne sur le territoire de I'ancienne Gaule du VI au XII siècle. I.- Les noms issus du germanique continental et les créations gallo-germaniques. II.- Les noms latins ou transmis par le latin, Paris, CNRS.

MORVAN, M., 1995, «A propos d'une thèse de doctorat d'études basques: Les origines linguistiques du basque : I'ouralo-altaïque », BMB, n 139, pp. 33-47.

MORVAN, M., 1996, Les origines linguistiques de basque: I'ouralo-altaïque, thèse de doctorat, Université de Bordeaux III, publiée sous le titre Les origines linguistiques du basque, Presses Universitaires Bordeaux. 
NÈGRE, E., 1963, Les noms de lieux en France, Collection Armand Colin, Paris.

OLANO SILVA, V., «Toponimia gallega », RDTP, I., 1945, pp. 653-666 ; V., 1949, pp. 626-662 ; X., pp. 190-226, 1954.

ORPUSTAN, J.-B., 1990, Toponymie basque, Presses Universitaire de Bordeaux.

ORPUSTAN, J.-B., 1999, La langue basque au Moyen-Âge, Izpegi.

OSEIRA, cart., ROMÁNI MARTÍNEZ, M., 1989, Colección diplomática do mosteiro cistercience de Santa María de Oseira (Ourense), Consellería da Cultura, Saint-Jacques de Compostelle. Documents allant de 1025 à 1310 .

OYHARÇABAL, B., 1989, «Variété dialectale et unification littéraire », in Euskal Herriak / Pays Basques, T. II, Les cahiers de I'IFOREP, n० 57 , Paris.

OYHARÇABAL, B., 1998a, «A propos de la langue basque », in La question basque, Denis Laborde, coord., Ed. L'Harmattan, Paris, pp. 41-55.

OYHARÇABAL, B., 1998b, «R. L. Trask. The history of Basque », in Lapurdum III, pp. 317-333.

PEREIRA-MENAUT, G., 1997, « Un pobo e unha natio moi particulares », in Galicia fai dous mil anos. O feito diferencial galego. I. Historia, G. Menaut-Pereira, coord., Saint-Jacques de Compostelle, Ed. Musée du Peuple Galicien, vol. 1, pp. 237-249.

PIEL, J. -M., 1945, Os nomes germánicos na toponimia portugesa, I. Adaes-Novegildo. Lisbonne, 1937. II. Oldroes-Zendo. Lisbonne.

PIEL, J. -M., 1948, «Nomes de posssessores latino-cristãos na toponimia asturo-galego-portuguesa », Biblos, 23, pp. 143-202.

PLine I'ANCIEN, 1850-1851, Nat. Hist. de Pline, avec la traduction en français, par M. Emile Littré, Paris, 2 vol.

PLINI SECUNDI, C., 1906, Naturalis Historiae, vol. I, Libri I-VI, post Lvdovici Iani obitvm, recognovit et scriptvrae discrepantia adiecta edidit Carolvs Mayhoff, MCMVI, Lipsiae in aedibvs B. G. Tevbneri. Edition de Carl Mayhoff, qui a repris et renouvelé I'oeuvre de Jan après la mort de celui-ci, Leipzig, Teubner ; version latine seule et pas d'index.

PLINE L'ANCIEN, 1950, Nat. Hist., Livre I, texte établi, traduit et commenté par Jean Beaujeu, introduction d'Alfred Ernout, Ed. Les Belles Lettres, Paris.

PLINE L'ANCIEN, 1998, Nat. Hist., Livre III, texte établi, traduit et commenté par Hubert Zehnacker, Ed. Les Belles Lettres, Paris.

PTOLÉMÉE, C., 1883, T. I, 1901, T. II, Klaudiou Ptolemaiou Geôgraphikê uphêgêsis Claudii Ptolemaei Geographia. E codicibvs recognovit, prolegomenis, annotatione, indicibvs, tabvlis instrvxit Carolvs Müllervs. Volvminis primi pars prima. Parisiis, A. Firmin-Didot.

PTOLÉMÉE, 1932, Géographie, édité par E. L. Stevenson, Geography of Claudius Ptolemy, New York (traduction seule). 
RAVIER, X., 1963, « Le suffixe toponymique pyrénéen «-un». Le problème de ses relations avec d'autres suffixes à caractéristique nasale de l'Ibéro-Aquitain », Via Domitia, XII, fasc. 5, pp. 57-86.

RAYMOND, P., 1863, Dictionnaire topographique des Basses-Pyrénées, Paris.

REGISTRES FRANÇAIS. Délibérations du Corps de Ville, T. I (1565-1580) et T. II (1580-1600), Ed. Lamaignère, Bayonne, 1900-1906.

ROCAS, cart., DURO PEÑA, E., 1972, El monasterio de San Pedro de Rocas y su collección documental, Instituto de Estudios Orensanos 'Padre Feijoo', Orense. Contient des documents allant de 1007 à 1472 .

ROHLFS, G., 1952, « Sur une couche pré-romane dans la toponymie de Gascogne et de l'Espagne du nord », RFE, 26, pp. 209-256.

ROHLFS, G., 1955, 1956, « Una forma no investigada en la toponimia del sur de Francia y de la España septentrional (el sufijo -és, -iés) », traduit du français par J. M. Enguita, Archivo de Filología Aragonesa, $\mathrm{XL}$, in I Congrès Interntional de Langue et Littérature du Midi de la France, 7 au 11 septembre 1955, publié ultérieurement in Studien zur romaschen Namenkunde, Munich, 1956, pp. 114-126.

ROHLFS, G., 1970, Le Gascon, Etudes de philologie pyrénéenne (avec 3 cartes), 2édition, entièrement refondue, Tübingen-Pau.

SAINT-JOUAN, R., 1966, Le nom de famille en Béarn et ses origines suivi du Dictionnaire anthroponymique du Béarn pour I'an 1385, t. I et II, réed. Librairie du Palais, 1992.

SALABERRI, P., 1994, Eslaba aldeko euskararen azterketa toponimiaren bidez. Onomasticon Vasconiae 11, Euskaltzaindia, Bilbao.

SAMOS, cart., LUCAS ÁlVAREZ, M., 1986, El tumbo de San Julián de Samos (siglos VIII-XII), Estudio introductorio. Edición diplomática. Apéndices e índices. Publicacións da Caixa Galicia, Saint-Jacques de Compostelle. Contient 249 documents allant de 785 à 1200.

SAN MARTÍN, J., 1991, «Introducción a la toponomástica guipuzcoana / Gipuzkoar toponomastikarako sarrera », in EUSKALTZAINDIA, Onomasticon Vasconiae 4. Actas de las I jornadas de onomástica, toponimia, Vitoria-Gasteiz, abril 1986 / I onomastika jardunaldien agiriak. Toponimia, Gasteiz, 1986ko apirila, Ed. Euskaltzaindia, pp. 249-278.

SÁNCHEZ-ALBORNOZ, C., 1983, El Reino de Asturias, Ed. IDEA, Oviedo.

SANTAMARINA, A., 1991, «Problemas para la restauración de topónimos gallegos », in EUSKALTZAINDIA, Onomasticon Vasconiae 4. Actas de las I jornadas de onomástica, toponimia, Vitoria-Gasteiz, abril 1986 / I onomastika jardunaldien agiriak. Toponimia, Gasteiz, 1986ko apirila, Ed. Euskaltzaindia, pp. 237-246.

SARMIENTO, Fr. M., 1923, Onomástico etimológico de la lengua gallega, Tui.

SCHUCHARDT, H., 1907, «Iberische Deklination », Sitzungsberichte der Wiener Akademie, 157 (II), pp. 1-90. 
SCHULTEN, A., 1927, «Las referencias sobre los Vascones hasta el año 800 después de J. C. », RIEB, XVIII, pp. 225-240.

SCHULTEN, A., 1943, Los cántabros y astures y su guerra con Roma, Madrid.

SOBRADO, cart., LOSCERTALES de GARCÍA VALDEAVELLANO, M., 1976, Tumbos del monasterio de Sobrado de los Monjes, 2 vol., Dirección General del Patrimonio Artístico y Cultural / Archivo Histórico Nacional, Madrid. Contient 541 documents allant de 787 à 1252.

STRABON, 1966, Géographie, T. II, Liv. III-IV, texte établi et traduit par François Lasserre, Collection des Universités de France, Paris.

SUÁREZ, J. C., 1992, Toponimia lenense : origen de algunos nombres en torno al Valle del Huerna, Real Instituto de Estudios Asturianos, Oviedo.

TRANOY, A., 1981, La Galice romaine. Recherches dans le Nord-Ouest de la péninsule Ibérique dans I'Antiquité, ouvrage publié avec le concours du Centre National de la Recherche Scientifique (Paris), de la Casa Velázquez (Madrid) et de I'Institut d'Etudes ibériques et ibéro-américaines (Bordeaux), Publications du Centre Pierre Paris (ERA 22), Paris.

UNTERMANN, J., 1992, «Aportaciones al estudio de las lenguas prerromanas del noroeste de la Península Ibérica », in Galicia : da romanidade á xermanización. Problemas históricos e culturais, Actas do encontro científico en homenaxe a Fermín Bouza Brey (1901-1973), pp. 367-397. 
Index

Grec

N $\alpha \beta \beta \alpha \sigma \tilde{\nu} 9 ; 11 ; 26$

\section{*}

*Arteaca 33

*Azenar-uri 41

*eo 21

*Goirice 53

*Lankara 44

*Lendoño 33

*mal 44

*Malpico 44

*Narica 44

*uilla Osterici 52

*Ustariz 52

\section{A}

A Raña 33

Afrique 7

Alanti $30 ; 46$

Alantone 46

Atondo (Navarre) 46

Alava $38 ; 44 ; 48$

Alderitz 52

ambas Asmas 34

Aparraca 44

Aparraqua 44

Aparraques 44

Appien $2 ; 7 ; 8 ; 11$

Aquitani 8 ; 37

Aquitania $8 ; 61$

Aracaeli 46

Aranaz 30

Arante

(Lugo) $30 ; 46$

aranton 46
Arantón

(Lugo) 46

Arantza 30

Aranza 30

Arcabrica 44

Arcachon 4

Argote 31

Arínes 31

Arinez 31

Ariñez 31

Arrati-Arteaga 32

Arratzu-Ubarrundia 43

Arros 32

Arrós 32

Artabres 12

Artabri 40

Arteaga $32 ; 33$

Artedo 33

Arteijo 33

Arteixiña 33

Arteixo 32

Artes 33

Artés 33

Arthez-d'Armagnac 33

Asba 34

Asie Mineure 10

Asma $33 ; 34$

Asme 34

Aspai 27 ; 34

Aspe $33 ; 34$

Assbe 34

Astáriz 52

Astures $19 ; 47 ; 48 ; 50 ; 56$

Asturiens $6 ; 14 ; 56$

Asturies $2 ; 13 ; 15 ; 16 ; 17 ; 20$; $21 ; 30 ; 41 ; 50 ; 53 ; 62$ 
Asua 34

-ate 45

Atondo 46

Austericus 52

Azantza 34

Azanza 34

Azkue $31 ; 42$

\section{B}

Badajoz 43

Badayoz 43

Baenis 2

bai- $2 ; 34$

Baïgorry 2

Bainis $2 ; 8$

baiona $2 ; 34 ; 35$

Baites 2

Baldáriz 52

barre- 2

Bayona 34 ; 35

Bayonne $2 ; 34 ; 35 ; 57 ; 61 ; 63 ; 66$

Béarn $1 ; 3 ; 26 ; 33 ; 42 ; 62 ; 67$

\section{Berisamo 9}

Bermeo 42

Betanzos 43

Betis 2

Biarritz 52

\section{Biárriz 52}

Biscaïens $39 ; 41 ; 53 ; 55$

Biscaye $15 ; 20 ; 21 ; 27 ; 32 ; 42$;

$44 ; 45 ; 50$

Boullón $3 ; 37 ; 47 ; 51 ; 52$

Brácara 43

C

Cabo de Nariga 44

Cadrolioco 9

Caelo 9

Callaeci $5 ; 6 ; 7 ; 8 ; 10 ; 11 ; 22$

Callaecia $1 ; 5 ; 8 ; 9 ; 11 ; 15$

Callaecus $7 ; 8$
Callaïques $7 ; 9 ; 10 ; 11 ; 12 ; 13$; $19 ; 21 ; 22 ; 24$

Cambo 34

Cantabres $14 ; 19 ; 25 ; 47 ; 55 ; 56$

Cantabria $1 ; 25$

Cantabrie $41 ; 47$

Caristes 38 ; $41 ; 53$; 54 ; 55 ; 56

Caro Baroja $10 ; 12 ; 13 ; 26 ; 36$; $46 ; 47 ; 48 ; 51 ; 55 ; 56$

castellum 9

Castille-La Manche 43

Castillo-Elejabeitia 32

Castropol 23

Catalogne 1

Cattarie 41

Ceán 40

Ceánuri 40

Cedeira 41

Celtes $10 ; 14 ; 27$

Cendea d'Iza 46

\section{Cettaria 41}

Chafarica 44

\section{Cileni 9}

\section{Contestani 34} 60

Coromines $1 ; 16 ; 20 ; 31 ; 36 ; 59$;

\section{Coto de Fonte Mayor 33}

Cuenca $43 ; 49$

Cuirice 53

\section{D}

Deba 41

Decimus Iunius Brutus 7

Deva 41

$\boldsymbol{E}$

Ega 44

Ego $21 ; 24 ; 53$

Egobe $22 ; 24$

Egovarri $21 ; 22 ; 23 ; 24 ; 53$

Egovarros 23 ; 53 
Elarin 43

Encartaciones $50 ; 54 ; 56$

Eo $21 ; 23 ; 24$

\section{Esmóriz 52}

Esteribar 52

-eta 45

Eube $21 ; 23$

Euve $21 ; 23 ; 24$

Eygon 42

Eygun 42

\begin{tabular}{l}
\hline $\boldsymbol{E}$ \\
Ézaro 42 \\
\hline $\boldsymbol{F}$
\end{tabular}

Filgueiras 33

Folgueira 33

forum Iriensium 9

Fredrick Jungemann 2

\section{$\boldsymbol{G}$}

Galaïques 48

Galatai 10

Galates 10

Galatia 10

Galič 10

\section{Galičina 10}

Galice $1 ; 2 ; 3 ; 4 ; 5 ; 7 ; 8 ; 9 ; 10$; $12 ; 13 ; 15 ; 19 ; 20 ; 21 ; 24 ; 25 ; 26$; $27 ; 29 ; 32 ; 33 ; 34 ; 35 ; 37 ; 38 ; 39$; $41 ; 42 ; 43 ; 46 ; 48 ; 51 ; 53$; 56 ; 60 ; $62 ; 68$

Galicia $2 ; 10 ; 11 ; 34 ; 58 ; 60 ; 61 ;$ $64 ; 65 ; 67 ; 68$

Galicie 10

Galicja 10

Galitsia 10

Galizien 10

Gallaeci $7 ; 10$

Galli 10

Gallia 10

Gauteguiz de Arteaga 32

Gavel 2
Gifford $2 ; 3 ; 28 ; 36 ; 39 ; 45 ; 46$; 49

\section{Goiri 52}

Goiriz $52 ; 53$

Goíriz 52

Guadalquivir $2 ; 15 ; 26 ; 49$

Gueldo 42

Guéthary 41

Guipuzcoa $21 ; 48$

Guipuzcoans $26 ; 36 ; 41 ; 53 ; 55$

\section{$\boldsymbol{H}$}

Halicz 10

Hispania 6 ; 58

Huarte-Arakil 46

Hübner $10 ; 22$

Hubschmid $5 ; 20 ; 44$

Humboldt $6 ; 22 ; 23 ; 24 ; 48$

Hydace 11

\section{$\boldsymbol{I}$}

ibai 2

-ica $44 ; 47$

-iga 44

Igueldo 42

-ika $44 ; 47$

Ilicis 34

Iria 35

Irigoyen $16 ; 17 ; 27 ; 34 ; 39 ; 40$; $45 ; 46 ; 50 ; 52 ; 53 ; 62$

Iruraitz-Gauna 44

Itinéraire d'Antonin $36 ; 38 ; 46 ; 47$

Izaro 42

\section{J}

Jules César $1 ; 8 ; 56 ; 63$

Kallaikoi $10 ; 11$

Keltoi 10 
$\boldsymbol{L}$

La Corogne $9 ; 12 ; 27 ; 28 ; 29 ; 31 ;$ $32 ; 33 ; 35 ; 36 ; 38 ; 40 ; 41 ; 42 ; 43$; $44 ; 45 ; 46 ; 47 ; 48 ; 51 ; 61$

La Rate 44

Labourd $22 ; 34 ; 36 ; 52$

Láncara $39 ; 43$

Langara 43

Lángara 43

Langarika 44

Larrate 44

Larrate de Vinuelas 44

Ledoño 33

Lena $15 ; 17 ; 19 ; 53$

López de Guereñu 43 ; 51 ; 52

\section{Lózara 43}

Lugo $9 ; 11 ; 15 ; 23 ; 24 ; 27 ; 28$; $29 ; 30 ; 32 ; 33 ; 34 ; 35 ; 37 ; 39 ; 40$; $41 ; 42 ; 43 ; 44 ; 46 ; 47 ; 49 ; 51 ; 52$

Lusitani 6

Lusitanie $6 ; 7 ; 12 ; 13 ; 14 ; 32 ; 36$

Lusitaniens $6 ; 12 ; 13 ; 14$

\section{M}

Malpica 44

Malpica de Bergantiños 44

Malpique 44

\section{Masma 33} 61

Menéndez Pidal $2 ; 22 ; 35 ; 36 ; 47$;

Michelena $2 ; 6 ; 12 ; 28 ; 29 ; 37$;

$39 ; 40 ; 41 ; 44 ; 46 ; 53 ; 54 ; 64$

Moguel 42

Monte de Subica 44

Moralejo Lasso 22 ; 44

\section{$\mathbf{N}$}

Nanclares de Gamboa 43

\section{Nariga 44}

Navarre $6 ; 28 ; 29 ; 30 ; 33 ; 36$. $37 ; 42 ; 44 ; 46 ; 52$
O

O Miño 2

Odericus 52

Oderitz 52

Oderiz 52

-oi 2

Olano Silva $21 ; 26 ; 34 ; 47 ; 53$

Oo 21

Orense $27 ; 33 ; 36 ; 39 ; 41 ; 44$; $45 ; 49 ; 66$

Oritz 52

Oriz 52

Orpustan

(Jean-Baptiste) $20 ; 34 ; 38 ; 52$

Orro 33

Oseira 65

Ost- / Austericus 52

Ostariz 52

Osteritz 52

Osteriz 52

Ostériz 52

$\boldsymbol{P}$

Padrón 9 ; 35

Pampelune $27 ; 30 ; 39 ; 45 ; 46 ; 49$; $52 ; 58 ; 59 ; 60$

Parga 44

Parochiale 32

Párraga 44

Parraqua 44

Párrega 44

Pays Basque $1 ; 3 ; 5 ; 12 ; 13 ; 14$; $19 ; 20 ; 26 ; 31 ; 32 ; 47 ; 48 ; 50 ; 51$; $54 ; 61 ; 62$

\section{Pazo de Láncara 43}

Pelica 44

pica 44

pico 44

Pline l'Ancien $8 ; 11 ; 22$

Pologne 10 
Pontevedra $29 ; 30 ; 35 ; 36 ; 38 ; 40$; $41 ; 42 ; 45 ; 47 ; 48$

Portugal $1 ; 8 ; 11 ; 27 ; 31 ; 35 ; 49$; $60 ; 62$

Punta de Pelica 44

Q

Q. Servilius Caepio 7

\section{$\boldsymbol{R}$}

Regnum Galiciae 10

Robledo 33

67

Rohlfs $4 ; 19 ; 20 ; 21 ; 32 ; 49 ; 66$;

Rome $5 ; 6 ; 7 ; 8 ; 12 ; 56$

S

San Cristóbal de Regodeigón 42

San Vicente de Arantón 46

San Xurxo de Artes 33

Sancti Jacobi de Goiriz 53

Sangüesa $30 ; 45 ; 46 ; 48 ; 49 ; 52$

Santander $1 ; 14 ; 57 ; 61$

Schuchardt 2

Sénat 7

Sierra de Uría 51

Strabon $2 ; 7 ; 11 ; 13 ; 14 ; 16 ; 24 ;$ $26 ; 35 ; 48 ; 68$

Subica 44

\section{$T$}

Tábara 44

Tállara 43

territorio Assue 34

-toi 2

Toloño 33

Toroño 33

$62 ; 68$
Tudela 44

Turquie 10

$\boldsymbol{U}$

uaigorri 2

Ukraine 10

Uría $48 ; 51$

Uritz 52

Uriz 52

Urria 49

Urrialdo 49

Urrialdu 51

Urriello 51

Urriellu 49

Urrós 49

Ustaize 52

Ustaritz 52

Ustariz 52

Ustáriz 52

Ustarriz 52

$\boldsymbol{V}$

Val d'Aran $16 ; 32$

Vardules $26 ; 41 ; 53 ; 54 ; 55 ; 56$

Vascones $12 ; 13 ; 14 ; 28 ; 37 ; 47$; $54 ; 55 ; 56 ; 59 ; 67$

Vegadeo 23

Viriathe 6

Viriatus $6 ; 7$

\section{Z}

Zama

(bataille de) 7

Zamora 44

Záncara 43 


\section{Notes}

${ }^{1}$ Iglesias, 1998b.

2 Iglesias, 1999.

3 Coromines, 1974.

4 Pidal, 1968.

5 Gavel, 1936, n० 45-46.

6 Jungemann, 1955.

7 Gavel, 1931, pp. 38-39.

${ }^{8}$ Euskaltzaindia, 1991, p. 221.

9 Santamarina, 1986/1991, p. 246.

10 De la Peña Santos, 1997, p. 145.

11 Mariño Paz, 1998, p. 28.

12 Hubschmid, 1960, p. 149.

13 Tranoy, 1981, p. 53.

14 Athénée (VIII, 330c, traduction de D. Roussel, cité par Tranoy, 1981, p. 92) cite le témoignage de I'historien grec Polybe qui avait voyagé en Espagne au côté de Scipion en 151 av. J.-C. : «Polybe - écrit Athénée - nous parle de la Lusitanie, une partie de I'Ibérie, ou de I’Espagne [Hispanie] selon le nom que les Romains donnent aujourd'hui à ce pays ». Le nom de I'Espagne ou Hispania est d'origine inconnue. On pense qu'il viendrait cependant du phénicien î-she-phannîm, «Côte des lapins » (Pline, 1998, commentaire de Zehnacker, p. 123, § 8). En effet, I'Ibérie était, d'après les auteurs antiques, un pays extrêmement abondant en lapins.

15 Humboldt, 1821, § XXXVIII.

16 Ce nom est également attesté dans une inscription trouvée en Navarre, dans le village de Gastiain (Vallée de Lana, Estella) comme le signale Ma Lourdes Albertos (1966, pp. 250-251). Ce nom antique rappelle curieusement, comme le signalait Luis Michelena (1987, p. 158, § 8), celui de la localité labourdine appelée Biriatu, autrefois Biriato, 1552. Michelena émettait également I'hypothèse selon laquelle Biriatu et Tirapu auraient peut-être pu être apparentés d'un point de vue étymologique : il faudrait alors, écrivait-il, supposer que Biriatu serait issu de < *briatu < *priatu et que Tirapu, autrefois Triapu, 1065, Triapo, 1100, serait issu de ce *Priatu à la suite d'une métathèse : *Priatu > Triapu. Quant à *Priatu, il aurait pu être issu du lat. priuatus à la suite d'une perte du - $\boldsymbol{v}$ - par dissimilation. L'exercice est, comme il reconnaissait lui-même, périlleux, quoique plausible. Mais pourquoi ne pas supposer, comme au demeurant Luis Michelena semblait le suggérer lui-même dans son article, que Biriatu est issu de l'anthroponyme attesté en Navarre Viriatus?

17 Tranoy, 1981, p. 53, n. 123. 
18 Consul en 138 av. J.-C. et chargé initialement de lutter contre les Lusitaniens qui, même après la mort de Viriathe, continuaient à pratiquer la guérilla et refusaient de se rendre; près de 50 ans après la mort de leur célèbre chef, ils n'étaient toujours pas soumis et en 105 av. J.-C. ils avaient même emporté une autre victoire sur l'armée romaine.

19 C'est dans une localité indigène appelée Cinginnia, qui n'a toujours pas été identifiée, que Brutus obtint sa première victoire face aux populations locales. Tite-Live raconte alors que, profitant de son succès, Brutus poursuivit sa route vers le nord à travers le territoire des Callaeci atteignant ainsi le fleuve Limaeas (actuel Lima, nord du Portugal). Les Romains croyant que c'était là le fleuve de l'oubli et que quiconque osait le traverser oubliait tout, même ses origines et son pays natal, prirent peur. Brutus, racontent dans un style quasi homérique les écrivains antiques, s'empara alors de l'enseigne que le signifier refusait de transporter sur l'autre rive et traversa le premier le fleuve afin que le reste de l'armée le suivît. Par la suite, son expédition n'alla pas au-delà du fleuve Miño ou Bainis, c'est-à-dire qu'il ne put entrer dans l'actuelle Galice car il eut à combattre un autre peuple de la Callaecia : les Bracari qui se battaient aux côtés de leurs femmes, ces dernières luttant jusqu'à la mort et préférant, raconte Appien, tuer leurs enfants et se donner la mort plutôt que de tomber aux mains de l'ennemi. Après cet épisode, Brutus abandonna la région et Rome ne s'intéressa plus sérieusement à ce qui constitue le territoire galicien actuel - dans lequel ses armées n'avaient pas au demeurant encore pénétré pendant près de quatre-vingt ans, jusqu'en 60 av. J.-C., année au cours de laquelle Jules César, qui avait reçu le gouvernement de l'Hispania Ulterior, entreprit, à la tête de trois légions, une incursion dans la Galice d'aujourd'hui afin d'y chercher des mines d'or et acquérir quelque gloire personnelle puisque, signale Alain Tranoy, « le voyage dans des régions dont la réputation de barbarie était bien établie suffisait à donner à celui qui l'avait réalisé un prestige nouveau, exprimé par le titre d'Imperator dont le gratifièrent ses soldats » (Tranoy, 1981, p. 131). Après quoi, il faudra attendre la fin des guerres cantabres menées par Auguste pour que la Galice soit définitivement intégrée dans I'Empire romain. Le terme Callaecia est quant à lui une invention romaine. Il s'agit d'un nom désignant une nouvelle structure géo-politique issue des réformes entreprises par l'empereur Auguste après la longue et pénible conquête du Nord-Ouest. Les érudits et les chercheurs ne sont cependant pas tombés d'accord au moment de dater ces réformes, les dates proposées oscillant entre les années 15, 13 et 9 av. J.-C. Nul n'est capable de dire si les habitants de cette province désormais appelée par les Romains Callaecia avaient conscience ou non d'exister en tant que natio, les seules certitudes étant que Rome, pour des raisons qui nous échappent en partie, considérait que les habitants de ce territoire formaient assurément sinon une nation, tout au moins une aire culturelle homogène - malgré une hétérogénéité linguistique admise de nos jours par tous les auteurs et dont les Romains eux-mêmes semblaient avoir conscience - et d'autre part il est clair que tous les indigènes ne pouvaient se désigner eux-mêmes comme Callaeci puisque ce nom, on l'a dit, n'était rien d'autre que celui d'un peuple attesté au cours du II ${ }^{\mathrm{e}}$ siècle av. J.-C. Le premier document où I'on constate qu'un individu se définit comme étant un Galicien, c'est-à-dire un Callaecus, apparaît dans une inscription funéraire du $\mathrm{III}^{\mathrm{e}}$ siècle trouvée à Tarragone : $\boldsymbol{Q}$. VOCONIVS RVFINVS CALL/AECVS. Le doute réside dans le fait qu'on ne sait pas si on doit considérer ce nom dans son sens restreint ou dans son rôle de nom de peuple éponyme. 
20 Tranoy, 1981, p. 375.

21 Tranoy, 1981, p. 372 \& Pereira-Menaut, 1997, p. 239.

22 Pereira-Menaut, 1997, p. 247. Lorsque un Espagnol va en Galice sans avoir pris la précaution de s'informer et qu'il décide de visiter les zones rurales, c'est-à-dire la quasi totalité du territoire, il peut être surpris et dérouté par ce qu'il voit. Alors que la nomenclature des villages, en l'occurrence galiciens, qu'il a consultée lui indique, par exemple, que la localité $X$ est une municipalité de 5.000 habitants (I'équivalent grosso modo du bourg d'Hasparren), lorsqu'il arrive sur place il ne voit, à sa grande surprise, rien ou presque rien. C'est qu'en réalité les localités galiciennes sont composées d'une multitude de paroisses qui à leur tour sont elles-mêmes composées d'une multitude de hameaux, le tout étant dispersé sur des kilomètres, cette dispersion étant probablement liée, on l'a vu, à des structures socio-politiques héritées de I'Antiquité selon, entre autres, Pereira-Menaut. Ce système très original serait alors une survivance pré-romaine qui n'aurait pas d'équivalent dans le reste de la Péninsule et qui expliquerait pourquoi on trouve plus de toponymes majeurs dans ce pays que dans tout le reste de I'Etat espagnol.

${ }^{23}$ Cherpillod, 1986, p. 183.

${ }^{24}$ Caro Baroja, 1988, p. 50

25 Entwistle, 1936, p. 38.

26 Lambert, 1994, p. 34.

27 L'historique du nom de ce peuple est un peu complexe car il semble y avoir eu confusion chez les auteurs anciens entre le peuple des Callaïques à proprement parler, c'est-à-dire au sens restreint, et le rôle de peuple éponyme qu'il fut amené à jouer par la suite en représentant l'ensemble des populations établies dans les conuentus de Braga et de Lugo. C'est encore Strabon (Géogr., III, 3, 3) qui nous explique comment ce nom fut étendu à l'ensemble des populations de cette région, «les autres peuples ayant des noms trop petits et trop obscurs ». A son époque, Pline l'Ancien le cite encore avec un sens restrictif, ce qui laisserait supposer qu'à son époque ce peuple existait encore en que tel. Le problème que pose ce populus en ce qui concerne sa localisation exacte n'a pas pu encore être tranché par les divers auteurs qui se sont penchés sur la question. A l'heure actuelle, le rapprochement le plus vraisemblable avec le nom des Callaïques est celui qui a été fait avec celui de l'antique nom de Porto: Cale, Portus Cale, Portucale (Hydace, $V^{\mathrm{e}}$ siècle), Portugale (VI ${ }^{\mathrm{e}}$ siècle). Cale était une ancienne localité indigène construite sur la rive sud du Douro. Le site n'étant pas favorable à la navigation, on construisit sur la rive nord une ville appelée Portus Cale, « le port de Cale » qui est à l'origine de l'actuel nom du Portugal.

28 Tranoy, 1981, p. 66.

29 Tranoy, 1981, p. 66.

30 Untermann, p. 393, n. 80.

31 Agud, M. + \& Tovar, A., DEV, T. V, 1992, 303, tiré de Michelena, L., BRSVAP, 11, p. 291. 
32 Caro Baroja, 1977, p. 38, n. 8.

33 Tranoy, 1981, p. 94.

34 Tranoy, 1981, p. 118, Caro Baroja, 1976, p. 252, n. 205.

35 Tranoy, 1981, p. 118.

36 Ces deux noms furent en effet synonymes, probablement de 19 à 7 ou peut-être 2 av. J.-C., étant donné qu'à cette époque la Galice et les Asturies furent incorporées par Auguste à la Lusitania d'après Strabon (cf. 1966, commentaire de François Lasserre, p. 50, n. 2).

37 De nombreux ouvrages de vulgarisation, la plupart du temps destinés principalement à l'enseignement de I'histoire du Pays Basque, attribuent en effet systématiquement aux Vascones des descriptions ne les concernant pas en réalité directement. En outre, Joaquín González Echegaray, dans l'un de ses ouvrages destiné principalement aux spécialistes et intitulé Los Cántabros (1997, 4éd., pp. 105-109), un peuple qui habitait grosso modo, l'actuelle région de Santander, attribue, cette fois aux seuls Cantabri, la description que Strabon faisait en réalité des Lusitaniens. Or, si cela n'est pas précisé, le lecteur, qui souvent n'a pas accès au texte de Strabon, ne peut pas le savoir. Un des seuls et rares passages - au nombre de trois ou quatre en tout de Strabon (Géogr., III, 4, 18), rappelons-le, concernant stricto sensu les Cantabres, et seulement les Cantabres, apparaît dans la troisième partie de son Livre III consacré à l'Ibérie proprement dite. Le passage, célébrissime, est le suivant : « Chez les Cantabres, par exemple, c'est l'époux qui apporte la dot à sa femme, ce sont les filles qui héritent et qui choisissent l'épouse à laquelle destiner leurs frères. Ces coutumes relèvent d'un régime de gynécocratie qu'on ne saurait en aucune manière qualifier de policé ». Ce court passage eut, entre autres, pour conséquence de déchaîner les passions en Pays Basque, encore et surtout au $X X^{\mathrm{e}}$ siècle, où on l'attribua aux Basques de I'Antiquité donnant ainsi naissance à un des mythes parmi les plus prisés du nationalisme basque contemporain : le «matriarcalisme basque ».

38 Iglesias, 1998b.

39 García Arias, 1977, p. 54.

40 Mariño Paz, 1999, pp. 102-103

${ }^{41}$ Coromines, 1972, pp. 163-164.

42 Coromines, 1972 , p. 163, n. 7.

43 Irigoyen, 1992a, p. 357.

44 Gavel, 1921, p. 87, § 41.

45 Iglesias, 1998b, p. 4.

${ }^{46}$ Irigoyen, 1992a, p. 358.

47 Allières, 1998, p. 316.

48 Allières, 1998, p. 316. 
49 Encyclopædia Britannica, 1929-1964, p. 909.

50 Cherpillod, 1986, p. 267.

51 Comme le signale le généticien André Langaney (Langaney / Clottes / Guilaine, 1998, pp. 41-43), pour expliquer l'étonnante homogénéité génétique des populations actuelles à travers toute la planète, la seule explication, d'après les recherches les plus récentes basées, entre autres, sur des simulations réalisées sur ordinateur, est d'admettre que le nombre des populations préhistoriques, à une époque pas trop lointaine, ait été très faible, «à la limite de l'extinction de leur population ». On estime ainsi que tous les êtres humains actuels descendent d'une seule et unique population d'environ 30.000 personnes - c'est-à-dire l'équivalent d'une ville comme Biarritz pour peupler l'ensemble de la planète - connus sous le nom de Homo sapiens sapiens et concentrée probablement dans certaines régions du Proche-Orient. Cette population serait apparue entre 150.000 et 100.000 av. J.-C. Ce sont des chasseurs-cueilleurs du Paléolithique, nos ancêtres directs: d'après les théories les plus récentes, ils auraient ainsi peuplé la Chine vers 67.000 av. J-C., la Nouvelle-Guinée et I'Australie vers 50.000 av. J.-C., I'Afrique entre 45.000 et 35.000 av. J.-C., I'Amérique, une première fois sans succès vers 45.000 av. J.-C. et une seconde fois vers 18.000 av. J.-C. et, en ce qui nous concerne, I'Europe vers 40.000 av. J.-C. Ces derniers, ceux qui s'établirent en Europe, sont appelés d'ordinaire « les homme de Cro-Magnon ». Or, il est également établi par la science actuelle que ces populations se déplaçaient vite et beaucoup. Et il en était de même à la fin des temps paléolithiques et au début du Néolithique, c'est-à-dire grosso modo vers 10.000 av. J.-C., époques au cours desquelles les mouvements de populations - ces dernières étant jusqu'à la fin du Paléolithique, rappelons-le, en nombre très faible (« N'oublions pas que le monde préhistorique est presque vide » rappelle Jean Clottes, cf. 1998, p. 85) - furent constants et très importants.

52 Langaney / Clottes / Guilaine, 1998, p. 36

53 Morvan, 1996.

54 On ne peut par ailleurs ne pas citer, ne serait-ce qu'à titre de curiosité, le témoignage, au début du XIX siècle, d'un philologue appelé Christian Gottlieb von Arndt, témoignage dont Michel Morvan fait état dans sa thèse (cette dernière étant controversée malgré une critique plutôt élogieuse de Jacques Allières). Ce qu'écrit Christian von Arndt est tout à fait étonnant pour son époque, dite d'ordinaire pré-scientifique : «Mais si en attendant on veut chercher des ancêtres ou des parents collatéraux à la langue basque dans d'autres régions du monde, alors on devrait de préférence les trouver au nord-est de notre continent, parmi les dialectes des Samoyèdes et d'autres populations nomadisant dans la Sibérie nord-orientale » (Morvan, 1996, p. 35). Or, le toponyme sibérien Lena (hydronyme) se trouve justement dans cette Sibérie dite nord-orientale dans une région où est de nos jours parlé le yakoute, une langue altaïque du groupe türk d'après Michel Morvan.

55 Rohlfs, 1970, pp. 53-54, § 77 et p. 67, § 159.

56 Rohlfs, 1970, p. 39, § 11.

57 Registres Français, T. II, 1900-1906, p. 39. 
58 Orpustan, 1999, p. 346.

59 Morvan, 1995, p. 45.

60 Rohlfs, 1970, p. 53, § 74.

61 San Martín, 1991, p. 270.

62 Moralejo, 1977, p. 135, n. 48.

63 Moralejo, 1977, p. 135, n. 48.

64 Ramón Menéndez Pidal (1968, pp. 247-248) signale que « una gente astur (sic) [en réalité galaïque] es señalada por Plinio, IV, 111, la de los Egivarri [il ajoute en bas de page : « Sigo la lección corriente de Plinio. La Teubneriana, hecha por MAYHOFF, pone 'Egi, Varri', con evidente error »], en cuya denominación es difícil no ver un gentilicio tomado del nombre de la ciudad o fortaleza, idéntico al de un caserío guipuzcoano, de Azpeitia, Eguibarr, repetido en el apellido del Labourd Eguiberri ; el primer elemento es egi, que en vasco moderno significa 'cresta, sierro, pico', sin duda como 'peña' en el español antiguo con significado de 'fortaleza, castillo' ; así que Egivarri es Peña Nueva, opuesto al Peña Vieja de los Picos de Europa ». Mais toute la démonstration du maître était également basée sur une leçon erronée, ce qui l'invalide. En outre, Don Ramón M. Pidal croyait également, à l'instar de Humboldt et à tort, que -varri était le basque barri. C'est en réalité à partir d'une forme Egovarri qu'il faut tenter d'analyser ce nom des Callaïques.

65 Pline, Livre I, éd. 1950, pp. 33-34.

66 Plini Secvndi, L. IV, 1906, p. 354.

${ }^{67}$ Iglesias, 1998 b, p. 11 § 25.

68 García Arias, 1977, p. 98.

69 Peuple d'origine celtique fixé à l'origine dans le Sud-Ouest de la péninsule Ibérique entre le Tage et le Guadiana et dont une partie émigra en Galice d'après Strabon (Géogr., III, 3, 4).

70 Jungemann, 1955, pp. 119-120.

${ }^{71}$ Irigoyen, 1986, p. 56, § 52.

72 Rohlfs, RFE, 26, 1952, p. 227.

73 Michelena, Apellidos Vascos, § 18.

74 Piel, 1948, p. 170.

75 Michelena, 1990, p. 33, § 2. 1. 7.

76 Piel, 1937, p. 44, § 114.

77 Michelena, § 54.

78 Lecuona, 1960, p. 134. 
79 Coromines, \& Pascual, 1980, T. I, p. 325.

80 Piel, 1937, p. 35, §§ 79, 80.

${ }^{81}$ Rohlfs, 1952, pp. 229-230.

82 David, 1947, p. 42.

83 Les cartes au 1: 25.000 qui sont en train de paraître depuis une vingtaine d'années (tout le territoire galicien n'est pas encore couvert) sont supervisées par une commission spéciale (Santamarina, 1986/1991, p. 246), constituée de toponymistes galiciens et d'un linguiste de I'Université, nommée par le Gouvernement de Galice qui supervise toutes les opérations étant donné, comme nous l'avions déjà indiqué, qu'en Galice il n'existe pas de bilinguisme galicien-espagnol. En effet, seules les formes galiciennes des toponymes ont une existence légale, les anciennes formes et graphies espagnoles des noms de lieux et de rues n'existant plus d'un point de vue légal d'après la « Loi de Normalisation Linguistique de Galice » de 1983 qui, dans son article premier, stipule que « les toponymes de Galice ont pour forme unique et officielle la forme galicienne ».

84 Moralejo, 1977, pp. 341-454. On a également le village d'Orense appelé Londoño et les hameaux biscaïens appelés Lendoño de Abajo / Beitia et Lendoño de Arriba / Goitia, localité d’Orduña, en basque Urduña, cf. également la montagne andalouse appelée Orduña, 1943 m., située dans la Sierra Arana, à $20 \mathrm{~km}$. au nord-est de Grenade, non loin d'une rivière appelée río Maitena, mais ici il peut s'agir, quoique cela devrait être démontré, de noms donnés après la Reconquête, ce qui ne peut être en revanche le cas en Galice.

85 Citons également la petite montagne appelée Arcogaña située à environ $16 \mathrm{~km}$. au sud de la ville de La Corogne (IGN, 1 : 25.000, Abegondo, 45-IV). En outre, non loin d'une montagne appelée monte de Tiribidi se trouve le monte de Lerín (cf. le village navarrais de Lerín, Lerin, 1059).

${ }^{86}$ Orpustan, 1990, p. 39, § 38.

${ }^{87}$ Irigoyen, pp. 53-54.

88 Jaupart, 1981, p. 17.

89 Mariño Paz, 1998, p. 71.

90 Pidal, 1968, p. 32.

91 Caro Baroja, 1945, rééd. 1990, p. 216.

92 M. Pidal, 1968, p. 119, n. 29.

93 Agud \& Tovar, 1989-1993, pp. [40-41].

94 Cependant, il s'agit très probablement, si on en croit Joseph Piel, des formes anciennes du toponyme espagnol Viariz (localité de Viariz, municipalité de Corullón, province de Léon), ce qui ne change rien à l'affaire car il est certain que l'origine du toponyme galicien Beariz est la même. Il 
existe également deux localités portugaises appelées Viariz (1. district de Baião, 2. district de Vila Real). Tous ces noms ibériques sont d'origine germanique.

95 Iglesias, 1998, pp. 281-288.

96 Orpustan, §6.

97 Orpustan, §53.

98 Díez Melcón, 1957, p. 123.

99 Michelena, Textos arcaicos vascos, p. 25.

100 Irigoyen, 1986, pp. 61-62, § 60.

101 Dauzat, et Rostaing, 1989, p. 124.

102 Dauzat et Rostaing, p. 125.

103 Irigoyen « Miscellanea toponymica et anthroponymica (III)», De re philologica linguae uasconicae IV, pp. 213-224, 1992.

104 Michelena, § 119.

105 Carré Aldao,

106 Michelena, 1989, p. 80, § 193.

107 Nègre, 1963, p. 30.

108 Jordán Cólera, 1998, pp. 267-279.

109 Moralejo, 1977, p. 66.

110 Moralejo, 1977, pp. 30-31, n. 20.

111 Situé à 44 km. à l'est de Badajoz, cf. l'ancienne localité d'Alava appelée Badayoz, autrefois Badajoz, 1463

112 Curieusement, ce suffixe, dont l'origine celte semble faire l'unanimité, n'est presque pas représenté dans la toponymie galicienne. Un seul village situé en bord de mer semble le porter: Malpica de Bergantiños (La Corogne) qui doit être cependant une formation tautologique : *mal, « hauteur » et pico / pica > Malpica, le village étant situé sur une presqu'île en forme de colline, une montagne de Lugo et d'Orense s'appelant également Malpique < $*$ Malpico. Le suffixe -ica semble figurer dans le nom de quelques hameaux : Chafarica (Lugo) et Arcabrica (Orense) et peut-être dans le nom du cap appelé Cabo de Nariga (< *Narica) ainsi que sans doute dans les endroits connus sous les noms de Punta de Pelica et Monte de Subica (tous situés dans province de La Corogne). Dans ces noms galiciens, il faut noter l'absence de sonorisation de l'occlusive sourde intervocalique. En théorie pourtant, ces dernières devraient toutes se sonoriser de façon systématique en galicien. L'évolution du nom du village de Lugo appelé Parga est à ce propos significative : Aparraca ou Aparraqua (époque romaine, cf. tribu galaïque des Aparraques) > Parraqua > Párrega, 1178 et Párraga (maison noble et seigneuriale) > Parga (nom actuel). Ainsi, on aurait dû avoir: -ika > -iga comme cela est le cas dans le nom Nariga, issu 
manifestement de *Narica. Mais curieusement cela n'est pas le cas pour les autres: Subica, Pelica, etc.

113 Ciérbide, 1991, p. 142.

114 Urtasun Antzano, 1997, pp. 497-506.

115 Irigoyen, 1990, pp. 16-17.

116 Irigoyen, 1985, pp. 1007-1017.

117 Salaberri, 1994, p. 984.

118 Caro Baroja, 1945, réed., 1990, p. 204.

119 Il s'agit en outre d'un prénom encore utilisé de nos jours dans le Caucase, une reine de Géorgie (1184-1212) l'ayant autrefois porté.

120 Op. cit., p. 204.

121 Caro Baroja, 1988, p. 84.

122 Caro Baroja, 1972, p. 456.

123 Humboldt

124 « Après ces villes viennent [les villes d'] Italica et Ilipa, situées sur le Bétis [Guadalquivir] Astigis, à quelque distance du fleuve, Carmo, Obulco ; puis, dans la région où furent vaincus les fils de Pompée, Munda, Atégua, Urso, Tuccis, Ulia et Aegua, toutes peu éloignées de Corduba [Cordoue]».

125 Irigoyen, 1986, pp. 230-231, § 70.

${ }^{126}$ Iglesias, 1998b, pp. 19-20.

127 Irigoyen, 1986, p. 232, § 72.

128 Caro Baroja indique également (1958, n. 30) : «La impresión que se tiene a primera vista es de que la romanización de los cántabros fue mayor que la de los astures y la de que éstos conservaron más elementos del antiguo estrato 'vascoide'. Nombres como el de la tribu de los 'gigurri', el de 'Arronidaeci', c. I, 1. II, 2679 y otros personales ('Neconi', c., I, 1. II, 5718, 'Andoto', etc.) nos acercan al complejo aquitano ».

129 Rohlfs, 1955.

130 Morlet, 1972, T. I, p. 44.

131 Morlet, 1972, T. I, p. 44.

132 Morlet, 1972, T. I, p. 36.

133 Boullón, 1994, p. 145.

134 Salaberri, 1994, p. 126.

135 Morlet, 1972, T. I, p. 14. 
${ }^{136}$ Irigoyen, 1986, p. 78, § 99.

137 Olano Silva, 1945, pp. 653 et 661.

138 On considère que Strabon a utilisé principalement les Histoires et l'Histoire de Pompée de Posidonius d'Apamée et que les citations d'auteurs antérieurs à 72 av. J.-C., date de l'érection du Trophée du Col de Perthus, c'est-à-dire d'auteurs tels que principalement Ephore, Eratosthène, Polybe (dont l'oeuvre intitulée l'Histoire universelle consacrée aux guerres hispaniques s'arrêtait à l'année 144 av. J.-C.), Artémidore et Asclépiade de Myrléa, ont été transmises à Strabon par Posidonius.

139 Caro Baroja, 1945, p. 216.

140 Schulten, 1927, pp. 225-240.

141 Gomez-Moreno, 1925, pp. 225-240.

142 Michelena, 1964, p. 127.

143 Michelena, 1981, pp. 39-40.

144 Oyharçabal, 1989, p. 18.

145 Caro Baroja, 1984, p. 296.

146 Louandre, 1931 , p. 135, L. III, XXVI.

147 Schulten, 1943.

148 Caro Baroja, 1988, p. 54. 